\title{
Agri-environmental Policies and Dutch Dairy Farmers' Responses
}

Gerlinda Sabrina Samson 


\section{Thesis committee}

\section{Promotor}

Prof. Dr J.H.H. Wesseler

Professor of Agricultural Economics and Rural Policy

Wageningen University \& Research

\section{Co-promotors}

Dr C. Gardebroek

Associate professor, Agricultural Economics and Rural Policy Group

Wageningen University \& Research

Dr R.A. Jongeneel

Assistant professor, Agricultural Economics and Rural Policy Group

Wageningen University \& Research

\section{Other members}

Prof. Dr A.G.J.M. Oude Lansink - Wageningen University and Research Prof. Dr R.P.O. Schulte - Wageningen University and Research Prof. Dr J. Buysse - Ghent University, Belgium

Prof. Dr H.D. Thiele - IFE Institut für Ernährungswirtschaft, Germany

This research was conducted under the auspices of Wageningen School of Social Science (WASS) 


\title{
Agri-environmental Policies and Dutch Dairy Farmers' Responses
}

\author{
Gerlinda Sabrina Samson
}

Thesis

submitted in fulfilment of the requirements for the degree of doctor at Wageningen University

by the authority of the Rector Magnificus,

Prof. Dr A.P.J. Mol, in the presence of the

Thesis Committee appointed by the Academic Board

to be defended in public

on Friday 27 October 2017

at 11 a.m. in the Aula. 
Gerlinda Sabrina Samson

Agri-environmental Policies and Dutch Dairy Farmers' Responses

185 pages.

PhD thesis, Wageningen University, Wageningen, the Netherlands (2017)

With references, with summary in English

ISBN 978-94-6343-675-5

DOI $10.18174 / 421690$ 


\section{Table of Contents}

1. Introduction 1

1.1 Background Dutch dairy sector and European policies 1

1.2 Problem statement 4

1.3 Research objective and research questions 6

1.4 Data and research methods 8

References $\quad 11$

2. Analysing Dutch Dairy Farmer Behaviour Towards the Provision of Public Goods:

The Added Value of an Economic Simulation Experiment 15

2.1 Introduction 16

$\begin{array}{ll}2.2 & \text { Background on experimental economics } \\ \end{array}$

2.2.1 Types of experiments 22

$\begin{array}{ll}2.2 .2 & \text { Objectives of experiments } \\ 2.2 .3 & 23\end{array}$

2.2.3 Design of a successful experiment 24

$\begin{array}{ll}2.2 .4 & \text { (Dis)advantages of experiments } \\ & 26\end{array}$

$\begin{array}{ll}2.2 .5 \quad \text { Validation of experiments } & 27\end{array}$

2.3 The economic simulation experiment 28

2.3.1 CAP options 29

2.3.2 Hypotheses tested in the economic simulation experiment 31

2.3.3 Set-up of the economic simulation experiment 32

2.3.4 Evaluation of the economic simulation experiment 34

2.4. Assessing the impact of the CAP reform using an economic simulation experiment 37

2.4.1 General results economic simulation experiment 37

2.4.2 The added value of the economic simulation experiment towards neo-classical economics $\quad 42$

2.5 Concluding remarks 45

$\begin{array}{lr}\text { Acknowledgements } & 47\end{array}$

References $\quad 48$

Appendix $2.1 \quad 52$

3. Explaining Production Expansion Decisions of Dutch Dairy Farmers 53

3.1 Introduction $\quad 54$

3.2 Developments in the Dutch dairy sector $\quad 57$

3.2.1 Milk prices and milk price volatility $\quad 57$

$\begin{array}{lll}3.2 .2 & \text { Manure policy } & 57\end{array}$

$\begin{array}{lll}3.2 .3 & \text { Land market } & 58\end{array}$

$\begin{array}{lll}3.2 .4 & \text { CAP reform } & 59\end{array}$ 
$\begin{array}{llr}3.3 & \text { Conceptual model } & 59\end{array}$

$\begin{array}{ll}3.4 & \text { Data and included variables }\end{array}$

$\begin{array}{lll}\text { 3.4.1 } & \text { Market conditions } & 67\end{array}$

$\begin{array}{lll}\text { 3.4.2 } & \text { Farmer's values, goals and strategies } & 68\end{array}$

$\begin{array}{lll}3.4 .3 & \text { Farm characteristics } & 70\end{array}$

$\begin{array}{lll}3.5 & \text { Empirical model } & 74\end{array}$

$\begin{array}{llr}3.6 & \text { Results } & 77\end{array}$

$\begin{array}{lll}3.6 .1 & \text { Market conditions } & 79\end{array}$

$\begin{array}{lll}\text { 3.6.2 } & \text { Farmer's values, goals and strategies } & 80\end{array}$

$\begin{array}{lll}\text { 3.6.3 } & \text { Farm characteristics } & 81\end{array}$

$\begin{array}{llr}3.7 & \text { Discussion } & 83\end{array}$

3.8 Conclusions $\quad 86$

$\begin{array}{lr}\text { References } & 89\end{array}$

$\begin{array}{lr}\text { Appendix } 3.1 & 94\end{array}$

4. Analysing Trade-offs between Milk, Feed and Manure Production on $\begin{array}{lr}\text { Dutch Dairy Farms } & 95\end{array}$

\begin{tabular}{ll}
4.1 & Introduction \\
\hline
\end{tabular}

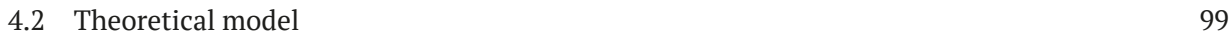

$\begin{array}{llr}4.3 & \text { Data } & 105\end{array}$

$\begin{array}{ll}4.4 & \text { Empirical model and estimation } \\ \end{array}$

4.5 Results and discussion $\quad 112$

$\begin{array}{lll}\text { 4.5.1 Milk production function } & 112\end{array}$

$\begin{array}{lll}\text { 4.5.2 } & \text { Feed production function } & 115\end{array}$

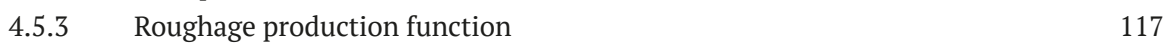

$\begin{array}{ll}\text { 4.5.4 Effects of dairy livestock expansion } & 120\end{array}$

$\begin{array}{ll}4.6 \text { Concluding remarks } & 124\end{array}$

$\begin{array}{lr}\text { References } & 125\end{array}$

5. Were Manure Application Norms Effective in Limiting Dairy Cattle on

$\begin{array}{lr}\text { Dutch Dairy Farms? } & 129\end{array}$

5.1 Introduction $\quad 130$

5.2 Overview Dutch manure policy 132

5.2.1 Development of the manure policy in the Netherlands 132

$\begin{array}{lll}\text { 5.2.2 Two types of manure surplus } & 136\end{array}$

$\begin{array}{llr}5.3 \text { Data } & 138\end{array}$

$\begin{array}{llr}5.4 & \text { Recent developments in the Dutch dairy sector } & 139\end{array}$

5.5 Model specification and estimation 143

$\begin{array}{lll}5.6 & \text { Results and discussion } & 144\end{array}$

$\begin{array}{lll}5.7 & \text { Concluding remarks } & 146\end{array}$

$\begin{array}{ll}\text { References } & 148\end{array}$

6. Synthesis 151

$\begin{array}{lll}6.1 & \text { Research objective and questions } & 151\end{array}$

$\begin{array}{ll}6.2 & \text { General conclusions and implications } \\ \end{array}$ 
6.3 Discussion 156

$\begin{array}{lll}\text { 6.3.1 Policy selection } & 156\end{array}$

$\begin{array}{lll}\text { 6.3.2 } & \text { Sample selection } & 157\end{array}$

$\begin{array}{lll}6.3 .3 & \text { Data } & 157\end{array}$

$\begin{array}{lll}\text { 6.3.4 } & \text { Research method } & 158\end{array}$

$\begin{array}{lll}\text { 6.3.5 Manure production } & 160\end{array}$

References 162

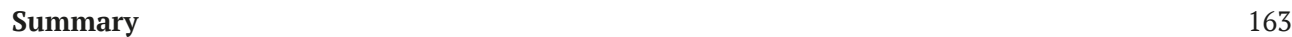

$\begin{array}{ll}\text { Acknowledgements } & 169\end{array}$

Biography 173

$\begin{array}{ll}\text { Education Certificate } & 175\end{array}$ 


\section{Introduction}

\subsection{Background Dutch dairy sector and European policies}

The Netherlands is one of the main dairy producers in the European Union (EU). The Dutch milk production per cow is among the highest of all member states. Due to the optimal climate conditions and the ideal strategic location in Europe, the international competitive position of the dairy sector is good. Thirty-five percent of the total Dutch milk production is marketed in the Netherlands, $45 \%$ in other EU member-states and 20\% in the world market (Rabobank, 2017).

During the last 15 years the structure of the Dutch dairy sector changed significantly. Compared to 2000, the total number of farms decreased by $29 \%$ to 16500 farms in 2016 . Currently the average farm size is around 56 ha, which is an increase of $47 \%$ compared to 2000. Also the number of animals increased by $64 \%$ to an average of 101 animals per farm in 2016. This growth resulted in an increase in average revenue per farm of 93\% (CBS, 2017). The milk production per cow increased significantly due to increasing the quality of housing and animal health, better animal feeding techniques and more efficient breeding. Because of this, nowadays an average dairy cow provides more than 8000 litres of milk per year, compared to 2500 litres in 1910 (CBS, 2017). The Dutch dairy sector can be characterized as a highly productive and competitive sector (i.e. its market share on the world dairy market is increasing (ZuivelNL, 2017) in the Netherlands as well as in Europe.

As an EU Member State, the Dutch dairy sector is affected by the European Common Agricultural Policy (CAP), which was introduced in 1957. At the start, this policy was developed in order to secure food supply to consumers and a reasonable income to producers in Europe. 
For the Dutch dairy sector, which consisted of relatively small producers with no influence on market prices (i.e. they were so-called price-takers), this meant that they received guaranteed minimum prices for their production that were generally higher than the world market price level (Dutch government, 2015). This price support policy induced farmers throughout Europe to produce more milk, which eventually led to overproduction of milk in the late seventies. Therefore in 1984 milk quotas were introduced to limit milk production in the European dairy sector. The milk quotas became an integral part of the Dutch milk production system. Dairy farmers were assigned a certain level of milk production rights which they could trade nationally (i.e. rent and buy or sell).

In the early 1990's, the CAP gradually evolved from a price support system into a direct income payment system (DP system) with an additional rural development component. Important steps in this process were: the MacSharry reform in 1992, Agenda 2000 in 1999, the Midterm Review in 2003 and the Health Check in 2008. Under this DP system Dutch dairy farmers received direct payment entitlements based on historical production levels; each farmer was granted rights corresponding to the payments he received during 2000-2002. Due to the shift from price support to a DP system, the milk quota system was less needed as an instrument to keep budget expenditure with respect to dairy under control. Therefore, as part of the 2003 reforms, it was decided to gradually increase milk quotas and fully abolish them in 2015 (soft-landing). Contrary to many other European member states, in the Netherlands the milk quotas were still binding at the time of full abolishment (i.e. the Dutch milk production was more than the national reference level of milk quotas in 2015).

In 2014 the European Common Agricultural Policy for 2014-2020 was implemented. The main goal of this policy, implemented under two pillars (see figure 1.1), is to reach a more sustainable development of the agricultural sector (Dutch government, 2015). The starting point is to make farmers less dependent on subsidy payments in order to induce them to innovate and eventually to increase efficiency and competitiveness (European Commission, 2011). As part of the new policy, the DP system switched gradually from a payment system based 


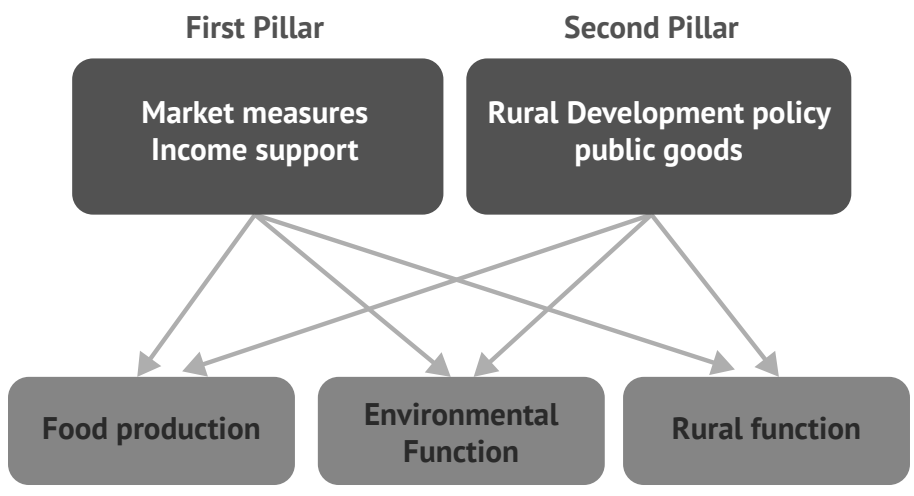

Figure 1.1 Pillars of the European Common Agricultural Policy

Source: European Commission (2017)

on historical production levels to a system in which fixed payments per hectare of agricultural land are paid to farmers. In the Netherlands all eligible dairy farmers will receive equal payments per hectare in 2019. Also there will be targeted payments to specific groups (e.g. young farmers).

The Dutch dairy sector is a key user of land and water resources in the Netherlands. Maintaining a sustainable environment is high on the agenda of the European Union. This is reflected in the second pillar of the CAP which contains the rural development program. Amongst others, this program financially supports the improvement of (European) water quality and other environmental measures (European Commission, 2011).

Besides the Common Agricultural Policy, there are European environmental policies in order to manage the use of (animal) manure. These policies are regulated through the European Nitrate Directive (Council of European Communities, 1991), which includes measures on the production and use of nitrogen and phosphate from animal manure, and which is linked to the Common Agricultural Policy through cross compliance. Farmers only receive their first pillar payments if they fulfil certain environmental and sustainability requirements (European Commission, 2011). 
Following the EU Nitrate Directive, the Netherlands is assigned a maximum level of total phosphate from animal manure production (national phosphate production ceiling). This level is equal to the phosphate production level of 2002. Also, as of 2006 the Dutch government put constraints on the quantity of (animal) manure that legally may be applied on land. If a farm exceeds the norm, it has a manure surplus, or so-called farm surplus, which is penalised by letting them pay a fine for every $\mathrm{kg}$ of animal manure in excess.

In combination with the milk quotas, which put a maximum limit on milk production and thus indirectly on manure production as well, the Dutch manure production of dairy farmers stayed within EU policy norms on the production and use of animal manure. However, when the milk quotas were abolished, a potential environmental risk for the Dutch dairy sector emerged as limits to milk production, and thus manure production, disappeared. Therefore, the Dutch government sharpened its manure policy in order to ensure that the Netherlands satisfies European environmental standards in the future as well. As of 1 January 2016, dairy farms that have an overproduction of animal manure are obliged to process all of these surpluses off-farm. Moreover, if they want to increase their milk production (the reference level is their milk production level of 2013), they are obliged to increase in land as well, as more land means more application and disposal space for the (increased) animal manure. In addition, a system of phosphate rights will be introduced in 2018. Under this system farms are not allowed to produce more phosphate than the number of rights they have obtained based on their livestock at 2 July 2015 (Dutch government, 2016).

\subsection{Problem statement}

Already since the start of the European Common Agricultural Policy in the 1960s, there have been many changes and revisions of this policy in order to cope with a changing, and challenging European agricultural environment. These changes also had their impact on the Dutch dairy sector, which is regulated through Dutch and European agricultural and 
environmental policies. In order to protect their competitive position in the European Union, the Dutch dairy farmers are challenged to adjust their farming strategies and become more sustainable through innovation of production techniques. Two main issues that significantly impacted Dutch dairy farmer behaviour are addressed below.

First, the changes in the Common Agricultural Policy regarding the subsidy payment system led to different responses and behaviour of farmers. Especially for intensive livestock systems, which include many Dutch dairy farms, the impact could be substantial. Under the DP system these (intensive dairy) farms received a substantial amount of subsidy, as payments were based on historical production levels. Under the new system, where payments are based on the amount of hectares a farm owns, these farmers will receive significantly less subsidy payments. We can expect dairy farms to adjust their farming strategy in order to maintain their income.

Second, the transition to the direct payment system made the milk quotas less needed. The resulting gradual increase and eventual abolishment of the milk quotas affected the Dutch dairy sector as a whole. Because the milk quotas were still binding when they were abolished, it was expected that the overall milk production in the Netherlands would increase in 2015 (Réquillart et al., 2008; Jongeneel, 2009; Jongeneel and Van Berkum, 2015). However, if the production of milk increases substantially it may eventually lead to lower market prices for milk, which makes production less profitable. Moreover, when farmers increase milk production after quota abolition, their animal manure production will increase as well. Due to the Dutch manure policy, new limitations and obligations to the use of (animal) manure exist. This affects the farmer behaviour with respect to optimizing production. They have to take decisions on optimal land allocation and manure processing costs into account as well.

The impact of policy changes on the agricultural sector as a whole and on the behaviour of farmers specifically, is a highly discussed topic in European policy analysis (e.g. Helming et al., 2010; Jongeneel et al., 2011; Bartolini and Viaggi, 2013). Farmers' responses to European 
farm policies are usually analysed using microeconomic producer theory (e.g. Gardebroek, 2004; Benjamin and Kimhi, 2006; Bartolini and Viaggi, 2013). However, one of the limitations of previous microeconomic models is that other aspects, such as physical conditions or socio-economic variables are not directly taken into consideration. This may reduce the predictive contents of such models. Especially the decision making process of farmers and their rationale behind specific farming strategies are most interesting to consider. This may improve the understanding of farmers' responses to changes in agricultural policies.

The analysis on the effects of milk quota abolishment and a changing manure policy on manure surpluses and (economic) farm management decisions is relatively scarce in literature. On the one hand several studies exist on the specific modelling of mineral-flows within a farm (e.g. Aarts et al., 1992; Buysse et al., 2005; Hadrich et al., 2008; Nousianen et al., 2011). Although these studies recognize the (technical) interactions between the several subsystems in a farm, i.e. milk output, feed production and manure management, they focus on optimal use of minerals and do not directly take manure policy measures into account. On the other hand, there are more applied agronomic studies that take manure policy into account and which focus on the Dutch dairy sector specifically (e.g. Evers et al., 2009; Krimpen et al., 2010), but in these studies an economic framework capturing the milk-feed-manure-nexus is lacking. A modelling approach in which the interaction between milk and manure production is integrated would substantially contribute to the understanding of the dynamics of Dutch dairy farms, and the way dairy farmers adjust their production levels in a changing political environment.

\subsection{Research objective and research questions}

All adjustments made in the Common Agricultural Policy and European manure policy had different impacts on the response and behaviour of the Dutch dairy farmers. Moreover, the impact of all individual farming choices together substantially affects the Dutch dairy sector 
as a whole. It is important to understand the dynamics and decision making processes in this sector. Especially for the Dutch government, so they can regulate the dairy sector well in order to maintain its current export position in the European market.

This thesis focuses on analysing Dutch dairy farmer behaviour in this changing political environment. It contributes to the literature in two ways. First, by analysing farmers' strategies and choices, it takes into account non-economic factors such as social characteristics of farmers and changing policy regulations. Second, the interaction between milk and manure production is integrated in the modelling approach.

The general objective of this research is to analyse the responses of Dutch dairy farmers in the situation of a changing agricultural and environmental policy context (i.e. transition from DP system to a flat-rate payment system, milk quota abolishment and the reformed Dutch manure policy), thereby taking into account economic as well as non-economic factors.

This objective leads to the following research questions, which are assessed in the separate chapters of this thesis:

1. What is the effect of a transition from the direct payment system to a flat rate payment system on the farm income and farming strategies of Dutch dairy farmers? (chapter 2)

2. Which economic and non-economic factors determine milk production expansion by Dutch dairy farmers? (chapter 3)

3. What are the interactions between Dutch milk and manure production and how can these relations be integrated in one modelling approach to analyse the effects of agricultural policy changes? (chapter 4)

4. Was the system of manure application norms restrictive for the dairy farms to increase in livestock? (chapter 5) 


\subsection{Data and research methods}

In order to study the research questions, yearly data (from the period 2001-2012) on various economic and non-economic variables were gathered from two databases. The first database is the Dutch Farm Accountancy Data Network (FADN, LEI Wageningen UR). This database consists of detailed farm information (such as farm characteristics and financial information) on a representative sample of farmers in the Netherlands. The second database is the LMM-database (Landelijk Meetnet Mestbeleid (in English: National Monitoring Network Manure), National Institute for Public Health and the Environment), which is used to monitor manure production in the Netherlands. This database contains detailed information (at the level of nutrients) on the production and use of organic and animal manure on Dutch farms. It also contains a representative sample of Dutch farmers. Originally, the analysis started with 2872 observations on 476 Dutch dairy farms, covering the period 2001 to 2010. Later this dataset was extended by including observations on farms in years 2011 and 2012. Due to data transformations and specification of variables, the final dataset includes 1193 observations on 334 Dutch dairy farms. Since farms usually remain in the panel for about five years, the dataset forms an unbalanced panel. The four research questions are analysed using different research methods. However, in every method economic and social factors are both taken into account.

In chapter 2 the first research question is analysed using an economic simulation experiment. This approach, which originates from other scientific disciplines such as natural sciences and psychology and which uses experiments to obtain naturally occurring data, has been picked up by economists in order to bridge the gap between economic theory and observation (Davis and Holt, 1993). Compared to traditional microeconomic approaches, experimental economics has several advantages that make it possible to analyze the actual process of farming and the reasoning behind the choices made by farmers on specific farming strategies. This way, experiments can be used as an extension to traditional economic research methods in order to better understand farmers' responses and behaviour to changes in the agricultural 
policy system. Besides analyzing the impact of an alternative direct payment system based on a flat rate and green payments in conjunction with an agri-environmental payment system, also the usefulness of economic simulation experiments in analyzing farmers' attitudes towards providing these ecosystem services is analyzed. For this, the characteristics of the experimental research method are compared to more traditional microeconomic research approaches.

The second research question is analyzed in chapter 3 using microeconomic investment theory in which non-economic factors are incorporated as well. It is assumed that farmers base their decision to expand in milk production on a comparison of expected benefits and costs of expansion. Several factors are involved in this decision making process. The first two sets of factors are the European and national policies and market conditions. These are external factors that cannot be influenced by the farmer. Besides these external factors, there are also two sets of internal factors that potentially have an important direct relation to the expansion decision. These include the values, goals and strategy of the farmer and the characteristics of the farm. The decision making on production expansion is analysed using a dynamic random effects probit panel data model.

The third research question is dealt with in chapter 4 where a microeconomic modelling approach is used that is extended by including manure production and policies. In this model the dairy farmer's decision is characterized by a short-run profit maximization problem where output supply and variable input demand are chosen at optimal levels given exogenous output and input prices and levels of quasi-fixed inputs. In order to capture essential trade-offs in farmers' decision making the production technology is decomposed in four sub-production functions: milk production, feed production, own roughage production and animal manure production. The interactions between these different production relationships are integrated in one approach in order to analyse the effects of agricultural policy changes. The production technologies for milk, feed and roughage are estimated using panel data, while an agronomic calculation approach is used to determine manure production. 
Chapter 5 answers the fourth research question using a short-run profit maximization problem. This problem is extended by including manure processing costs for dairy farms with a manure surplus. Using panel data techniques a shadow price equation for dairy cows is derived and estimated. From this equation the demand function for dairy cows is deducted, which allows to test for the interaction between manure surplus processing costs and the number of dairy cows demanded at farms. This approach specifically assesses the farmer behaviour towards making optimal choices on milk and manure production in the presence of manure policy regulations.

Chapter 6 presents the general conclusion. In this chapter the separate chapters are integrated and a general view on the research objective is given. Also a discussion on the results is provided. 


\section{References}

Aarts, H.F.M., Biewinga, E.E. and Keulen van, H. (1992). Dairy farming systems based on efficient nutrient management. Netherlands Journal of Agricultural Science 40: 285-299.

Bartolini, F., Viaggi, D. (2013). The common agricultural policy and the determinants of changes in EU farm size. Land Use Policy 31: 126-135.

Benjamin, C., Kimhi, A. (2006). Farm work, off-farm work, and hired farm labour: estimating a discrete-choice model of French farm couples' labour decisions. European Review of Agricultural Economics 33: 149-171.

Buysse, J. Huylenbroeck van, G. Vanslembrouck, I. and Vanrolleghem, P. (2005). Simulating the influence of management decisions on the nutrient balance of dairy farms. Agricultural Systems 86: 333-348.

CBS (2017). Official statistics for the Netherlands. Melkveebedrijven: aantal melkkoeien gestegen (in English: Dairy sector: number of dairy cows increased). Retrieved March 2017, from https://www.cbs.nl/nl-nl/achtergrond/2016/33/ melkveebedrijven-aantal-melkkoeien-gestegen.

Council of European Communities (1991). The Nitrates Directive. Official Journal of the European Communities 34: L 375.

Davis, D.D., Holt, C.A. (1993). Experimental economics. Princeton University Press, USA, Princeton.

Dutch government (2015). Landbouwbeleid (in English: Agricultural policy). Retrieved July 2015, from http://www.rijksoverheid.nl/onderwerpen/landbouw-en-tuinbouw/ landbouwbeleid.

Dutch government (2016). Wijziging van de Meststoffenwet in verband met de invoering van een stelsel van fosfaatrechten (in English: Change of manure policy with regard to system of phosphate rights). Tweede kamer der Staten generaal. Kamerstuk 34 532, voorstel van Wet. The Netherlands, The Hague. 
European Commission (2011). Proposal for a regulation of the European parliament and of the council establishing rules for direct payments to farmers under support schemes within the framework of the common agricultural policy. European Commission, Brussels, $108 \mathrm{pp}$.

European Commission (2017). European Network for Rural Development. Retrieved June 2017, from http://enrd.ec.europa.eu/enrd-static/policy-in-action/ rural-development-policy-overview/introduction/en/introduction_en.html.

Evers, A.G., Haan de, M.H.A. and Sebek, L. (2009). Economisch perspectief verlaging fosforgehalte in krachtvoer (in English: Economic perspectieves on reducing phosphate levels in concentrates). Lelystad, The Netherlands: Animal Sciences Group, Wageningen UR.

Gardebroek, C. (2004). Capital adjustment patterns on Dutch pig farms. European Review of Agricultural Economics 31: 39-59.

Hadrich, J.C. Wolf, C.A. Black, J.R.Harsh, S.B. (2008). Incorporating Environmentally Compliant Manure Nutrient Disposal Costs into Least-Cost Livestock Ration Formulation. Journal of Agricultural and Applied Economics 40: 287-300.

Helming, J., Jansen, S., van Meijl, H., Tabeau, A. (2010). European farming and post-2013 CAP measures : a quantitative impact assessment study. LEI Wageningen UR. The Netherlands, The Hague.

Jongeneel, R. (2009). Een tijd van komen en gaan, in: Peerlings, J. and Gardebroek, C. (Eds.), Van boterberg naar biobased : de Nederlandse landbouw in perspectief (in English: Dutch agriculture in perspective). Wageningen Academic Publishers, The Netherlands, Wageningen.

Jongeneel, R., Burrell, A., Kavallari, A. (2011). Evaluation of CAP measures applied to the dairy sector. European Commission Directorate-General for Agriculture and Rural Development. Belgium, Brussels.

Jongeneel, R. and Van Berkum, S. (2015). What will happen after the EU milk quota system expires in 2015? An assessment of the Dutch dairy sector. LEI Wageningen UR. The Netherlands, The Hague. 
Krimpen van, M. Middelkoop van, J. Sebek, L. Jongbloed, A. and Hoop de, W. (2010). Effect van fosforverlaging in melkveerantsoenen en varkensvoeders op fosfaatexcretie via de mest (in English: Effects of phosphate reduction in the ration of dairy cows and pigs on phosphate excretion from manure). Wageningen UR Livestock Research. The Netherlands, Lelystad.

Nousianen, J. Tuori, M. Turtola, E. and Huhtanen, P. (2011). Dairy farm nutrient management model. Model description and validation. Agricultural Systems 104: 371-382.

Rabobank (2017). Cijfers en trends melkveehouderij (in English: Facts and figures Dutch dairy sector). Retrieved March 2017, from https://www.rabobankcijfersentrends.nl/index. cfm?action=branche \&branche=Melkveehouderij.

Réquillart, V. Bouamra-Mechemache, Z. Jongeneel, R. and Penel, C. (2008). Economic analysis of the effects of the expiry of the EU milk quota system. Institute D’Economie Industrielle (IDEI). France, Toulouse.

ZuivelNL (2017). Ketenorganisatie van de zuivelsector (in English: Chain organisation of dairy sector). Retrieved March 2017, from http://www.zuivelnl.org/. 


\section{Analysing Dutch Dairy Farmer Behaviour Towards the Provision of Public Goods: The Added Value of an Economic Simulation Experiment ${ }^{1}$}

\section{Abstract}

The objective of this chapter is to examine the value of experiments for assessing the impact of the proposed Common Agricultural Policy of 2013 on farm income and farming strategies. We focus specifically on the impact of an alternative direct payment system based on a flat rate and green payments. We show the added value of an economic simulation experiment to existing economic microand sector modeling analysis when analyzing farmer behaviour. It is shown that the suitability of and rewards for the provision of green services play a significant role in their uptake by farmers and the support for them. These results are useful in implementing a revised direct payments system in the Netherlands for the future.

\footnotetext{
Paper by Gerlinda S. Samson, Cornelis Gardebroek and Roel A. Jongeneel, Land Use Policy 34 (2013) 321 - 331. Doi: 10.1016/j.landusepol.2013.04.005
} 


\section{$2.1 \quad$ Introduction}

Since the start of the European economic integration, agriculture has played a major role in European policies. Under the current European Common Agricultural Policy (CAP), Dutch farmers receive payment entitlements based on historical production levels; each farmer is granted rights corresponding to the payments he received during 2000-2002 (Dutch Government, 2011). These so called direct payments are conditional on satisfying minimum standards with respect to nature, environment, sustainability and animal welfare (crosscompliance). If farmers fail to meet these criteria, their payments are decreased or completely cancelled.

In 2013 the current CAP will be reformed. In October 2011, the European Commission published their proposal for this reform (European Commission, 2011). The main aim of the proposal is to redistribute, redesign and better target support to farmers, by enhancing competitiveness and improving sustainability. The base of allocating direct payments to farmers is planned to change from entitlements based on historical production levels into a flat rate payment per eligible ha.

Helming et al. (2010) conclude that the transition to flat rate farm payments and the abolition of direct payments will potentially lead to a reduction in production and an induced increase in agricultural prices in the EU. The average gross value added per farm will decrease and the total area used for agricultural production will decrease as well (Helming et al., 2010: p. 12). Vrolijk et al.(2010:p.47) argue that an abolishment of direct payments will result in less stable farm incomes, as the subsidies are a significant part of farm incomes nowadays. Consequently, the abolishment of direct payments is argued to speed up the process of structural change in the agricultural sector, although this will differ by country given the heterogeneity in original subsidy levels and differences in the implementation of the direct payment system over EU Member States. Focusing on the Dutch dairy sector, Jongeneel et al. (2012: p. 75) state that the proposed changes of the direct payment system will negatively affect the financial position 
of farms. On average, the loss of income for this sector is estimated to be $€ 7000$ per year per farm. The relative more intense farms, i.e. the farms having a larger density of livestock per hectare, are affected more than extensive ones.

A new element in the CAP reform proposal is the introduction of a so-called 'green payment' (European Commission, 2011). This will be paid for agricultural activities meeting climatic and environmental policy goals, such as payments for crop diversification, ecological focus areas and permanent grassland. For this greening component, the European Commission proposes three (controversial) requirements (European Commission, 2011). These include (i) uptake of permanent grassland per individual farm, (ii) growing at least three types of crops for farms with a minimum agricultural area of 3 ha, and (iii) $7 \%$ of the eligible farm area, excluding permanent grassland, needs to be an ecological focus area, i.e. set-aside area. This 'package' is highly criticized by many European national governments as too rigid. In May 2012, Commissioner Dacian Cioloş announced therefore some adjustments to the propositions of the European Commission. One option might be dispensation of the requirements for farms producing under a label (certification) or supplying agricultural landscape management services. Also the propositions on crop diversification and permanent grassland might be relaxed. Nevertheless, the 7\% set-aside requirement will most likely be maintained (European Commission, 2012). Whereas generally greening has been associated with voluntary farmer behaviour (e.g. farmer participation in CAP agri-environmental schemes), the requirements associated with the green payment are compulsory in order to obtain this payment. The proposed green payments go beyond the already existing cross-compliance requirements (European Commission, 2011).

The Dutch government supports these reform proposals in principle although they would like the greening component to be more ambitious (Dutch Government, 2012). One potential option to achieve this would be to move money from the first pillar to the second pillar of the CAP which could strengthen the provision of a broad array of green services. However, questions arise whether it is realistic to involve more farmers in the provision of green 
services in order to reach the policy goals set by the European Commission. Besides the standard agricultural activities, such as dairying, Dutch farms already exploit other agricultural activities as well, such as agricultural landscape management. This means that farms in return for a financial compensation voluntarily provide so-called green and blue services to maintain the landscape (agri-environmental schemes). These activities are different from the compulsory cross-compliance requirements. Figure 2.1 shows the number of Dutch farms involved in agricultural landscape management.

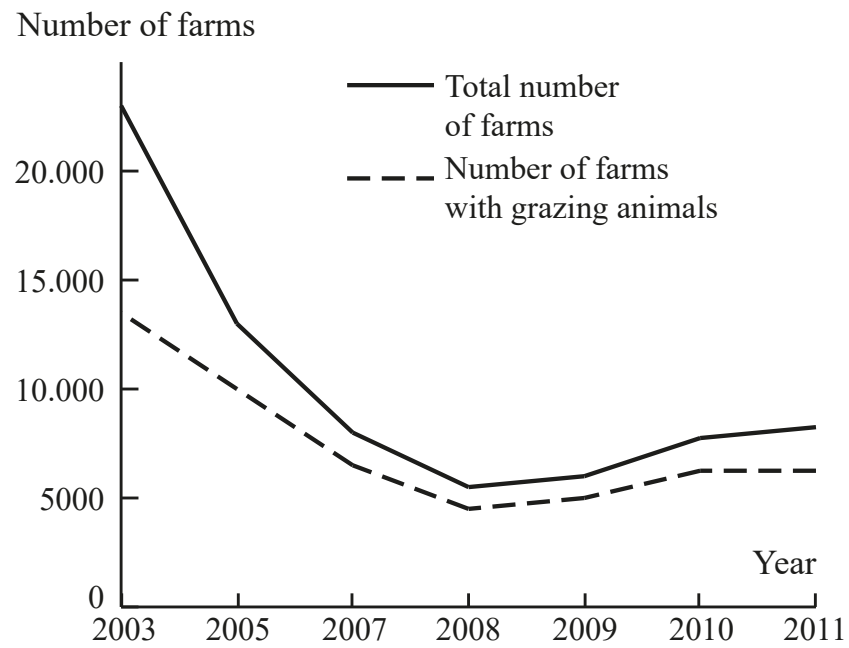

Figure 2.1 Number of farms participating in agri-environmental schemes.

Source: CBS (2012)

As can be seen, after a period of rapid decline, in 2008 the number of farms participating in agricultural landscape management started to increase again. Nevertheless, this recent growth is very modest and there are doubts whether the total number of farms involved in agricultural landscape management will increase further in the coming years (Berkhout and Roza, 2012: pp. 91-92). 
In their study on social and green services by farmers, Prins and Smit (2011: p. 11) state certification as one of the most effective options to stimulate agricultural landscape management and communal awareness. One critique, however, seems the increasing administrative burden and complex control of the requirements for obtaining the certification label. Other measures, such as performance-related payments for supporting nature, where farmers obtain payments per implemented agricultural service, are found to be effective as well (e.g. a so-called points-system, where farmers can earn valuable points for services stimulating agricultural landscape management and contributing specific services to the local economy (Hodge, 2009: p. 43)). A reason why (voluntary) support for the greening component might not be that high in the Netherlands, could be the low trust farmers have in the government. Trust plays a significant role in the choice to supply public goods that are rewarded by the government (Jongeneel et al., 2008). Also farmers are afraid that the administrative burden will rise when providing (more and/or different) green services. Some farmers argue that if the subsidy for the (extra) effort they need to put in for providing the agricultural services is not sufficient, they rather prefer to not obtain the subsidy at all.

Ideally a farmer is compensated for all the extra efforts in the provision of green services (Wilson and Hart, 2000; Vanslembrouck et al., 2002; Mettepenningen et al., 2013). However, there will be cuts in the agricultural budget. In the proposals on the Multiannual Financial Framework for the period 2014 to 2020, the European Commission advocates to reallocate direct payments between and within (i.e. transition from historical model towards a regional model) Member States. For the Netherlands, such a reallocation will lead to a decrease of around 11\% of the net ceilings for direct payments in the period 2013 to 2020 (Venema et al., 2013: p.14). Consequently, there will be less resources available for subsidies on landscape management as well, which will potentially reduce the number of farms involved in providing these services even further. Not surprisingly, the level of subsidy payments is therefore another hot topic in the current debate on stimulating the provision of green services by farmers. 
The impact of the proposed changes of the direct payments on the agricultural sector as a whole and on the behaviour of farmers is a highly discussed topic in European policy analysis. Farmers' responses to European farm policies are usually analysed using microeconomic producer theory (see e.g. Gardebroek, 2004; Benjamin and Kimhi, 2006; Bartolini and Viaggi, 2013). Traditionally, microeconomic models are based on a reduced form representation of the actual production process (i.e. a production function distinguishing inputs and outputs, but treating the actual process of farming largely as a black box) and on data subtracted from existing "natural" markets (Davis and Holt, 1993: p. 3). Nevertheless, when these models become more specific and complex, this leads to rather stylized results, as these traditional economic models rely on several assumptions and do not allow for deviations from these.

For this reason, one of the limitations economists are often accused of is not taking the relevant natural environment into consideration accurately when developing models, which reduces the predictive contents of economic models. Other scientific disciplines, such as natural sciences but also psychology, make use of experiments to obtain naturally occurring data. This approach has been picked up by economists recently in order to bridge the gap between economic theory and observation, and is nowadays known as experimental economics (Davis and Holt, 1993: p. 4).

The objective of this chapter is to examine the value of experiments for assessing the impact of the proposed Common Agricultural Policy of 2013 on farm income and farming strategies. We focus specifically on the impact of an alternative direct payment system based on a flat rate and green payments in conjunction with an agri-environmental payment system. In this study we focus on the Dutch dairy sector, which takes a special interest because this sector benefits from direct payments under the current CAP. The proposed reform potentially has a major impact on the income of dairy farmers and will possibly affect their behaviour significantly. The characteristics of the experimental research method are compared to more traditional microeconomic research approaches. 
This chapter contributes to the literature in two respects. First, we focus on changes in EU policies for providing ecosystem services on private land, a topic that is currently high on the agenda in both policy and academia. Second, we discuss the usefulness of economic simulation experiments in analyzing farmers' attitudes towards providing these ecosystem services.

This chapter continues in section 2.2 by providing a basic review on experimental economics, since this research method is relatively new and not frequently used in land use literature. This is relevant for a well-understanding of the principles of the method. In section 2.3 we outline, and critically evaluate, the experimental set-up of an economic simulation experiment used by the Dutch Agricultural Economic Research Institute (Zijlstra et al., 2011). This experiment was performed to analyze Dutch dairy farmer behaviour towards the provision of public goods under an alternative direct payments system. The results of the economic simulation experiment provide input for the assessment on the added value of using such experiments in analyzing farmer behaviour. These results are presented in section 2.4 . In that section we also further contribute to the current dialogue on the introduction of the proposed CAP reform in the Netherlands and the potential impact of this on farm income and farming strategies, as well as to the current debate on the provision of ecosystem services on private land. Finally, in section 2.5 we provide conclusions.

\subsection{Background on experimental economics}

As stated in the introduction, experiments were recently introduced in (agricultural) economics (see e.g. Chan et al., 1999; Anderson et al., 2008; Uler, 2011). It therefore makes sense to first provide some background information on experimental economics before we move to investigating the added value of using an economic simulation experiment besides the traditional economic analysis methods. 


\subsubsection{Types of experiments}

Throughout the years, different types of experiments have been developed in economics. Depending on its goal, one should carefully set up an experiment as this influences the type of outcome obtained. It is also possible to combine different types of experiments. Harrison and List (2004) developed a useful classification of 4 types of experiments, which is based on the goal of the experiment. Table 2.1 summarizes this categorization.

The first category identified in Table 2.1 contains conventional laboratory experiments. In this type of experiments the participants are people that are not directly involved in the topic of the experiment. This is referred to as a standard subject pool, and often students are used for this. The experiments are conducted in an abstract environment, for example, the experiment may be carried out on a computer where the participants play a virtual game. The freedom respondents have in reacting is regulated beforehand.

The second category contains artefactual field experiments, which are the same as laboratory experiments, only instead of a standard subject pool, they use participants that are directly involved in the topic of the experiment such as policy makers or farmers.

Table 2.1 Types of experiments

\begin{tabular}{|c|c|c|c|c|}
\hline Class & Type & Participants & $\begin{array}{l}\text { Natural } \\
\text { environment }\end{array}$ & $\begin{array}{l}\text { Imposed } \\
\text { regulations }\end{array}$ \\
\hline 1 & Conventional laboratory experiments & $\begin{array}{l}\text { Standard subject } \\
\text { pool }\end{array}$ & No & Yes \\
\hline 2 & Artefactural field experiments & $\begin{array}{l}\text { Non-standard } \\
\text { subject pool }\end{array}$ & No & Yes \\
\hline 3 & Framed field experiments & $\begin{array}{l}\text { Non-standard } \\
\text { subject pool }\end{array}$ & Yes & Yes \\
\hline 4 & Natural field experiments & $\begin{array}{l}\text { Non-standard } \\
\text { subject pool }\end{array}$ & Yes & No \\
\hline
\end{tabular}

Source: Harrison and List (2004) 
The third category includes framed field experiments. This type of experiments also uses directly involved participants as subject pool and an imposed set of rules, but in contrast to the artefactual field experiment, they also include a natural setting in the experiment. This setting can be related to the product, assignment or information set, depending on the goal and experimental set-up.

The fourth category consists of natural field experiments, which are similar to framed field experiments, but which are fully carried out in the natural environment of the participants. Often, these participants are not even aware of participating in the experiment, which shows that regulations are not set beforehand.

\subsubsection{Objectives of experiments}

As stated in section 2.2.1 different types of experiments lead to different outcomes. For this reason it makes sense to look at the different objectives of experiments in more detail. These objectives can be categorised in four groups (Schram, 2005). First, testing behavioural hypotheses; second, theory stress tests; third, testing for empirical regularities; and fourth, advising policy makers.

Most experiments fall into the first category of testing behavioural theories. These experiments contribute to traditional, neo-classical economic models by bridging the gap between theory and practice. Theory can be tested in an experiment in two ways; first, experiments can provide more insight into the working of institutions, and second, they can be used to test the underlying behavioural assumptions of economic theory. Experiments carried out for testing theories, may lead to adjusting these theories, and provide as such a way to speak to theorists.

The second objective relates to defining the external validity of economic theories. This can be done by including so-called stress tests in the experiment. These allow for testing 
assumptions by relaxing them in a controlled way, allowing for conclusions on the external validity of theories to be drawn. External validity can also be increased by comparing the results of the experiment with other empirical evidence. More about external validity is provided in section 2.2.5.

The third objective relates to experiments used for searching empirical regularities. Sometimes, research reveals relationships between variables which were not found before. Experiments can then be used to provide more insight into these specific relationships. This might then positively impact on the development of economic theory.

Since experiments provide extensive information on the behaviour of economic agents, they can be used as a source for making policy, which is the fourth type of objective we describe here. The wide range of articles that describe experiments used for this purpose show the importance of it. One example is the study by Uler (2011), who investigates the net impact of tax levels on the provision of public goods by farmers, using a controlled laboratory experiment. The results of his experiment provide important conclusions for setting better targeted government policies regarding the provision of public goods. Kachelmeier and King (2002) emphasize the usefulness of using laboratory experiments when assessing policy issues regarding accounting. Also the experiment described in this study provides important information for the current debate on setting efficient future direct payments policies.

\subsubsection{Design of a successful experiment}

Besides selecting the type of an experiment, based on the objective of the research, there are several design and procedural issues which should be taken into account in order to set up a successful experiment (Davis and Holt, 1993: p. 20).

First, there are 'procedures and regularities'. In order to make replication possible, one should follow and report standard practices and procedures in an experiment. 
Second, there is 'motivation'. Rewards are helpful to motivate participants to take part in an experiment. Smith (1982) points out the importance of providing rewards to participants. He describes several principles (i.e. non-satiation, dominance and relevance) that must be satisfied in this context. Together these principles ensure the saliency of the experiment (Davis and Holt, 1993: p. 24). Furthermore, if the reward used is a monetary reward, it will reduce the concerns about heterogeneous individual preferences towards the reward since rationally all participants will put a value on money.

A potential problem of monetary rewards is that it reduces the respondent's focus on the real task. Using financial incentives to let respondents think more carefully about their task to perform, might lead to replacing intrinsic motives with extrinsic ones. This is not desirable if the objective of the experiment is to test for intrinsic motivations; actions maximizing intrinsic payoffs may not be the same as actions maximizing economic payoffs (Read, 2005). Moreover, even in case monetary rewards are successful in inducing respondents to take their task more seriously, it does not necessarily invoke them to make rational choices. In fact, some evidence exists of experiments with monetary payoffs in which respondents show irrational behaviour even if they are confronted with their irrational behaviour (Read, 2005).

Monetary rewards might be helpful in taking away any biased (or sub-optimal) behaviour of respondents (Davis and Holt, 1993: p. 25). However, Holt (1992) shows that a successful experiment can be designed where subjects show optimal behaviour without financial incentives. Read (2005) states that many studies show that in experiments respondents can be motivated by monetary as well as non-monetary rewards. Moreover, if these non-monetary rewards are what we are interested in for studying, there is no reason to use monetary rewards instead (Read, 2005).

Third, there is 'un-biasedness'. To achieve natural results, participants should be unaware about what type of behaviour is expected in the experiment. A researcher should therefore 
find a balance between providing just enough relevant information to motivate participants without providing suggestive expressions to them.

Fourth, there is 'calibration'. Incorporating standardization into the generation of data provides a clear basis for analysing and evaluating the research.

Fifth, there is 'design parallelism'. This indicates that an experiment should correspond closely to the real world; it should be constructed in a way that economic events can occur naturally. Parallelism refers to the idea that behaviour of individuals and performance of institutions that have been tested in an experiment will be the same in a non-experimental setting where similar ceteris paribus conditions apply. There is a strong link with external validity which will be explained in section 2.2.5.

\subsection{4 (Dis)advantages of experiments}

Experiments are being discussed for their advantages and disadvantages as a tool for (micro) economic analysis. Often stated advantages of experiments, compared to traditional, neo-classical microeconomic analytical methods, are the better possibilities to replicate and control an experiment. Traditional models are, in contrast, usually estimated based on non-controlled historical data (i.e. examining economic behaviour of agents via extrapolation of data of the past). Using experiments has the possibility to test new arrangements or products and makes it possible to analyse new cases.

'Replication' is the possibility for other scientists to perform the experiment in the exact same way, thereby verifying the findings independently (Davis and Holt, 1993: p. 14). In order to use an experiment as a tool to analyse certain microeconomic behaviour, it should be set up carefully. Describing this process accurately makes it possible for other researchers to repeat the experiment. 
'Control' is the ability to manipulate the imposed regulations of an experiment in such a way that observed behaviour can be used to evaluate alternative theories and policies (Davis and Holt, 1993: p. 15). Even natural field experiments can to some extent be used to provide a minimum test of theory. For this it is necessary that the environment, in which the experiment is conducted, is fully understood by the researcher. Also potential changes in the environment should be taken into account. Through this control of experiments, researchers are able to systematically rule out alternative explanations and problems such as adverse selection, moral hazard or relational contracting (Just and $\mathrm{Wu}, 2009$ ). If an experiment is performed under the appropriate conditions and in a controlled environment, one can test hypotheses accurately.

Opponents of using experiments in economics argue that the real world is too complex to control for in an experiment, and therefore an experiment cannot provide exclusive conclusions on theories. Technical difficulties in setting a controlled environment exist, especially when the experiment tests individual preferences. For example, behavioural questions concerning risk attitude may be difficult to address in a laboratory. Some critics therefore claim that experiments are best used as complements to other empirical techniques (Davis and Holt, 1993: p. 18).

\subsubsection{Validation of experiments}

Two concepts that are important in validating any research, including experiments, are internal and external validity. Internal validity of an experiment refers to the degree to which confident conclusions about causal relationships can be drawn from the research, and external validity of an experiment refers to the possibility of generalization of the findings in the research and whether these can be extended to make predictions about the whole population (Schram, 2005). Especially the external validity might be a problem in experimental economics (Just and Wu, 2009). Even if experiments are performed according to exact the same decision making processes as used in practice, they might not sufficiently reflect reality 
(Loewenstein, 1999). For example, lack of reality is found in laboratory-type experiments where participants play a virtual computer game.

Often experiments take place in a laboratory environment instead of a realistic field context. Harrison and List (2004) however, point out the importance of including a field context in the experiment. The absence of a field context might influence participants' perceptions of the importance of the research and their participation in it, and may lead to a failure in applying specific relevant field heuristics as well. For this reason there might exist contradictories between individual's behaviour in the field and in the experiment.

Just and $\mathrm{Wu}$ (2009) argue that in order to achieve external validity, the design of the experiment should carefully incorporate economic theory. For this Binmore's criteria are helpful (Binmore, 1999). These criteria state that economic theory can only be expected to predict well if the following requirements are met. First, the assignment provided to the participant is presented in an understandable way and is easy to perform. Second, participants are faced satisfactory incentives. Third, there is sufficient time reserved in the experiment to make trial and error adjustments.

\subsection{The economic simulation experiment}

A recent study on the impact of a changed direct payments system on the participation in green services and resulting incomes of Dutch farmers uses an economic simulation experiment (Zijlstra et al., 2011). In this section we will outline the set-up of this simulation experiment used, and critically evaluate it. 


\subsubsection{CAP options}

The economic simulation experiment was developed by the Dutch Agricultural Economic Research Institute (LEI) and carried out in November through December 2010. In commission by and consultation with the Dutch Ministry of Economic Affairs, Agriculture and Innovation the purpose of the simulation experiment was to investigate the impact of the propositions concerning the direct payments by the European Commission for the 2013 CAP reform. Policy advisors and experts from the dairy sector were involved in the preparation and set up of the simulation experiment as well. The two key questions assessed were first, what are the choices (operational, tactical, strategic) made by farmers if new policies are used in order to determine the level of direct payments provided to them, and second, will these new policies lead to the desired farmer behaviour with respect to the provision of public goods.

Before the actual simulation experiment took place, farmers were informed during plenary meetings with policy advisors and experts from the dairy sector about the contents of the simulation experiment. In this meeting, farmers got to interact and were asked for their first opinion regarding the proposed changes of the current direct payment system. Next, the simulation experiments were performed at the farm. Experts from the dairy sector ran the simulation experiment with each farmer individually. After all farmers were visited, their results from the simulation were discussed in plenary meetings with the same policy advisors and experts from the dairy sector as before. Farmers deliberated on how they intend to respond with their farming strategy to changes in the current direct payment system, and gave their final opinion on the expected effects of these changes. This increased the value of the research by combining and underpinning the quantitative results of the experiment with qualitative information resulting from the plenary sessions with farmers. After these plenary meetings policy advisors came together to discuss and reflect on the results of the group meetings; this was useful in interpreting the results of the experiment in a wider context and checking the (external) validity of the results. The main results are provided further down in this chapter. 
In total 35 dairy farmers were selected to participate in the simulation experiment. Their farms were located in three different areas within the Netherlands, which are referred to as 'East-sand', 'West-peat' and 'South-sand'. Twelve dairy farms were selected in 'East-sand', 11 dairy farms in 'West-peat' and 12 dairy farms were selected 'South-sand'. The first two regions included areas that are ecologically valuable. In these regions it was interesting to see whether farmers change their participation in providing landscape services under the proposed CAP. In the South-sand region dairy farmers may experience a drop in income when transiting from the current to the proposed CAP, which made it worthwhile to investigate changes in farm strategy because of this expected income drop.

The simulation experiment consisted of two runs with different treatments; the first run was based on the current CAP, and the second run was based on the proposed CAP. Under the current CAP, farmers received direct payments based on historical production levels. There were no extra payments included for the provision of public goods, i.e. green and blue services.

Under the proposed CAP, which was based on the propositions by the European Commission to revise the direct payments from 2013 onwards, each group of farmers received direct payments in the form of a "flat rate" surcharge of $€ 250$ per ha. However, for each farmer the scenarios were different in receiving a "top-up” reward, these are payments for extra agricultural effort, and rewards for green and blue services provision. The farmers located in 'Eastsand' received a top up payment of $€ 500$ per ha, if their farm was located in a Natura 2000 area, and if they produced no more than the maximum manure excretion level of $250 \mathrm{~kg} \mathrm{~N}$ per ha. Farmers that did not fulfill the maximum manure excretion level of $250 \mathrm{~kg}$ per ha would not receive the top-up payment. However, these farmers were forced to reduce their emissions by investing in emission- reducing technologies and for that they could obtain an investment subsidy, e.g. to build a N-emission-free stable. Hence, some farmers in 'East-sand' chose to become more extensive. Moreover, in both situations, the maximum application standard of manure was $250 \mathrm{~kg}$ per ha. In exchange for receiving a top-up reward of €200 per ha, farmers in 'West-peat' were obliged to maintain permanent grassland. A second precondition was 
that the farms should be located in a Less Favored Area, but this was already ensured with the selection of the farms for the simulation experiment. Farmers in 'South-sand' were not offered any top-up rewards.

\subsubsection{Hypotheses tested in the economic simulation experiment}

In the simulation experiment, two hypotheses were tested. It could be argued that the more intensive farms which receive a relatively large amount of direct payments under the current system, will face the largest effect, i.e. relatively biggest decrease in payments, when a transfer to a system based on a flat rate and top-up rewards is implemented, and vice versa. But, due to the availability of top-up payments, farmers in 'East-sand' and 'West-peat' can smooth this effect.

The first hypothesis tested in the simulation experiment was that farmers will respond by focusing their farming strategy on generating more income if they expect a decrease in income from subsidy payments under the proposed payment system. A possible strategy change could be the uptake of green and blue services provision.

Under the current CAP the organization of all kinds of green and blue services is differentiated into ministries, provinces, water boards, water companies etc., and they are only partly linked to the direct payments. Under the proposed CAP in the simulation experiment all these services were included in one system only and paid for by the government in the form of green payments. The green- and blue services that farmers could choose to implement under the proposed CAP were based on the system as it currently exists under the current CAP, but they were adapted to local conditions and sometimes new requirements were set. Note that this were other services than the compulsory services farmers already needed to provide if their farm is located in a nature protection area, such as Natura 2000. The payments for these new service packages were determined relying on the compensation of income foregoneprinciple. As such it recognized the opportunity costs farmers face when deciding to supply 
the green and blue services, while it also tried to avoid over-compensation. Note that under the proposed CAP farmers could choose to provide services which they could not provide under the current CAP.

The second hypothesis tested in the simulation experiment was that farmers are more willing to implement green and blue services, if the services fit better to the current farm situation and if the opportunity costs are feasible.

The green and blue services farmers could choose to provide under the proposed CAP in the simulation experiment, included three main categories; nature/biodiversity/landscape, recreation, and water. All these services were individual agreements between the government and the farmer. Collective agreements involving more than one farmer were not present in the simulation experiment. The appendix shows more details on the types of green and blue services as well as their rewards.

\subsubsection{Set-up of the economic simulation experiment}

In this section we have a further look into how the simulation experiment was actually run. Figure 2.2 shows the construction of the economic simulation experiment, with the (individual) farmer being the key-decision maker in the simulation experiment.

In the simulation experiment farmers were asked to indicate their farming strategy between 2010 and 2020. The outcome of each simulation was the net income and land use of the farm in 2020, which were calculated based on the decisions made by the farmer during the run. After both runs of the simulation experiment, i.e. a first run using the current CAP and a second run using the proposed CAP, the differences between the two runs were reflected as changes in net income and land use in 2020. These differences were compared to analyze the impact of the proposed changes in the CAP on the behaviour of farmers. 


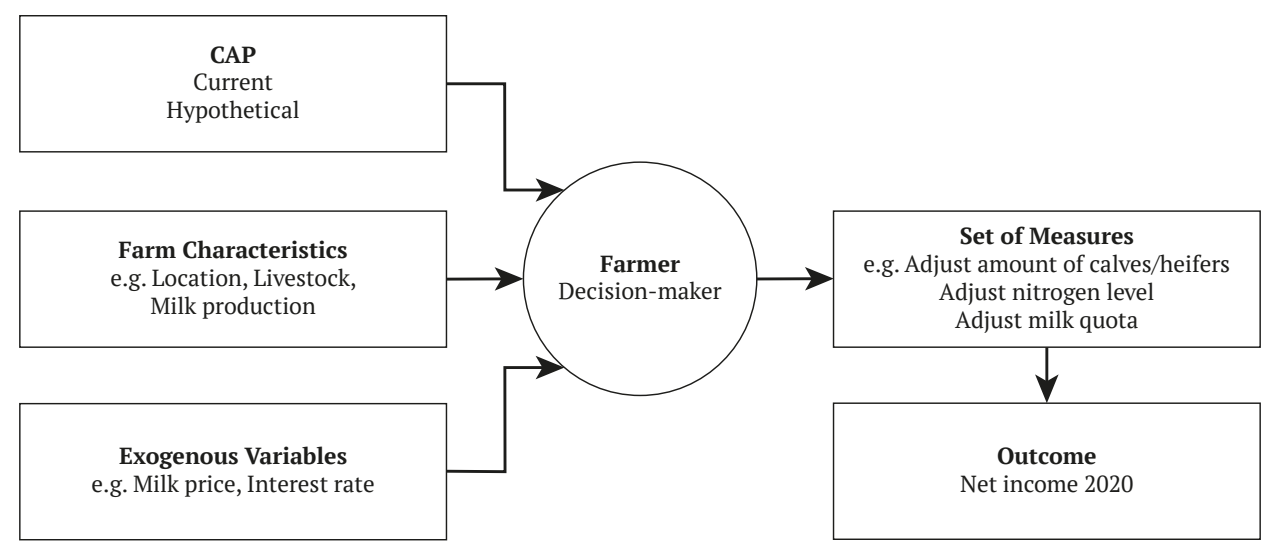

Figure 2.2 Contents of economic simulation experiment

Source: adapted from Zijlstra et al. (2011)

The base situation, or starting situation of the simulation, was the situation of the farm in the year 2009. The selected farmers were all participating in the Dutch FADN, which enabled the researchers to allow a farmer to simulate different scenarios with information coming from his own farm. In this way, farmers are able to take realistic decisions when deciding on their farming strategy. Also they will face relevant and realistic outcomes of their decisions. This increased the value of the simulation results.

The farmers were asked to yearly adjust their farming strategy towards their expectations between 2010 and 2020. The simulation experiment incorporated several variables that could be modified by the farmers in order to do so. First, farmers could choose to make adjustments on their farm. These included 1) adjusting milk quota: farmers filled in the amount of own quota and amount of leased quota per year; 2) adjusting genetic quality of dairy herd: farmers indicated the annual percentage change in milk yield, which implicitly reflects their breeding strategy; 3) adjust fodder ration: farmers filled in the amount of concentrates intake per cow; 4) adjust amount of calves and heifers: farmers indicated the grow in their dairy herd; 5) adjust amount of land (ha): farmers filled in the amount of own and rented land by year; 6) adjust nitrogen output: farmers filled in the level of nitrogen output from their herd, 
and 7) adjust grazing system: here the famers filled in two values. First, the percentage change of quality of grass they were planning to achieve by improved grassland management. Second, they indicated the percentage of cows grazing in the fields by year. During the second run, considering the propositions of the CAP reform, there was one more measure farmers could adjust: 8) provision of green and blue services: here farmers selected the services they would like to provide (see appendix).

Second, farmers could modify several exogenous variables according to their expectations on the future. Although in reality these exogenous variables are determined by the market, in the simulation it was possible for farmers to change these currently unknown variables in correspondence to their expectations. The relevant exogenous variables include 1) price of milk; 2) price of concentrates; 3) private household income; 4) private household expenditures, and 5) interest rate.

Several technical and economic expressions (e.g. milk production, manure excretion level, labour costs) were underlying the economic simulation experiment and determined the calculation of the net income in 2020 based on the proposed farming strategy as indicated by the famers. The formulas used were fixed; only if a farmer chose to change the expected value of exogenous variables or implement certain measures, these changes influenced and worked through in the formulas and outcomes. The basis of the formulas is widespread: they are acknowledged accounting formulas, relationships based on economic theories and expert-knowledge (more information on formulas can be obtained from Agro Centre (2009).

\subsubsection{Evaluation of the economic simulation experiment}

In sections 2.2.1 and 2.2.2 it was explained that different types of experiments, with different objectives exist. The experiment discussed in this study can be categorized as a framed field experiment: the participants are directly involved in the topic of the experiment (i.e. farmers from the field), the experiment is performed in a natural environment (on their own farm 
with their own farm details) with a fixed set of rules (i.e. online simulation experiment using CAP policies), and the information-set includes a field context (i.e. based on farmers' own company details and including (potential) policies on direct payments).

The setting of this experiment was primarily explorative and made it possible to investigate the acceptance of new policies and to reflect on farmer behaviour regarding these policies. Therefore, the results of this study are highly useful in supporting policy makers to design specific direct payments policy measures and to ex-ante learn more about their potential uptake by farmers and problems.

An important advantage of using an experiment is the possibility of collecting natural data; the farmers make their own choices in the simulation experiment, instead of decisions being generated by a model based on restrictive assumptions regarding rationality, single-objective maximization and ignorance of phenomena such as trust in policy makers (e.g. time inconsistency), heterogeneous expectations, etc. Since the experimental approach does not impose any restrictions on the participant's behaviour beforehand, this contributes to realism in the experimental research approach relative to the one relying on neo-classical microeconomics. The formulas used in generating scenario outcomes in the simulation experiment are widely acknowledged accounting formulas, and relationships based on economic theories, complemented by expert-knowledge. This combination of using fundamentals from theory and relying on standard accountancy practice is assumed to further contribute to balanced outcomes fitting closely to reality. Since the experiment uses simulation, in which the CAP policies are controlled and fully transparent, it is possible to repeat the experiment in the same way and obtain similar results. Nevertheless, in practice the same farmers may react differently when being confronted with the same choices and therefore different results could be obtained in a subsequent experiment.

In the experiment no direct monetary reward is present. Instead of money, the farmers obtained insights into the current debate on possible changes in the European direct 
payments system and how these changes may affect their own farm business. In contrast with non-selected farmers, participating farmers were offered the opportunity to simulate with their own farm details, which may help them to find the best farming strategy towards these CAP changes. With regard to the principles for ensuring saliency (Smith, 1982), the principle of non-satiation is not applicable to this experiment since it did not include a situation where participants had to choose between different options with equivalent rewards. The principle of dominance is met; participants were not required to make any costs to take part in the experiment (except for some time and travel costs). However, they under scribed that the outcomes of the simulation experiment were valuable to them in order to anticipate on developments of the CAP in future. The principle of relevance is met; simulating with own farm data increased the willingness to participate in the experiment. Read (2005) confirms that respondents can also be motivated by non-monetary rewards in experiments, especially if these rewards match with participants' interests.

If one of the main reasons to use rewards in experiments is to provide an incentive to participate, this experiment clearly succeeded. The advantage for farmers that participate is that they have the opportunity to anticipate on possible changes earlier than other farmers that are not participating in the experiment. In the context of the experiment, this is the reward that motivates farmers to participate. Hence, when asked, farmers explicitly confirmed this. A counter effect of this is however, that it could lead to farmers experimenting with their farming situation, instead of providing realistic answers.

One can question the representativeness of the experiment. Limitations were set when selecting the participating farmers for the experiment; farmers needed to fulfil specific requirements (e.g. being a dairy farmer and being a participant in the Dutch FADN network) and were thus not randomly selected. Also the location of the different participating farms were pre-specified and not randomly assigned throughout the Netherlands. Although 
this might be justified given the explorative character of the study, it precludes an easy generalization or aggregation of the outcomes to the Dutch dairy farm population ${ }^{2}$.

\subsection{Assessing the impact of the CAP reform using an economic simulation experiment}

In this section we first list the results of the experiment on measuring farmer behaviour

towards the proposed CAP reform. Second, we discuss the added value of experimental economic results to more traditional microeconomic studies. Thereby we will show the contribution of the simulation experiment to the current dialogue on the impact of an alternative direct payment system and the support towards the provision of green services, as well as the contribution to the debate on the provision of ecosystem services on private land.

\subsubsection{General results economic simulation experiment}

The first hypothesis tested in the economic simulation experiment was on the effects of a change from the current direct payment system towards a system with flat rate payments and top up payments. We argued that farmers will respond with their farming strategies to expected effects of a change in the payment system on their farm income.

The economic simulation experiment we described in section 2.3 estimated the impact on net farm income in 2020 under the different farming strategies. Large differences were found between the different farms in each group and between the groups themselves. These differences were firstly due to variations in intensity in $\mathrm{kg}$ milk per ha and farm location, and were secondly dependent on the level of current direct payments and possible top-up levels under the proposed CAP as well. Compared to the current farm income, the average

2 Zijlstra et al. (2011: 48) discuss how the farming types in the simulation experiment relate to the Dutch dairy farm population. 
income of farmers in 'East-sand' went up by $€ 5500$ when the proposed CAP, as studied in the simulation experiment, was implemented. For the farms in 'West-peat' this rise in income was estimated on average to be $€ 7000$. This was mainly due to the top-up rewards farms could apply for under the proposed CAP in this region. On average, the income for farms in 'South-sand' decreased between $€ 20.000$ tot $€ 40.000$. According to the farmers this amount was comparable to the amount of direct payments they received under the current CAP. Note, that these findings differ from the results reported in Jongeneel et al. (2012: p. 75). The main reason for this is the difference in the number of farms under investigation; Jongeneel et al. (2012: p. 26) included all farms that receive direct payments under the current CAP, whereas the simulation experiment focused on a few farms in specific areas only.

The economic simulation experiment showed that in setting farming strategies two factors play a significant role. First, economic motives appeared to determine the optimal allocation of production factors, suggesting that farmers try to minimize costs or maximize profits, as is assumed as well in neo-classical microeconomic theory. Second, rewards and the possibility for uptake in the current farming strategy were the main drivers for farmers to provide green and blue services. These two factors will be outlined shortly below.

Overall, the farming strategies showed a development towards an increase in farm scale and growth of production. Reflecting on the selected adjustments in farming strategies in the simulation, it was shown that this pattern is driven by motives concerning income preservation, increasing milk production (which is possibly linked to the abolishment of the milk quota in 2015) and technical innovation aimed at increasing the labour productivity. Diversification, either through the provision of green and blue services or starting a new side-line, such as cheese-making besides dairying only, played a significant factor in farming strategies in the farms selected for the simulation as well. Nevertheless, in general the simulation experiment showed that hardly any differences exist between the strategic measures chosen by farmers under the current CAP or under the proposed CAP. Table 2.2 shows the responses of the different farmer groups in the simulation. 
Table 2.2 Selected measures by farmers in the simulation experiment

\begin{tabular}{|c|c|c|c|c|c|c|}
\hline \multirow[b]{3}{*}{$\begin{array}{l}\text { Strategy } \\
\text { Measures }\end{array}$} & \multicolumn{6}{|c|}{ Times selected by farmers } \\
\hline & \multicolumn{2}{|c|}{ 'East-sand' } & \multicolumn{2}{|c|}{ 'West-peat' } & \multicolumn{2}{|c|}{ 'South-sand' } \\
\hline & $\begin{array}{l}\text { Current } \\
\text { CAP }\end{array}$ & $\begin{array}{l}\text { Proposed } \\
\text { CAP }\end{array}$ & $\begin{array}{l}\text { Current } \\
\text { CAP }\end{array}$ & $\begin{array}{l}\text { Proposed } \\
\text { CAP }\end{array}$ & $\begin{array}{l}\text { Current } \\
\text { CAP }\end{array}$ & $\begin{array}{l}\text { Proposed } \\
\text { CAP }\end{array}$ \\
\hline \multicolumn{7}{|l|}{ Obtain growth } \\
\hline Increase milk production & 12 & 12 & 8 & 8 & 12 & 12 \\
\hline Increase land & 6 & 6 & 6 & 6 & 6 & 6 \\
\hline Increase hired labour & - & - & 2 & 1 & 2 & 2 \\
\hline \multicolumn{7}{|c|}{ Implement other activities } \\
\hline $\begin{array}{l}\text { Provide green and blue } \\
\text { services }\end{array}$ & - & 3 & 4 & 5 & 7 & 8 \\
\hline $\begin{array}{l}\text { Start new form of } \\
\text { agriculture }\end{array}$ & 1 & 1 & 1 & 1 & 2 & 2 \\
\hline Diversification & - & - & 2 & 2 & - & - \\
\hline \multicolumn{7}{|l|}{ Farm management } \\
\hline Optimization $^{\mathrm{a}}$ & 7 & 8 & 10 & 8 & 8 & 8 \\
\hline Adjust arable land use $\mathrm{b}^{\mathrm{b}}$ & 6 & 6 & 1 & 1 & 3 & 3 \\
\hline $\begin{array}{l}\text { Increase value added } \\
\text { product }\end{array}$ & - & - & 3 & 2 & - & - \\
\hline \multicolumn{7}{|l|}{ Other } \\
\hline $\begin{array}{l}\text { Cooperation with other } \\
\text { sectors }^{c}\end{array}$ & - & 1 & 1 & 1 & - & - \\
\hline Cease farming & - & - & 1 & 1 & - & - \\
\hline
\end{tabular}

a "Optimization" means improving the farm management on feed and fodder, manure and animal health.

$\mathrm{b}$ "Adjust arable land use" means changing the allocation of land used for pasture and land use for growing corn.

c "Cooperation with other sectors" means dairy farmers working together with arable farmers.

Source: adapted from Zijlstra et al. (2011)

Table 2.2 shows four types of strategies with the measures taken under that specific strategy. Within the group 'East-sand', differences in strategies were found between intensive and extensive farmers. The majority of the farmers stayed or became less intensive; they increased both in milk production and in land size. This had to do with the manure policy; if farms produce at the maximum manure excretion level of $250 \mathrm{~kg} \mathrm{~N}$ per ha, they received an additional top-up payment. However, some intensive farms stayed intensive or became even more so, i.e. increased milk production, in combination with making an investment in emission reduction-technologies aimed at reducing nitrogen emissions. Although these farms chose to forgo the top-up payment, they intended to do so, given their preferences to combine increasing milk production (and by that expanding farm returns and increasing 
farm scale) with emission-reduction. Also in 'West-peat' and 'South-sand' the main strategy was farm scale increase. Nevertheless, farms there were implementing other activities than dairy-farming as well. Diversification and starting a new sideline were driven by motives of spreading risk and being less dependent on government subsidies. Providing green and blue services can be seen as a form of diversification as well.

The second hypothesis tested in the economic simulation experiment was on the willingness of farmers to provide green and blue services. We argued that the willingness is higher if the services fit better to the current farm situation and if the opportunity costs are feasible.

As stated before, the European Union proposes compulsory requirements on greening in their member states. As reflected in the simulation experiment, which was commissioned by the Dutch Ministry of Economic Affairs, Agriculture and Innovation, the Dutch government is interested to learn more about options of implementing a greening payment. The option of a so-called 'choice-menu for green services', in which farmers can choose the services that suit them best in their farming strategy, and the administrative burden is kept low, was investigated in the economic simulation experiment.

Although the green and blue services, as offered for adoption in the simulation experiment, were region-specific, the reasoning of many farmers about them was the same. In general farmers felt that providing services should be beneficial to them (i.e. generate income). In practice this means that the reward should at least cover the extra costs involved by providing the service. That opportunity costs for providing green services matter was already hypothesized in section 2.3.2, and this was confirmed in this study. Farmers felt that the rewards for green services in the simulation experiment were too low. However, from the experiment it became clear that the opportunity costs have to be seen within a medium to long-run farm strategy choice context, whereas this inter-temporal optimization aspect is likely to be ignored either by the existing neo-classical approaches as well as in the formulas policy makers use to calculate the rewards. 
Table 2.3 Selected green and/or blue services

\begin{tabular}{llll}
\hline & & \multicolumn{2}{c}{ Times selected by farmers } \\
Service & 'East-sand' & 'West-peat' & 'South-sand' \\
\hline Nature/biodiversity/landscape & & & - \\
Field boundaries & 0 & 4 & - \\
Improve habitat meadow birds & - & 3 & - \\
Botanical meadows & - & - & 4 \\
Implement hedgerow & 0 & - & 1 \\
Wet vegetation management & 1 & - & 4 \\
Permanent meadows & - & & 3 \\
Recreation & & 1 & \\
Footpath on farmland & 2 & & - \\
Water & & 0 & - \\
Environmentally friendly banks & - & 1 & 5 \\
Ecological ditch management & - & - & - \\
Ecological maintenance water system & 0 & 1 & 7 \\
Rewetting & - & - & \\
Water conservation & 0 & & \\
\hline
\end{tabular}

a One farmer in 'West-peat' chose to implement all green and blue services in his farming strategy to get a clear view on the total impact of providing green and blue services on the net income of his farm. He was experimenting rather than providing realistic responses.

Source: adapted from Zijlstra et al. (2011: pp. 69-72)

Table 2.3 shows the percentages of several green and blue services that were selected under the proposed CAP by farmers in the three groups. As was shown earlier, during the simulation every group had its own selection of green and blue services to choose from. Each farmer could choose more than one service.

From the simulation experiment it was found that when the proposed CAP will be implemented, farmers will not often choose to provide green and blue services. However, if a farmer will provide green services, it mostly likely involves a combination of services. Also, it was found that if the service already (partly) was provided (i.e. through cross-compliance criteria) the farmers were less reluctant to provide more of this service. In that case the services were probably found to be not disruptive for their current farming practice and for that reason not considered as too 'costly'. This finding was found in other studies as well (Wilson and Hart, 2000; Defrancesco et al., 2008; Mettepenningen et al., 2013). The results of the simulation 
experiment showed that economic motives have priority over environmental motives and social responsibility.

\subsubsection{The added value of the economic simulation experiment towards neo-classical economics}

In this section we contrast the simulation experiment with neo-classical microeconomic modelling approaches. For this, we will set out the relevant aspects of neo-classical production theory and state the assumptions made within. This is especially interesting because it allows us to show the added value of the economic simulation experiment to neo-classical theory.

Scientists often refer to several criteria in order to evaluate theories. These criteria include congruence with reality, generality, tractability and parsimony (Wilkinson, 2008: p. 8). Congruence with reality means that a theory should be able to explain observations from reality well and make reliable predictions about economic behaviour. Generality and tractability are somewhat in the same direction. The first states that theories should be applicable to a wide range of phenomena and the second means that theories should be applicable to a wide range of different situations. Parsimony means that one should balance the amount of assumptions; too many assumptions make the theory too abstract to reflect real-world situations properly, but with too few assumptions it is hard to set a theory which is applicable in the wider context. Sometimes additional criteria are given such as precision and psychological plausibility. Precision means the ability to provide exact numerical figures to describe observed, or predicted, behaviour and psychological plausibility refers to incorporating human reasoning into models in order to make them more accurate and useful in predicting behaviour (Wilkinson, 2008: p. 10).

Neo-classical economic theory meets the first 4 requirements. Within neo-classical economics, several assumptions are stated in order to make theory applicable to reflect on reality in a 
wider context (see e.g. Thijssen, 1994; Boots et al., 1997). One of these assumptions includes farm households behaving rationally. The requirements precision and psychological plausibility, as stated above, are founded within the field of behavioural economics. This type of economic analysis uses emotional and cognitive factors for explaining the economic behaviour of agents. By making a combination of neo-classical economics and psychology, it puts the bounded rationality of agents at stake (Wilkinson, 2008: p. 11).

Experimental economics is a separate branch of economics. Although it is different from behavioural economics, i.e. information is gathered by using experiments, rather than by observing behaviour in the field, in this case several parallels can be shown and additions to neo-classical theory can be made.

Via the simulation experiment, information on the selected measures of farmers was obtained, where it was explicitly allowed for that farmers make their choices within a multiple year time horizon. This way, it is possible to analyse the farmer behaviour behind the selection of farming strategies of farmers. Neo-classical microeconomic models usually treat several factors as quasi-fixed and as such leave no or limited space for farmers to specifically alter these choices. Moreover, they rather treat the decision process as a black-box (e.g. assuming profit maximization or cost minimization, see further in this section). For researchers using these models, it is therefore not possible to analyse these decisions in detail. This is where the economic simulation experiment can be of true added value in analysing farmer behaviour.

The simulation experiment is used to measure specific behaviour of farmers. By this, it does not impose prior assumptions, such as rationality, on farmer behaviour, but rather tests for these. Through this, the reliability of the results increases since in practice farmers sometimes make decisions which cannot be considered fully rational within a narrow profit maximization-perspective. This is contradicting to neo-classical microeconomic theory in which heterogeneity among farmers would be captured beforehand by setting assumptions. We can stretch this a little further by pointing out the treatment of inter-temporal decisions. 
In its essence, neo-classical theory is static; for example if prices go up, the supply of a product will go up as well. However, in practise this might not be the case. A farmer selling slaughter cattle might not increase supply directly if prices go up. If he is expecting prices to rise even further in future, he might consider to wait and see how prices develop. Using experimental economics makes it possible to analyse this kind of inter-temporal decisions as it easily allows for more dynamic analyses.

A second well-known assumption made in neoclassical microeconomics when analysing farm households is optimizing behaviour subject to technical constraints that limit production possibilities (Jehle and Reny, 2011: p. 118). This can be translated into farmers acting according to cost minimization or profit maximization. In the simulation, optimizing behaviour was not imposed in the analysis. Interestingly however, it was found that economic motives (i.e. cost minimization) play a significant role in setting farming strategies. In this sense the outcomes of the experiment support the assumption of optimization as made in neo-classical economics.

Neo-classical theory further assumes that farm households maximize their short-run profits subject to in- and output prices by choosing optimal input and output levels (Thijssen, 1994). In the simulation experiment choosing farming strategies is also limited to adjusting inand output quantities. However, by using an experiment one can be more flexible in setting farming strategies. For example, the result might be not choosing optimal levels in the short-run but in the long-run instead.

In the simulation experiment, farmers had to make expectations on future prices; input (e.g. price of concentrates) and output (i.e. milk price) prices were set by farmers in accordance to their expectations on future prices, which may differ among farmers. Allowing for heterogeneous price expectations is a great advantage of the experiment. It makes it possible to distinguish between farmer behaviour and expectation formation of farmers. Although microeconomic models allow for price expectations, these are usually defined uniformly by 
the researchers. Also, farmers could adjust the values of farm characteristics according to their farming strategies and set different values for the future. This means that the experiment allows inputs to be variable rather than being fixed, as can be the case for some inputs in neo-classical economics. For example, land is often considered as a fixed factor input in the short run, but in the simulation experiment a farmer can increase or decrease the amount of land over time.

The neo-classical model also assumes production factors to be homogenous (Jehle and Reny, 2011: p. 140) whereas an experiment does not impose this restriction. For example, the simulation showed that the quality of land is determinative for the provision of green and blue services; farmers were located in different areas of the Netherlands, i.e. on different qualities of land. The experiment coped with this by allowing the farmers to provide different green and blue services. Also the top-up reward of one group ('West-peat') was linked to being located in a Less Favoured Area.

\subsection{Concluding remarks}

This chapter contributes to the current dialogue on the 2013 changes in the Common Agricultural Policy in the Netherlands and the potential impact of this on farm income and farming strategies, thereby focusing specifically on an alternative direct payment system based on a flat rate, and including green payments. For this the added value of using the economic simulation experiment besides traditional economic research methods was shown and evaluated.

It is expected that the transition from direct payments based on historical references to flat rate payments will negatively affect the income of Dutch dairy farms, and make the income less stable. The economic simulation experiment analysed in this chapter shows that farmers make their short-run decisions within a longer run strategy-choice framework. With regard 
to the provision of green services, it was found that the reward for the (extra) effort farmers need to put in should be sufficient to cover the additional costs. The importance of adequate financial compensation confirms earlier findings obtained by more traditional microeconomic (modelling) approaches. Even when participation is not voluntary but rather compulsory, obligations will be imposed on farmers' knowledge about the associated financial cost-benefit implications. For example, enforcing farmers to participate in an unattractive deal is likely to induce or increase non-compliance behaviour of farmers with European legislation. As a result an increase and intensification of monitoring, inspection and sanction mechanisms might be necessary to still get farmers in line with European policy ambitions.

The experimental approach showed that allowing farmers to adjust the structure of their farm (optimize strategy choice), will have implications for the final income impacts. Studies using a static approach have a tendency to provide an upper-bound of the negative income effects and a lower bound of the positive income effects. Via optimizing their strategy farmers may further mitigate negative impacts on income.

As regards the methodological approaches, it is concluded first that the use of a simulation experiment provides a more flexible approach than a neo-classical microeconomic model. It contributes to the neoclassical microeconomic theory in several ways. In particular where standard neo-classical models presume (short-run) cost minimization or profit maximization; in the simulation experiment this was not presumed. Second, the simulation experiment is more flexible in the context of farming strategies; in neo-classical models strategies are limited to adjusting only in- and output quantities. Third, in neo-classical models the production factors are assumed to be homogenous, whereas in the simulation experiment we allow them to be heterogeneous. Fourth, the simulation experiment with farmers allows for heterogeneous price expectations, formulated by the farmers themselves whereas neoclassical models usually use uniform price expectations defined by the modeller. 


\section{Acknowledgements}

We are grateful to the Zijlstra et al. (2011) team to allow the authors to play an onlooker role and closely following the experiments when they were actually carried out. 


\section{References}

Agro Centre (2009). Spelsimulatie, een handleiding voor de gebruikers (in English: Game simulation, a user guide). Agro Centre for Strategic Entrepreneurship, The Hague, $62 \mathrm{pp}$.

Anderson, L.R., Mellor, J.M., Milyo, J. (2008). Inequality and public good provision: An experimental analysis. The Journal of Socio-Economics 37: 1010-1028.

Bartolini, F., Viaggi, D. (2013). The common agricultural policy and the determinants of changes in EU farm size. Land Use Policy 31: 126-135.

Benjamin, C., Kimhi, A. (2006). Farm work, off-farm work, and hired farm labour: estimating a discrete-choice model of French farm couples' labour decisions. European Review of Agricultural Economics 33: 149-171.

Berkhout, P., Roza, P. (2012). Landbouw-economisch bericht 2012 (in English: Agricultural economic report 2012). LEI Wageningen UR, The Hague, 217 pp.

Binmore, K. (1999). Why Experiment in Economics? The Economic Journal 109: F16-F24.

Boots, M., Oude Lansink, A., Peerlings, J. (1997). Efficiency loss due to distortions in Dutch milk quota trade. European Review of Agricultural Economics 24: 31-46.

CBS (2012). Official statistics for the Netherlands. Retrieved July 2012, from http://www.cbs. nl/nl-NL/menu/home/default.htm.

Chan, K., Mestelman, S., Moir, R., Muller, R.A. (1999). Heterogeneity and the voluntary provision of public goods. Experimental Economics 2: 5-30.

Davis, D.D., Holt, C.A. (1993). Experimental economics. Princeton University Press, Princeton, 572 pp.

Defrancesco, E., Gatto, P., Runge, F., Trestini, S. (2008). Factors affecting farmers’ participation in agri-environmental measures: A northern Italian perspective. Journal of Agricultural Economics 59: 114-131. 
Dutch Government (2011). Inkomenssteun (in English: Government support. Retrieved May 2011, from http:/www.rijksoverheid.nl/onderwerpen/europeeslandbouwbeleid-en-visserijbeleid/gemeenschappelijk-landbouwbeleid/ inkomenssteun.

Dutch Government (2012). Brief ideeën over het toekomstige gemeenschappelijke landbouwbeleid 2014-2020 (in English: Ideas on the future common agricultural policy 2014-2020). Retrieved July 2012, from http://www.rijksoverheid.nl/ documenten-en-publicaties/brieven/2012/07/10/brief-ideeen-over-hettoekomstige-gemeenschappelijke-landbouwbeleid-2014-2020.html.

European Commission (2011). Proposal for a regulation of the European parliament and of the council establishing rules for direct payments to farmers under support schemes within the framework of the common agricultural policy. European Commission, Brussels, 108 pp.

European Commission (2012). Concept paper on greening. European Commission, Brussels, 3 pp.

Gardebroek, C. (2004). Capital adjustment patterns on Dutch pig farms. European Review of Agricultural Economics 31: 39-59.

Harrison, G.W., List, J.A.(2004). Field experiments. Journal of Economic Literature 42: 1009-1055.

Helming, J., Jansen, S., van Meijl, H., Tabeau, A. (2010). European farming and post-2013 CAP measures : a quantitative impact assessment study. LEI Wageningen UR, The Hague, $95 \mathrm{pp}$.

Hodge, I. (2009). The further development of agri-environmental schemes: extending and defending conservation values. In: Brouwer, F., van der Heide, C.M. (Eds.), Multifunctional rural land management: economics and policies. Earthscan, London, pp. 33-52.

Holt, C.A. (1992). ISO probability matching. University of Virginia, Virginia, 14 pp.

Jehle, G.A., Reny, P.J. (2011). Advanced microeconomic theory. Pearson, Harlow, 656 pp. 
Jongeneel, R.A., Polman, N.B.P., Slangen, L.H.G. (2008). Why are Dutch farmers going multifunctional? Land Use Policy 25: 81-94.

Jongeneel, R.A., De Bont, K., Jager, J., Van Doorn, A., Naeff, H., Smidt, R. (2012). GLB hervorming 2014. Effecten van toeslagvarianten voor de Nederlandse landbouw (in English: Reformation Dutch implementation common agricultural policy 2014). LEI Wageningen UR, The Hague, 96 pp.

Just, D.R., Wu, S.Y. (2009). Experimental economics and the economics of contracts. American Journal of Agricultural Economics 91: 1382-1388.

Kachelmeier, S.J., King, R.R. (2002). Using laboratory experiments to evaluate accounting policy issues. Accounting Horizons 16: 219-232.

Loewenstein, G. (1999). Experimental economics from the vantage-point of behavioural economics. The Economic Journal 109: F25-F34.

Mettepenningen, E., Vandermeulen, V., Delaet, K., Van Huylenbroeck, G., Wailes, E.J. (2013). Investigating the influence of the institutional organisation of agri-environmental schemes on scheme adoption. Land Use Policy 33: 20-30.

Prins, H., Smit, A.B. (2011). Vermaatschappelijking van het GLB. Kunnen agrarische natuurverenigingen inspiratie opleveren? (in English: Social aspects of the common agricultural policy). LEI Wageningen UR, The Hague, 66 pp.

Read, D. (2005). Monetary incentives, what are they good for? Journal of Economic Methodology 12: $265-276$.

Schram, A. (2005). Artificiality. The tension between internal and external validity in economic experiments. Centre for Research in Experimental Economics and Political DecisionMaking, Amsterdam, $14 \mathrm{pp}$.

Smith, V.L. (1982). Microeconomic systems as an experimental science. The American Economic Review 72: 923-955.

Thijssen, G. (1994). Supply response and dynamic factor demand of Dutch dairy farms. European Review of Agricultural Economics 21: 241-258.

Uler, N. (2011). Public goods provision, inequality and taxes. Experimental Economics 14: 287-306. 
Vanslembrouck, I., Van Huylenbroeck, G., Verbeke, W. (2002). Determinants of the Willingness of Belgian Farmers to Participate in Agri-environmental Measures. Journal of Agricultural Economics 53: 489-511.

Venema, G.S., Van der Veen, H.B., Jongeneel, R.A., Jager, J.H., Silvis, H.J., Verhoeven, W., Kwaak, T. (2013). Financiële gevolgen Regeerakkoord en Meerjarig Financieel Kader van de EU voor de land- en tuinbouw. Een vergelijking met andere mkb-sectoren (in English: Financial consequences of Dutch policy on agriculture ). LEI Wageningen UR, The Hague, $24 \mathrm{pp}$.

Vrolijk, H.C.J., De Bont, C.J.A.M., Blokland, P.W., Soboh, R.A.M.E. (2010). Farm viability in the European Union. Assessment of the impact of changes in farm payments. LEI Wageningen UR, The Hague, $67 \mathrm{pp}$.

Wilkinson, N. (2008). An introduction to behavioral economics. Palgrave Macmillan, Basingstoke, 300 pp.

Wilson, G.A., Hart, K. (2000). Financial imperative or conservation concern? EU farmers' motivations for participation in voluntary agri-environmental schemes. Environment and Planning A 32: 2161-2185.

Zijlstra, J., De Wolf, P., Prins, H., Doornewaard, G., Smit, A., Daatselaar, C. (2011). Meer groei dan vergroening. Mogelijke gevolgen GLB 2014-2020 voor melkveehouders en akkerbouwers (in English: Possible consequences of common agricultural policy 2014-2020). Livestock Research Wageningen UR, Wageningen, 74 pp. 


\section{Appendix 2.1}

Hypothetical payments for green and blue services for different groups

Annual rewards ${ }^{1}$

\begin{tabular}{|c|c|c|c|}
\hline Service & 'East-sand' & 'West-peat' & 'South-sand' \\
\hline \multicolumn{4}{|l|}{ Nature/biodiversity/landscape } \\
\hline \multirow[t]{2}{*}{ Field boundaries } & $€ 1020$ (pasture) & & \\
\hline & $€ 1652$ (arable land) & & \\
\hline Improve habitat meadow birds & & $€ 599$ & \\
\hline Botanical meadows & & $€ 1165$ & \\
\hline \multirow[t]{2}{*}{ Implement hedgerow } & $€ 47$ per a (new) & & $€ 47$ per a (new) \\
\hline & $€ 27$ per a (existing) & & $€ 27$ per a (existing) \\
\hline Wet vegetation management & $€ 1211$ & & $€ 1211$ \\
\hline Permanent meadows & & & $€ 144$ \\
\hline \multicolumn{4}{|l|}{ Recreation } \\
\hline Footpath on farmland & $€ 84$ per $100 \mathrm{~m}$ & $€ 84$ per $100 \mathrm{~m}$ & $€ 84$ per $100 \mathrm{~m}$ \\
\hline \multicolumn{4}{|l|}{ Water } \\
\hline Environmentally friendly banks & & $€ 77$ per $100 \mathrm{~m}$ & \\
\hline Ecological ditch management & & $€ 200$ per 1000 m & \\
\hline Ecological maintenance water system & $€ 179$ per $100 \mathrm{~m}$ & & $€ 179$ per $100 \mathrm{~m}$ \\
\hline Rewetting & & $€ 250$ & \\
\hline Water conservation & $€ 260$ at once & & $€ 260$ at once \\
\hline
\end{tabular}

${ }^{1}$ All rewards are indicated per ha unless stated otherwise $(\mathrm{a}=$ are $)$

Source: Adapted from Zijlstra et al. (2011: pp. 69-72) 


\section{Explaining Production Expansion Decisions of Dutch Dairy Farmers ${ }^{1}$}

\section{Abstract}

The abolition of dairy quotas in Europe in 2015 has been accompanied by uncertainty on expansion of the European dairy sector. The objective of this study is to analyse which factors determine milk production expansion by Dutch dairy farmers. A conceptual model is developed that shows how policies, market conditions, and farmers'values and goals affect their expansion decisions. Three investment theories are combined and form the basis for a dynamic random effects probit model. Data are obtained from the Dutch Farm Accountancy Data Network (FADN) covering the period 2001 through 2010, with 1390 observations on 354 dairy farms included in the sample. The results indicate that Dutch dairy farms can potentially increase milk production in the future.

\footnotetext{
Paper by Gerlinda S. Samson, Cornelis Gardebroek and Roel A. Jongeneel, NJAS - Wageningen Journal of Life Sciences 76 (2016) 87-98. Doi: 10.1016/j.njas.2015.11.007
} 


\subsection{Introduction}

As part of the 2008 Health Check of the Common European Agricultural Policy (CAP), milk quotas were gradually increased since 2009 (soft landing), and fully abolished in April 2015 (European Commission, 2011). Until 2004-2005 there was a net overrun of the total milk quota in the EU. However, as of 2005-2006 this overrun changed into a net underuse of the milk quota, which increased rapidly over the years. In the year 2011-2012 only Austria, Ireland, Germany, Cyprus, Luxembourg and the Netherlands were producing more milk than their national quotas allowed (European Commission, 2012).

The impact of abolishing milk quotas on the dairy sector as a whole and on the behaviour of dairy farmers is a highly discussed topic in European agricultural policy. Especially since in the Netherlands milk quotas were still binding when they were abolished, it is interesting to study what happens to Dutch milk production after quota abolishment. Whereas the total amount of quotas was limited and the value of quotas was falling (eventually they lost value since they expired (Jongeneel et al., 2010)) a significant part of active Dutch dairy farmers followed an expansion strategy, thereby exploiting economies of scale. It is expected that the overall milk production in the Netherlands will substantially increase after abolishment of the quota (Jongeneel, 2009). Jongeneel and Van Berkum (2015) predict this increase to be 17 per cent in the next ten years, which can be attributed to changes in the expected market conditions (e.g. milk price), structural issues (e.g. land, buildings and machinery) and other drivers.

Various studies analysed the effects of milk quota abolition on production levels in European Union Member States. Lips and Rieder (2005) used a CGE framework to analyse the effects of quota abolition together with an elimination of export subsidies on dairy production levels. For 2015 , an overall increase of $33 \%$ in production levels and a $22 \%$ decrease of the milk price, relative to the base year 1997, was projected. Bouamra-Mechemache et al. (2008) analysed the impact of a gradual increase of milk quota for EU member states using a spatial equilibrium 
model that includes international trade flows. They found that when milk quotas are fully abolished, the international trade effects for EU member states will be similar to the effects of a $2 \%$ gradual increase in milk quotas starting in 2009. They found that, for the Netherlands in particular, the contribution to the overall increase in EU milk production after quota abolishment is estimated to be $40 \%$. Witzke et al. (2009) studied regional effects of quota abolition, using non-linear mathematical programming models. They found that the effects of milk quota abolition depend on quota rents. In regions with high quota rents (such as regions in the Netherlands or in Austria), production levels are expected to increase after abolition. An expected decline in milk prices will mostly affect regions with low quota rents (such as regions in UK or Sweden or the new EU member states), pressuring them to, partially, withdraw from the market. De Frahan et al. (2011) evaluated effects of abolishing milk quotas in combination with milk price reductions on milk supply and farm income of Belgian dairy farms. They analysed effects by embedding cost functions into a profit maximization model using data of the Belgian farm accountancy data network. Their main results showed that after abolishment of the milk quotas and assuming a reduction in milk prices of $20 \%$, aggregate milk supply and farm income will be at the same level as in their base year 2006. Using an output distance function approach, Emvalomatis (2012) analysed changes in revenues from milk production and productivity growth on German dairy farms, using land, labour, capital, livestock and materials as explanatory factors. The total factor productivity growth rate was estimated to be $1.1 \%$ with technological progress as main contributor. Läpple and Hennessy (2012) simulated Irish production expansion after milk quota abolishment at different milk price scenarios. For their basic simulation model they used livestock size and milk yield as explanatory factors for milk output. They found that the rate of structural change, productivity growth and the level of milk prices will be important drivers for milk output in future. Relative to 2008, the aggregate milk supply of Ireland is estimated to potentially increase with $41 \%$ after quota abolishment. If the option to increase in land area is also taken into account, this increase can be even higher. The case of Ireland is especially of interest since Ireland, just as the Netherlands, compared to other EU countries, is considered to potentially expand most in milk production after quota abolishment. 
Most of the studies mentioned above try to assess how milk production changes after quota abolition. This study tries to shed some light on this issue indirectly, by focusing on the decision process of milk production expansion at the farm level. The aforementioned studies are mainly based on pure economic perspectives and do not incorporate non-economic factors, which we believe are also relevant to the specific decision making process on production expansion by dairy farmers. In this study we investigate Dutch dairy farmers' decisions on milk production expansion taking both economic and non-economic factors into account. Although our analysis is based on data from the quota period, we do believe that important conclusions can be drawn that are useful to assess the dairy sector in the post quota period. This study contributes to the current literature in two ways. First, an inclusive analysis of the decision making characteristics that are relevant in explaining production expansion behaviour of Dutch dairy farmers has not yet been performed, and this can provide important insights in the possible scenarios after quota abolishment. In our approach therefore not only economic, but also social and environmental variables are used in explaining expansion decisions. Second, several studies focus at a macro-level on possible impacts of quota abolishment (for a study in the Netherlands see Jongeneel et al., 2010). However, micro level modelling specifically allows for heterogeneity between individual farms, and therefore provides more information on the specific behaviour of individual farmers. Such studies are relatively scarce in the current discussion on the impact of milk quota abolishment on milk production levels. Hence, research at the individual farm level of the Dutch dairy sector is conducted.

This chapter continues in section 3.2 with an overview of developments in the Dutch dairy sector. It is important to have some context information since several changes affected the Dutch dairy sector recently. Section 3.3 presents the conceptual model used as a basis for our empirical analysis. Next, in section 3.4 the data are described with specific attention to the included model variables and their definitions. Section 3.5 discusses various econometric issues and presents the empirical model. Estimation results are presented in section 3.6 and discussed in section 3.7. Finally, section 3.8 provides general conclusions. 


\subsection{Developments in the Dutch dairy sector}

This section describes several general developments in the Dutch dairy sector. This provides useful background information but also defines external factors that are present in the conceptual model defined in the next section.

\subsubsection{Milk prices and milk price volatility}

Milk prices are an important element in the debate on impacts on milk production expansion after milk quota abolishment. The effect of changing milk prices on production expansion is complex. Based on several (macro-level) projections by FAO, FAPRI and EC on developments in the EU dairy sector, Jongeneel et al. (2010) show that the demand for dairy products will increase in the coming years. This has an upward effect on milk prices. However, it is expected that discussions with the WTO on further trade liberalisation will influence conditions on agricultural commodity markets and as such will also have impact on the market for milk. The trend towards more trade liberalisation reduces the use of agricultural trade distorting measures. This will push down the EU prices for agricultural commodities, including milk prices, in the coming years. With the gradual reduction of guaranteed milk prices in the EU, milk prices are stronger related to world market prices. This increases price volatility for farmers (Jongeneel et al., 2011).

\subsubsection{Manure policy}

After the abolishment of milk quotas, dairy farms do not face production limits anymore. However, new bottlenecks for production expansion will most likely arise. One of these is the manure surplus production level.

Manure surpluses are a major problem in the Netherlands for decades, especially in intensive livestock production, but also in part of the dairy sector. Farmers often produce more 
manure than they can apply at their land. European guidelines (Nitrate Directive) prescribe a maximum manure application level of $170 \mathrm{~kg} \mathrm{~N}$ per ha. Until 2017 the Netherlands obtained a so-called derogation, which allows dairy farmers to apply 230 or $250 \mathrm{~kg} \mathrm{~N}$ per ha (depending on the location of the farm) on farms where $70 \%$ of the total farm area consists of grassland. Still it is expected that also in the future the nationally set maximum manure application level will be exceeded, especially after the milk quota abolishment in 2015 , and dairy farms will increase production, often without obtaining more land.

The Dutch government implemented a new manure policy from 1 January 2015 onwards (Dutch Government, 2014a). Dutch dairy farms are restricted to so-called phosphate reference levels. If farms produce more manure than they are maximally allowed to apply on their land, they are obliged to dispose their manure production surplus (Dutch Government, 2014b), for example by exporting the manure to neighbouring countries as Belgium or Germany, getting involved in contracts with manure processing firms, or manure can be processed into energy by burning it.

Farmers have to anticipate these policy changes when considering milk production expansion. Moreover, they need to consider more efficient manure production on their farms or arrange manure supply to other farms to remain below the maximum manure application level set on their farms. Hence, when analysing production expansion behaviour of Dutch dairy farmers, it is realistic to take the manure surplus production level into account.

\subsubsection{Land market}

Another bottleneck for production expansion after milk quota abolishment is the availability of agricultural land. In attempting to reduce the manure emissions per ha, a farmer can consider to increase in land size. However, prices for agricultural land in the Netherlands rose between 2000 and 2010 on average by 3.65\% per year from respectively 35985 euro per ha to 47500 euro per ha (LEI Wageningen UR, 2013). This makes investing in land for farms 
relatively expensive. In the Netherlands agricultural land is scarce, and typically the only way to obtain more land is when neighbouring farms exit farming and agricultural land becomes for sale.

\subsubsection{CAP reform}

As of 2014, a new Common Agricultural Policy (CAP) was introduced in the EU. In the agreement made by the EU commission, EU Parliament and EU Council (European Commission, 2013), several obligations towards the use of agricultural land with respect to obtaining subsidy payments were set. Thirty per cent of the direct payments will only be paid to farmers if they comply with the following rules; they need to diversify land use and they need to maintain permanent grassland. Alternative measures for agricultural management may only be taken if their environmental effects are equal to the effects of the measures above. This new policy may have implications on the production systems of farmers as they cannot use all land freely in milk production. However, in practice the implications for the Dutch dairy sector will most likely be limited since several (national) conditions on these alternative measures are imposed (for example dairy farms may face limitations to renew grassland).

\subsection{Conceptual model}

This section discusses the conceptual model that is the basis for the empirical analysis of decisions on dairy production expansion. It is assumed that farmers base their decision to expand on an intertemporal comparison of expected benefits and costs of expansion, making this a dynamic decision making process.

Figure 3.1 gives an overview of the factors involved in this dynamic decision making process. The first two sets of factors are the policies and market conditions that were discussed in the previous section. These are external factors that cannot be influenced by the farmer. 


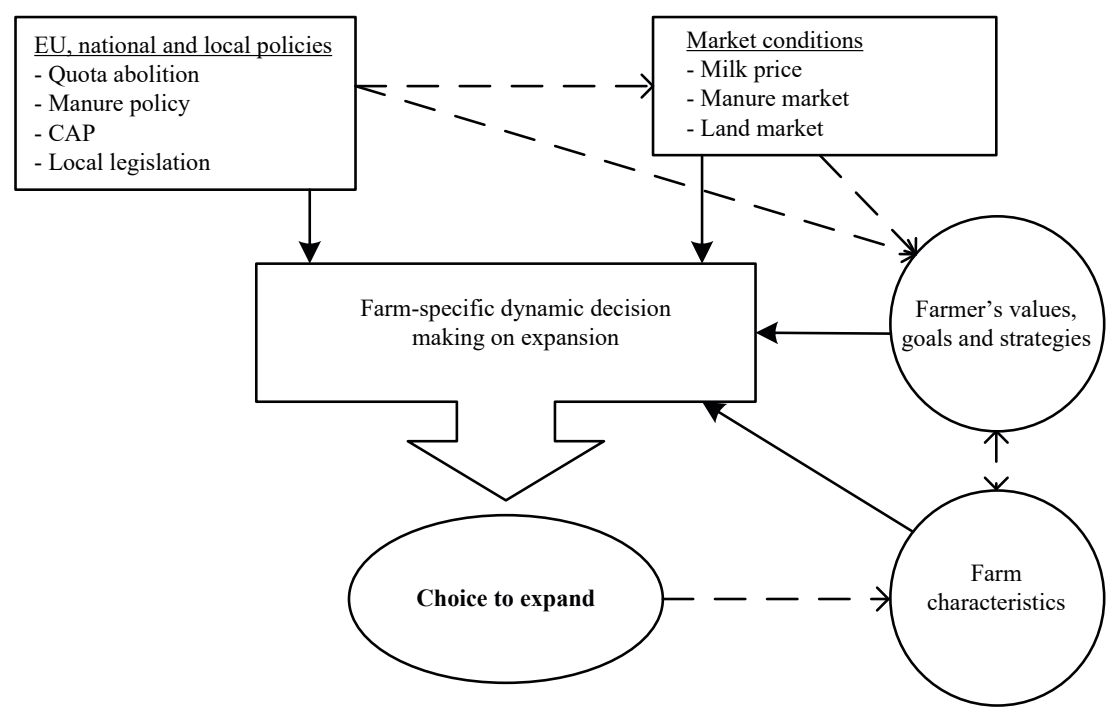

Figure 3.1 Conceptual model explaining farm expansion decisions

Source: own elaboration

The solid arrows indicate that policies and market conditions have a direct impact on the dynamic expansion decision making process. The dashed arrow indicates that policies also have an impact on market conditions, but this relation is less relevant in our model. Besides these external factors, there are also two sets of internal factors that potentially have an important direct relation to the expansion decision. These are indicated with solid lines and include the values, goals and strategy of the farmer and the characteristics of the farm. Also here interactions between the different sets of factors exist and are indicated with dashed lines (e.g. changes in market conditions may induce farmers to change their strategy). However, for the analysis of expansion decisions only the direct impacts are relevant. Note that decisions on expansion also affect the farm characteristics.

In defining farm strategies, farmer attitudes and values have become more important over the years (Lans et al., 2014; O’Rourke et al., 2012; Solano et al., 2006; Van der Ploeg, 1993). A study using farmer attitudes and values is Bergevoet et al. (2004), who found that differences in milk 
quotas can be explained by the differences in farming strategies of farmers, which are the result from variations in farmers' goals and objectives. These results were obtained using the theory of planned behaviour, which states that differences in behaviour among others can be explained by differences in personal goals and intentions. Bergevoet et al. (2004) used the typology of goals developed by Willock et al. (1999) that distinguishes five categories; success in farming, sustainability, quality of life, status, off-farm work. Also Schmitzberger et al. (2005) recognizes the importance of considering farmers' attitudes towards farming. Their classification of farming strategies resulted in the definition of eight types; the yield optimiser, the traditionalist, the innovator, the support optimiser, the idealist, the part time farmer, the forced farmer and the social farmer. The classification by Valbuena et al. (2008) is comparable and based on farmers' attitudes towards four variables including continuity of farming, production strategy, diversification of farm, and subsidy schemes. This results in five different agent types: hobby, conventional, diversifier, expansionist conventional, expansionist diversifier.

Frawley and Reidy (1986) analysed farm strategies, among other production expansion behaviour, by studying which farm characteristics influence farm strategies. In figure 3.1 this is represented by the dashed arrow between farm characteristics and farmer's values, goals and strategies. Frawley and Reidy (1986) found relevant relationships between several farm categories: farm structural factors (land area, milk supply), farm practices (feed characteristics, degree of dairy specialization), farm performance (milk yield per cow, stocking rate), farmers' demographic factors (age, fulltime farming), and farm planning (succession).

The studies mentioned above show that it is important to take farm and farmer characteristics into account when explaining milk production expansion behaviour. Ondersteijn et al. (2003) explain the strong link between farmer characteristics and strategies by the fact that in the Netherlands farms are mainly run as family farms where the farmer is the single manager and entrepreneur of the business. This means that the farming strategy chosen depends mainly on the farmer's attitudes and preferences. The decisions taken by the farmer influence 
the technical, financial and environmental farm results. In general, recognizing different farming strategies and farming styles is relevant in addressing various agricultural questions. Moreover, analysing underlying farming characteristics contributes to a better understanding of agricultural processes (Van der Ploeg et al., 2009).

That farmers have different strategies is also empirically observed. Samson et al. (2013) describe the evolvement in two different types of farms in the Netherlands. The relatively smaller farms, which cannot compete with larger farms, differentiate from their main production and change farming strategy by implementing side-activities (such as cheese-making or recreation), or they exit farming. The relatively larger and more competitive farms potentially buy the land that becomes available when smaller farms exit. These farms grow larger and possibly become even more competitive by increasing production and decreasing the cost of production. In recent years, many Dutch farmers already invested in stable space which indicates that they were already anticipating on production expansion after quota abolishment. Figure 3.2 shows that the number of farms is steadily decreasing whereas the number of animals increases. This implies a development towards fewer, but larger farms.

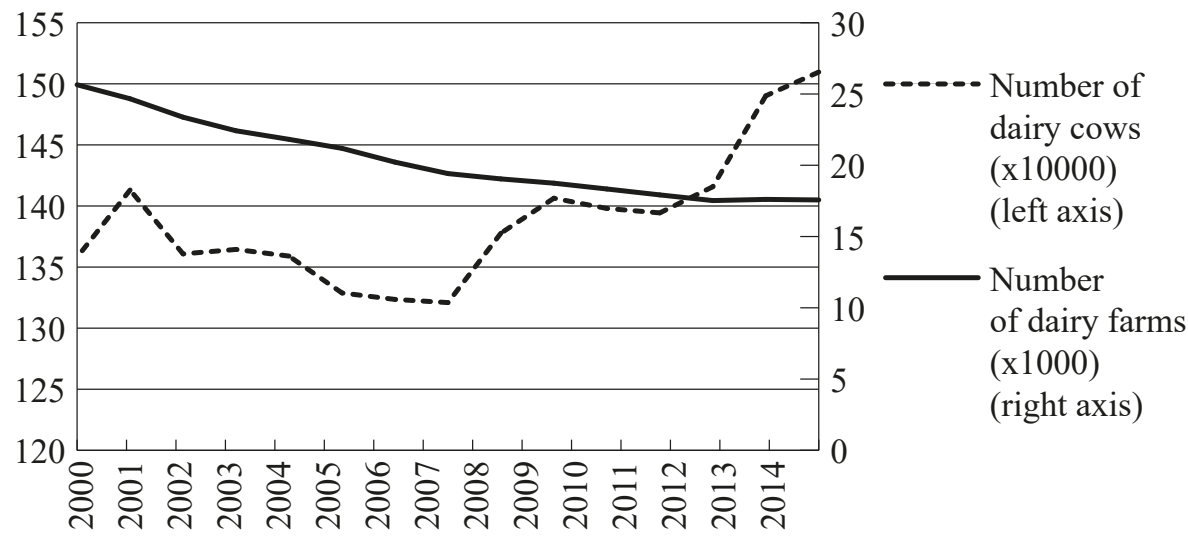

Figure 3.2 Development of the Dutch dairy sector Source: CBS (2013) 
A central element in the conceptual model as given in figure 3.1 is the farm-specific decision making process on production expansion, which involves comparing the stream of expected revenues from expansion with the costs of investment. This means that the decision making process of the farmer is actually a dynamic problem under uncertainty that is represented by the following optimal value function:

$$
V\left(p_{i t}, K_{i t}, Z_{i t}\right)=\max _{I_{i t}} E_{t}\left[\sum_{t=0}^{\infty} \rho_{t}\left[\pi\left(p_{i t}, K_{i t}, Z_{i t}\right)-C\left(I_{i t}\right)\right] \mid \Omega_{i t}\right]
$$

Subject to:

$$
K_{i t+1}=I_{i t}+[1-\delta] K_{i t}
$$

The optimal value function (1) states that farmer $i$ in each period $t$ has to decide on whether to invest in stable capacity $\left(I_{i t}>0\right)$, disinvest $\left(I_{i t}<0\right)^{2}$, or do nothing $\left(I_{i t}=0\right)$ by comparing the stream of expected discounted future profits with the incurred cost of investment $C\left(I_{i t}\right)$ in year $t$, given all information that farmers have available at period $t$, represented by a set of variables $\Omega_{i t}$. The investment adds to the available depreciated capital stock in year $t\left([1-\delta] K_{i t}\right)$, where $\delta$ is the depreciation rate, so that in the next period $K_{i t+1}$ is available, as given by equation (2). The total amount of capital available in year $t$ is used in production together with other quasi-fixed inputs $Z_{t}$ (such as labour and land) and variable inputs (such as animal feed, veterinary costs and energy). The yearly optimal profits from production are given by the short-run profit function $\pi($.$) , which implies that farmers choose optimal output$ supply and input demand quantities given output and input prices (represented by the vector $p_{i t}$ ), the amount of capital $K_{i t}$, and other quasi-fixed inputs $Z_{i t}$. Optimal short-run profits in year $t$ are discounted by a factor $\rho_{t}$, which is defined as $\rho_{t}=1 /[1+r]^{t}$, where $r$ is an interest rate. The information available as captured by $\Omega_{i t}$ includes information on European and national policies, and proposed changes therein, market conditions and local conditions that affect expansion such as local legislation regarding noise and odour nuisance. It also captures

2 Although the theoretical model allows for disinvestments, these are hardly observed in our dataset, and therefore will not be considered any further. 
farmer characteristics that define the way expectations are formed and personal values, goals and strategies as discussed above.

Farmers typically do not invest in stable capacity every year but only once in a while. This has been recognized in the empirical economic literature for long time and various explanations have been given for this. Fixed asset theory (Chavas, 1994) states there exists a wedge between the new value of an investment (acquisition costs) and the scrap value (salvage value) when disinvesting. When the dynamic marginal value of investment (dynamic shadow price) is in between these values, farmers will not invest, nor disinvest. Another branch of literature states that the cost of investment function $C\left(I_{i t}\right)$ includes fixed adjustment costs, such as costs of building and environmental licenses, costs of restructuring the production process, search costs etc. The additional expected benefits of a relatively small change in production capacity would not outweigh these adjustment costs, providing an additional explanation for the many zero investments observed among farmers (Oude Lansink and Stefanou, 1997; Gardebroek, 2004). A third branch of literature stresses that due to (partial) irreversibility of an investment and uncertainty on future prices and policies it may not be optimal to invest immediately if the net present value of an investment only just covers the investment cost but instead it may be more optimal to wait. This option theory of investment states that the investment threshold that results is increasing in the sunk investment costs, revenue volatility, the probability of a policy change, and the interest rate, and decreasing in the trend of the revenues (Dixit and Pindyck, 1994; Wossink and Gardebroek, 2006; Hinrichs et al., 2008).

The fixed asset theory and adjustment cost theory lead to formal investment decision rules based on comparing dynamic shadow prices (marginal benefits) with marginal investment costs, whereas option theory results in investment decision rules based on net present value calculation, so focusing on total expected benefits and costs. This makes it mathematically difficult (and beyond the scope of this chapter) to derive a unified decision rule based on these three theories. Nevertheless, all three theories explain the existence of investment thresholds and provide insight in relevant variables that determine these thresholds. Moreover, once the 
(marginal) value of investment exceeds the threshold, the expected benefits determine the size of the investment. Therefore, we can write the decision to expand as:

$$
I_{i t}= \begin{cases}1 & \text { if (marginal) expected investment benefits }>\text { investment threshold } \\ 0 & \text { if (marginal) expected investment benefits } \leq \text { investment threshold }\end{cases}
$$

\subsection{Data and included variables}

Data for this study were obtained from the Dutch Farm Accountancy Data Network (FADN). Farms having dairy farming as their main source of income were selected for the sample. Originally, the analysis started with 2872 observations on 476 Dutch dairy farms, covering the period 2001 to 2010. Since farms usually remain in the panel for about five years, the dataset

formed an unbalanced panel. A total of 111 (23\%) farms were in the panel the whole period (10 years), 60 (13\%) farms were in the panel from year 2006-2010, and 50 (11\%) farms were in the panel from year 2006-2009. Together these farms included $47 \%$ of the total observations in the panel. Due to data transformations and specification of variables, the model was estimated using 1390 observations on 354 farms.

It is challenging to assess production expansion behaviour of Dutch dairy farms under a milk quota regime. However, as stated earlier, Dutch dairy farms anticipated on production expansion after quota abolishment by increasing stable capacity, although it might have not been fully utilized (for example because farmers were not prepared to invest in additional quota anymore, but rather preferred to invest in the 'hardware' of their farms). The average occupancy of stable places at Dutch dairy farms in our dataset is 0.71 (0.18 sd.) in 2010, indicating that farms indeed underutilized stable capacity. This is partly due to the combined impact of the prevailing milk quota system and steady annual increase in milk yields per cow. Contrary to the use of herd size in literature on production expansion and structural change of farms (Läpple and Hennessy, 2012; Huettel and Jongeneel, 2011), production expansion of 
Dutch farmers is measured as investments in extra stable space. It is a binary variable that takes the value one when farms invested in capital and increased in stable places at the same time (i.e. so we catch the investments in stable place only and filter out other type of investments, such as investments in machinery), and zero if one of these conditions is not met.

Based on the conceptual model discussed in the previous section various economic, social and environmental variables are selected that explain production expansion behaviour. Below we hypothesize the relations between the selected variables and production expansion behaviour of farmers. We also provide definitions of the variables included.

Since the FADN mostly includes economic information, we were limited in which variables to include in the analysis. This especially affected the selection of non-economic factors, such as psychological factors and the (social) attitude of the farmers, which were not present in the database. In general such types of social variables are difficult to measure and information is hardly available. Information on location is relevant to include as well. In the Netherlands several farms are located in, or close to, Natura 2000 areas and Ecological Focus Areas. This means that they cannot expand in land, which is eventually needed to expand in milk production. However, information on this variable was only available for a small part of our sample. Including this variable would lead to many missing observations and as such the representativeness of the sample. Information on relevant municipal or provincial polices regarding farm expansion was also not available. Although no specific policy variables are included, the effects of policy changes are likely to be implicitly included in the way farmers form expectations on their future benefits and costs of expansion. Moreover, the farm-specific means of these relevant unobserved variables are captured by the unobserved farm-specific effects that are dealt with in the empirical approach. 


\subsubsection{Market conditions}

Milk price. Equation (1) shows that optimal expansion decisions are based on maximizing the expected stream of benefits minus costs of expansion. An important element in the expected stream of benefits are the expected milk prices that determine yearly profits. We therefore hypothesize that if milk prices are expected to go up farmers will expand in milk production capacity. Expected milk price is measured per kg milk production in euros. Therefore the milk prices vary over farms and over years. The way expectations are approximated is discussed in the empirical section.

Milk price volatility. According to the option theory of investment that was discussed in section 3.2, volatility in revenues increases the threshold for investment. We therefore hypothesize that the higher the milk price volatility, the less eager farmers are to expand in milk production. In order to create a variable to measure (expected) milk price volatility, we follow the approach of Aramyan et al. (2007) and Oude Lansink et al. (2001). They use the following formula to generate a weighted farm-specific price variance measure:

$$
\operatorname{var}\left(p_{i t}\right)=0.5\left(p_{i t-1}-E_{t-2}\left\{p_{i t-1}\right\}\right)^{2}+0.33\left(p_{i t-2}-E_{t-3}\left\{p_{i t-2}\right\}\right)^{2}+0.17\left(p_{i t-3}-E_{t-4}\left\{p_{i t-3}\right\}\right)^{2}
$$

The expected prices are based on an estimated panel AR(1) process.

Manure production surplus. It is expected that after quota abolition a new limit for production (expansion) will be the manure production surplus (section 3.2.2). We hypothesize that manure surplus increases the threshold for expansion so that the higher the current manure production surplus per ha, the less likely farmers are to expand in production. The manure production surplus is measured as the costs of manure disposal per ha. For the amount of ha the agricultural area is taken.

Nitrogen. As stated in section 3.2.2, application norms for nitrogen from manure are set. Similarly to the manure production surplus variable, we hypothesize that the higher the 
nitrogen production level per ha, the less likely farmers are to expand in production. The balance between the level of nitrogen production at the farm at the beginning and at the end of the year is called the nitrogen balance, and is measured in $\mathrm{kg}$ nitrogen per ha.

Land area. Different values for the use of agricultural land can be distinguished. Land can be used for feed production, and it provides space for manure disposal. For years, milk quotas were linked to land. This means that farms could only increase milk quotas by increasing their land as well. Since 2006 transactions of milk quotas without land became possible, and the coupled payments were replaced by decoupled payments. These payments are freely transferable, however a farm needs to have 1 ha of land in order to be able to utilize the direct payments. This provides a third value of land. If a farm is able to press down their variable costs, it becomes more competitive and has better possibilities to expand in milk production. The above mentioned values for land reflect the three ways for a farm to reduce their variable costs by increasing in land area. Although options to expand the land area are limited and depend on the local land market (Cotteleer, 2008), we hypothesize that a positive change in land area positively influences the production expansion behaviour of farmers. Land area is measured in number of hectares.

\subsubsection{Farmer's values, goals and strategies}

Age. We hypothesize that younger farmers are more eager to invest in order to expand production than older farmers who may exit farming in the upcoming years (Aramyan et al., 2007; Oude Lansink et al., 2001). They may form expectations in different ways and value expansion differently. In order to allow for a non-linear effect also the square of age is included in the model.

Continuity. We hypothesize that almost retiring farmers without a successor are less likely to expand in production compared to almost retiring farmers with a successor (Aramyan et al., 2007; Oude Lansink et al., 2001). The latter may have the objective to expand in order to leave 
a more viable farm business to the successor. Farm's continuity is measured as the farmer having a successor or not and is linked to the age of the farmer; it is a binary variable which takes the value one if a farmer is below 50 years old or if a farmer is over 50 years old, but has a successor. It is zero if the farmer is over 50 and/or has no successor.

Fulltime farming. We hypothesize that if a farmer works fulltime on dairy production, he is more willing to expand in milk production, than if he has other sources of income besides dairying. To indicate fulltime farming a binary variable is included, which takes the value one if farmers work fulltime on dairy farming (i.e. $1976 \mathrm{hrs}$. per year or more $=38 \mathrm{hrs}$. per week times 52 weeks per year).

Diversification. Different farming strategies represent differences in farming behaviour (Van der Ploeg et al., 2009). By deriving information on diversity in farming strategies, for example a farmer involved in cheese-making or involved in landscape management, distinctions can be made between production oriented dairy farmers, diversifying farmers and more environmentally focused farmers (Bergevoet et al., 2004). Farmers having dairying as their only source of income are expected to show different behaviour than farmers that have additional sources of income as well. Dependency on other sources of income determines the expansion behaviour of farms. We hypothesize that if farms are less focused on pure milk production, they are less likely to expand in production. Three variables are included to measure other sources of income besides dairy production. They are calculated as the income from these activities per kg milk production and include: landscape management, recreation, and on-farm milk processing such as producing cheese or butter.

$42 \%$ of the farms in the dataset were engaged in diversification; $54 \%$ in landscape management, $15 \%$ in recreation and $2 \%$ in on-farm milk processing. If these percentages are compared with the situation for the Netherlands as a whole, comparable numbers are found. Most of the diversifying Dutch dairy farms are engaged in landscape management (76\% in 2009). Besides this, farms mainly engage in recreation and on-farm milk processing 
(resp. 14\% and 10\% in 2009). The total number of farms engaged in some kind of side-activity lies in reality a bit lower, at 23\% (Berkhout and Van Bruchem, 2010). Although only 2\% of the farms are engaged in on-farm milk processing, the ratio of total earnings from that activity to the total income from all side-activities together is almost as high as the ratio of total earnings from landscape management; respectively $40 \%$ and $46 \%$. The ratio of earnings from recreation is $15 \%$.

Livestock. A farm can have different strategies to increase its dairy herd; they can buy more dairy cows, or they can keep and grow more calves and heifers. Most Dutch farmers choose the second option in order to increase the dairy herd. It takes two years before calves and heifers can be considered as productive dairy cows. An increase in dairy herd eventually then leads to an increase in milk production on farm. Nevertheless, keeping more calves and heifers also increases the feed costs, which makes the farm less competitive. This might press the effect on production expansion down. We hypothesize that an increase in livestock, has a positive effect on production expansion, since more livestock means more stable capacity needed. Livestock is measured as the number of calves and heifers.

\subsubsection{Farm characteristics}

Farm size. An important variable in de the context of investment theory is farm size (Aramyan et al., 2007; Oude Lansink et al., 2001). Reasoning from neoclassical economic theory, smaller farms, compared to larger farms, have the benefit to reduce their costs relatively easily due to economies of scale (i.e. increasing in production). The higher the margin between the market milk price and a farm's costs of production, the more competitive a farm is. We therefore hypothesize that, although it may be harder for smaller farms to expand (due to financial constraints, specialization and skills of the operator, etc.), smaller farms are more likely to expand in production than bigger farms, in order to increase their profitability. Farm size is measured as the milk production in $\mathrm{kg}$. 
Modernity. The current state of the machinery and other capital-stock on farm is an important determinant for production expansion (Aramyan et al., 2007). The more modern the farm is, the more up to date is the capital stock, and the more capable a farm is to expand in production. It is more difficult for farms to expand production when the capital stock is relatively old. However, if a farm just invested in new capital, for example by building a new stable, it might reduce investments to increase production for a while, in order for a farm to financially recover. Modernity measures the status of the current capital and is calculated as the balance sheet value divided by the replacement value of buildings, machines, tools and installations.

Feed costs. Feed costs determine for a large part the marginal costs of farms, and are expected to increase further in the future due to increasing agricultural commodity prices (Jongeneel et al., 2010). This means that if farms expand in milk production, they will face a relatively large increase in feed costs, which affects the margin between the market milk price and a farm's production costs. It is likely that feed costs will determine the pattern of expansion in milk production in the future. We hypothesize that the larger the feed costs, the less likely farms are to expand in milk production. Feed costs is a compound variable of the expected expenditures on concentrates, roughage, and milk products feed to livestock, and is calculated per kg milk production. Expected feed costs are an important determinant of the stream of expected short-run profits in equation (1).

Production intensity. Intensive farms have a relative benefit in fixed costs compared to extensive farms; they can divide the costs over a larger amount of milk production, keeping the average fixed costs per production unit low. However, compared to extensive farms, they face a relative loss in variable costs; they have higher costs associated with feed and manure disposal. The question arises whether the effect of low average fixed costs per unit production can overcome the effect of high variable costs. It is tested whether intensive farms have more potential to expand in production than extensive farms. Production intensity is measured as the amount of milk production in kg per ha. For the amount of ha the area used for fodder and grassland is taken. 
Labour productivity. In the Netherlands, most farms are family farms run by mainly family labour. Therefore, labour is considered a fixed factor of production. If labour productivity is high, farms are pressing down their fixed costs per unit of production. Facing lower costs makes the farms more competitive. We hypothesize that labour intensive farms are more likely to expand in production than less labour intensive farms. Information on labour is measured as the total time (in hours) worked on the farm, either by family members or hired workers. Labour productivity is calculated as the amount of milk production in kg per labour time in hours.

Excess production. Since the data used for estimating our model were collected in the period when milk quotas were binding, it is relevant to incorporate this in the model. If a farm produced permanently more milk than was allowed under the farm's milk quota, it might have been a reason to buy more milk quotas, and expand in production. We hypothesize that excess milk production is an indicator for explaining production expansion decisions; if there was excess production during the last years, the farmer might be more willing to increase in milk production this year. Excess milk production is measured as the reference milk quota level of the farm minus the actual milk production level of the farm. It is a binary variable which takes the value one if the calculated amount is negative.

External finance. If a farmer wants to invest in order to expand production, he might opt for a loan at the bank. Whether or not the bank decides to provide finance depends on the financial situation of the farm. The financial status of the farm is indirectly linked to farm expansion; the higher the level of external finance of a farm, the less likely a farmer is to obtain another loan in order to invest in production expansion (Aramyan et al., 2007; Oude Lansink et al., 2001). This is a form of adjustment costs as hypothesized in section 3.3. However, if a farm obtains a loan to invest, for example in order to expand in production, the level of external finance will go up. Therefore, a high level of external finance might indicate that the farmer already invested to expand in production. We hypothesize that the higher the current level of external finance, the less likely a farmer is to expand in production. Because in the process 
of opting for a loan the bank especially considers the amount of external finance per kg milk production, this variable is used as a variable to measure the dependency on external finance.

Landownership. A farm with a higher share of rented land has a different position when opting for a loan at a bank than a farm having relatively more land in ownership. This is because owned land can serve as collateral for external finance. We hypothesize that the higher the share of rented land towards the total land of a farm, the less likely a farmer is to expand in production. Landownership is measured as the share of rented land and calculated as the amount of rented land divided by the sum of rented and owned land.

Table 3.1 Descriptive statistics of variables in dataset

\begin{tabular}{|c|c|c|c|c|}
\hline Category & \multicolumn{2}{|l|}{ Variable } & Dimension $^{\mathrm{a}}$ & $\begin{array}{l}\text { Sample mean } \\
\text { (s.d.) }\end{array}$ \\
\hline Dependent variable & \multicolumn{2}{|c|}{ Investments in stable capacity } & Binary, 1=yes & $0.07(0.25)$ \\
\hline \multirow[t]{5}{*}{ Market conditions } & \multicolumn{2}{|l|}{ Milk price } & Euros & $0.32(0.03)$ \\
\hline & \multicolumn{2}{|c|}{ Milk price volatility } & Euros & $0.45(0.06)$ \\
\hline & \multicolumn{2}{|c|}{ Manure production surplus } & $($ Euros $/ \mathrm{ha}) * 10^{2}$ & $0.17(0.61)$ \\
\hline & \multicolumn{2}{|l|}{ Nitrogen } & $(\mathrm{Kg} / \mathrm{ha})^{*} 10^{2}$ & $0.02(0.22)$ \\
\hline & \multicolumn{2}{|l|}{ Land area } & $\mathrm{Ha}^{*} 10^{1}$ & $0.07(0.26)$ \\
\hline \multirow{8}{*}{$\begin{array}{l}\text { Farmers' values, } \\
\text { goals and strategies }\end{array}$} & \multicolumn{2}{|l|}{ Age } & Years ${ }^{*} 10^{2}$ & $0.50(0.10)$ \\
\hline & \multicolumn{2}{|l|}{ Age-squared } & Years-squared*10 $10^{4}$ & $0.27(0.11)$ \\
\hline & \multicolumn{2}{|l|}{ Continuity } & Binary, $1=y e s$ & $0.80(0.40)$ \\
\hline & \multicolumn{2}{|l|}{ Fulltime farming } & Binary, $1=y e s$ & $0.95(0.22)$ \\
\hline & \multirow[t]{3}{*}{ Diversification } & $\begin{array}{l}\text { Landscape management } \\
\text { income }\end{array}$ & $\left(\right.$ Euros/kg)*10 $10^{-1}$ & $0.04(0.08)$ \\
\hline & & Recreation income & $(\text { Euros } / \mathrm{kg})^{*} 10^{-1}$ & $0.01(0.09)$ \\
\hline & & $\begin{array}{l}\text { On-farm milk processing } \\
\text { (cheese, butter) }\end{array}$ & $(\text { Euros } / \mathrm{kg})^{*} 10^{-1}$ & $0.03(0.29)$ \\
\hline & \multicolumn{2}{|l|}{ Livestock } & $\begin{array}{l}\text { Number of calves } \\
\text { and heifers } * 10^{1}\end{array}$ & $6.35(4.02)$ \\
\hline \multirow{8}{*}{$\begin{array}{l}\text { Farm } \\
\text { characteristics }\end{array}$} & \multicolumn{2}{|l|}{ Farm size } & $\mathrm{Kg}^{*} 10^{6}$ & $0.65(0.38)$ \\
\hline & \multicolumn{2}{|l|}{ Modernity } & Ratio & $0.35(0.12)$ \\
\hline & \multicolumn{2}{|l|}{ Feed costs } & $(\text { Euros } / \mathrm{kg})^{*} 10^{-1}$ & $0.66(0.18)$ \\
\hline & \multicolumn{2}{|c|}{ Production intensity } & $(\mathrm{Kg} / \mathrm{ha})^{*} 10^{4}$ & $1.34(0.44)$ \\
\hline & \multicolumn{2}{|c|}{ Labour productivity } & $(\mathrm{Kg} / \text { hour })^{*} 10^{3}$ & $0.16(0.07)$ \\
\hline & \multicolumn{2}{|c|}{ Excess production } & Binary, 1=yes & $0.48(0.39)$ \\
\hline & \multicolumn{2}{|l|}{ External finance } & Euros/kg & $1.57(0.66)$ \\
\hline & \multicolumn{2}{|l|}{ Landownership } & Share & $0.34(0.28)$ \\
\hline
\end{tabular}

${ }^{a} \mathrm{Kg}$ refers to kg milk production.

Source: own elaboration 
Table 3.1 gives definitions, units and mean values of the included variables. This table also shows that about $7 \%$ of the farms in the sample invested in more stable capacity in the period 2000-2010.

\subsection{Empirical model}

The conceptual model introduced in section 3.3 provides the basis for a binary choice model to analyse production expansion decisions. In section 3.4 the explanatory variables to be included were introduced. In this section we will discuss various econometric specification issues which eventually lead to our empirical model.

Farm production expansion may change some of the farm characteristics in the same period (e.g. an increase in production expansion indicates an increase in farm size, and vice versa). To solve for these potential endogeneity problems, lagged values of some variables are included in the model. Taking lags of variables enables to force the order of events. Moreover, in the conceptual model it is assumed that farmers maximize the expected stream of benefits and costs from expansion, leading to optimal expansion decisions for each year. Although farmers may differ in the way they form expectations, we assume that developments in certain variables in recent years have an impact on this process. Therefore, for variables on which expectations are formed on development patterns in the past, we combine values of the three most recent years into a weighted lagged variable. If both endogeneity is expected and the past is important to take into account as well, weighted one-year, two-year and threeyear lags are combined into a weighted lagged variable.

The weighting of the lags is chosen to vary over years, allowing for recent information to be more important in taking current decisions, than earlier years (i.e. weightings for the lags are chosen as $0.5,0.3$ and 0.2 respectively). Using weighted lags is preferred over including lags of each of the years separately, in order to impose uniformity of the sign of the estimated effects. 
Table 3.2 Dealing with endogeneity and expectations in the dataset

\begin{tabular}{|c|c|c|c|}
\hline & \multicolumn{2}{|l|}{ Include past development patterns } \\
\hline & & Yes & No \\
\hline & Yes & $\begin{array}{l}\text { Include weighting of lag } 1 \text {, } \\
\text { lag } 2 \text {, lag } 3 \text { of: } \\
\text { - Milk price } \\
\text { - Milk price volatility } \\
\text { - Excess production } \\
\text { - External finance } \\
\text { - Landownership }\end{array}$ & $\begin{array}{l}\text { Include lag } 1 \text { of: } \\
\text { - Manure production surplus } \\
\text { - Nitrogen } \\
\text { - Farm size } \\
\text { - Modernity } \\
\text { - Feed costs } \\
\text { - Production intensity }\end{array}$ \\
\hline 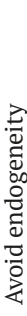 & No & $\begin{array}{l}\text { Include weighting of current value, lag } 1 \\
\text { and lag } 2 .\end{array}$ & $\begin{array}{l}\text { Include current value of: } \\
\text { - Land area } \\
\text { - Age } \\
\text { - Age } \\
\text { - Continuity } \\
\text { - Fulltime farming } \\
\text { - Diversification } \\
\text { - Livestock } \\
\text { - Labour productivity }\end{array}$ \\
\hline
\end{tabular}

a The weighted lag is used because it is likely that the financial situation of a farm in the past is considered when opting for a loan, and not just one year.

${ }^{\mathrm{b}}$ The weighted lag is used for the same reason as at the external finance variable.

Source: own elaboration

With separate lags included, parameters may have different signs, which make analysing the composite effects difficult. Moreover, multicollinearity problems arise if multiple lags are included separately in the model. Our solution for endogenous variables and the inclusion of weighted lagged values to mimic expectation formation leads to four possible data transformations that are summarized in table 3.2.

In the section 3.3 it was already stated that major investments are usually done once in a certain time period; it takes several years before an investment needs to be replaced. If a farm just made an investment to increase production capacity, it will most likely not invest in the next year. Therefore, a lagged dependent expansion indicator is added in the model, which is in line with the dynamic decision making process described in section 3.3. 
Farmers base their decisions on production expansion on the performance of the farm over the past years. This impels the use of panel data in analysing expansion decisions. The use of panel data enables us to deal with unobserved heterogeneity among farms, including unobserved factors that are relevant in expansion decisions as discussed in section 3.3. Given the large number of farms included in the sample and because of estimation reasons, we assume that the residual terms consist of a conventional residual element and a farmspecific random effect. The latter captures unobserved time-invariant differences in farmers' attitudes, values and goals, but also unobserved farm characteristics such as differences in efficiency and productivity and local conditions ${ }^{3}$. These assumptions lead to the use of a dynamic random effects probit model to analyse expansion behaviour of Dutch dairy farmers.

Taking into account the above mentioned econometric specification issues, our empirical model is specified as follows:

$I_{i t}^{*}=\alpha I_{i t-1}+x_{i t}^{\prime} \beta+s_{i}+u_{i t}$

where $I_{i t}=1$ if $I_{i t}^{*}>0$ and $I_{i t}=0$ if $I_{i t}^{*} \leq 0$

where $I_{i t}$ is a latent variable which is the unobserved difference between the (marginal) expected investment benefits and the investment threshold as explained in section 3.3. $I_{i t-1}$ is the first lag of the dependent variable (lagged production expansion) and $\alpha$ is the corresponding parameter to be estimated; $\beta$ is the parameter vector for the included explanatory variables $x_{i t}, s_{i}$ are time-invariant individual specific effects that are assumed to be normally distributed, homoscedastic and time invariant across individuals; $u_{i t}$ is the remaining disturbance. It is assumed that the error terms $u_{i t}$ are i.i.d. across farmers and time and independent of all $x_{i t}$. Assuming random farm effects, the dynamic random effects probit panel data model is estimated using the Gaussian-Hermite quadrature method (Baltagi, 2008: 242-243).

\footnotetext{
3 There is a rich literature on efficiency and productivity analysis on dairy farms in various European countries, including the Netherlands. Some examples are (Reinhard et al., 1999; Reinhard and Thijssen, 1999; Emvalomatis et al., 2011). However, since this requires rather different approaches we do not explicitly deal with this but rather assumes that average differences in efficiency are captured by the unobserved farm-specific effects.
} 
A well-known problem for dynamic random effects probit models is the initial conditions problem (Wooldridge, 2005). For the first year of observation the lagged dependent variable will correlate with random effects leading to inconsistent estimates. In order to solve for this initial conditions problem Wooldridge's (2005) solution is used. Wooldridge models the distribution of the unobserved individual specific effects conditional on the initial value and any exogenous independent variables. The approach of Wooldridge is based on balanced panels. However, if no attrition bias (selection bias) is present, the approach is also consistent for unbalanced panels. Using the Wooldridge approach the final equation estimated is:

$$
I_{i t}^{*}=\gamma I_{i t-1}+\sum_{v=1}^{V} x_{v i t}^{\prime} \beta_{v}+\underbrace{\alpha_{0}+\rho I_{i 0}+\sum_{v=1}^{V} \bar{x}_{v i}^{\prime} \lambda_{v}+a_{i}}_{s_{i}}+u_{i t}
$$

where $v=1, \ldots, V$ indicates the explanatory variables and $V$ is the total number of explanatory variables; $\alpha_{0}$ is the constant of the equation; $I_{i 0}$ is the production expansion of each farm $i$ for the first year they are present in the model and $\rho$ is the corresponding parameter to be estimated; $\bar{x}_{v i}$ is the average for every independent variable $v$ of farm $i ; \lambda_{v}$ is the corresponding parameter vector to be estimated; $\alpha_{i}$ are the time-invariant individual specific error terms of the equation measuring $s_{i}$ and are assumed to be normally distributed, homoscedastic and time invariant across individuals.

\subsection{Results}

In this section the estimation results are presented. Since the probit model is nonlinear, the parameter estimates are not equal to the marginal effects of the included variables. Therefore the parameter estimates are presented in the appendix. Table 3.3 shows the calculated marginal effects the model variables have on the decision to expand in stable capacity. The pseudo R-squared of the model is 0.19 and the count R-squared is 0.77 . 
Table 3.3 Marginal effects

\begin{tabular}{|c|c|c|c|c|}
\hline Category & \multicolumn{2}{|l|}{ Variable } & $\begin{array}{l}\text { Marginal } \\
\text { effect }^{\mathrm{a}}\end{array}$ & $\begin{array}{l}\text { Standard } \\
\text { error }\end{array}$ \\
\hline Dependent variable & \multicolumn{2}{|c|}{ Lagged investments in stable capacity $\left(\mathrm{y}_{\mathrm{t}-1}\right)$} & $-0.03^{\text {***** }}$ & 0.01 \\
\hline \multirow[t]{5}{*}{ Market conditions } & \multicolumn{2}{|c|}{ Milk price $\left(\mathrm{x}_{1}\right)$} & 0.26 & 0.50 \\
\hline & \multicolumn{2}{|c|}{ Milk price volatility $\left(\mathrm{x}_{2}\right)$} & -0.08 & 0.19 \\
\hline & \multicolumn{2}{|c|}{ Manure production surplus $\left(\mathrm{x}_{3}\right)$} & $0.02^{*}$ & 0.01 \\
\hline & \multicolumn{2}{|c|}{ Nitrogen $\left(\mathrm{x}_{4}\right)$} & 0.01 & 0.02 \\
\hline & \multicolumn{2}{|l|}{ Land area $\left(\mathrm{x}_{5}\right)$} & $0.02^{\text {** }}$ & 0.01 \\
\hline \multirow{8}{*}{$\begin{array}{l}\text { Farmers' values, } \\
\text { goals and strategies }\end{array}$} & \multicolumn{2}{|l|}{ Age $\left(x_{6}\right)$} & -0.52 & 0.66 \\
\hline & \multicolumn{2}{|l|}{$\operatorname{Age}^{2}\left(x_{7}\right)$} & 0.47 & 0.64 \\
\hline & \multicolumn{2}{|l|}{ Continuity $\left(\mathrm{x}_{8}\right)$} & 0.00 & 0.02 \\
\hline & \multicolumn{2}{|c|}{ Fulltime farming $\left(\mathrm{x}_{\mathrm{q}}\right)$} & -0.13 & 0.11 \\
\hline & \multirow[t]{3}{*}{ Diversification } & Landscape management income $\left(\mathrm{x}_{10}\right)$ & $-0.36^{\text {**as }}$ & 0.16 \\
\hline & & Recreation income $\left(\mathrm{x}_{11}\right)$ & -0.28 & 0.23 \\
\hline & & $\begin{array}{l}\text { On-farm milk processing (cheese, butter) } \\
\left(\mathrm{x}_{12}\right)\end{array}$ & 0.04 & 0.06 \\
\hline & \multicolumn{2}{|l|}{ Livestock $\left(\mathrm{x}_{13}\right)$} & $0.01^{\text {***ak }}$ & 0.00 \\
\hline \multirow{8}{*}{$\begin{array}{l}\text { Farm } \\
\text { characteristics }\end{array}$} & \multicolumn{2}{|l|}{ Farm size $\left(\mathrm{x}_{14}\right)$} & $-0.23^{* * * *}$ & 0.08 \\
\hline & \multicolumn{2}{|l|}{ Modernity $\left(\mathrm{x}_{15}\right)$} & $-0.34^{* * * * *}$ & 0.08 \\
\hline & \multicolumn{2}{|l|}{ Feed costs $\left(\mathrm{x}_{16}\right)$} & 0.03 & 0.04 \\
\hline & \multicolumn{2}{|c|}{ Production intensity $\left(\mathrm{x}_{17}\right)$} & $0.06^{* * * * *}$ & 0.02 \\
\hline & \multicolumn{2}{|c|}{ Labour productivity $\left(\mathrm{x}_{18}\right)$} & 0.06 & 0.19 \\
\hline & \multicolumn{2}{|c|}{ Excess production $\left(\mathrm{x}_{19}\right)$} & -0.02 & 0.02 \\
\hline & \multicolumn{2}{|c|}{ External finance $\left(\mathrm{x}_{20}\right)$} & $-0.10^{* * * *}$ & 0.03 \\
\hline & \multicolumn{2}{|c|}{ Landownership $\left(\mathrm{x}_{21}\right)$} & $0.17^{\prime \prime}$ & 0.09 \\
\hline
\end{tabular}

a Significance ${ }^{* * * * * *} 0.01 ;$; $0.05 ; " 0.10$

Source: own elaboration

As table 3.3 shows, the lagged dependent variable expansion variable is significantly different from zero and negative. This indicates that indeed last year's expansion has an impact on current expansion. Investments in stable size generally require a significant amount of money, and so it is not likely that farmers will invest in two subsequent years. Investments in stable size are made for a long term, and not on a yearly basis. Moreover, the significance of the lagged dependent variable shows that using a dynamic model, rather than a static model, for our analysis is relevant. This was also confirmed by estimating a static model and comparing both models. 


\subsubsection{Market conditions}

Until 2004 milk prices were relatively stable, but thereafter milk prices started to fluctuate. Remarkable in the years as of 2004 was a high price peak in 2006-2007, which reduced quickly again in 2008-2009. This price peak can be explained by several factors. Among other, at the world-level the dairy sector was facing high input costs and a reduction in milk production because of unfavourable weather conditions (Jongeneel et al., 2011). Also, at the European level, several decisions taken during the policy reforms in 2003, affected the milk prices (i.e. reduction of intervention prices; introduction of dairy premium; decoupling of direct payments (Jongeneel et al., 2011). These changes in policy led to fluctuating milk prices in the years 2004-2010.

In section 3.4 we hypothesized that milk prices and milk price volatility are important indi-

cators for analysing the impacts of quota abolishment and production expansion. However, for both variables no significant effects were found, which indicates that (fluctuations of) milk prices do not affect production expansion decisions. Apparently short run milk price developments (i.e. over the last 3 years) are not important in the decision making process on milk production expansion of Dutch dairy farmers. This could possibly be explained by the fact that Dutch dairy farmers had to deal with relatively stable milk prices for years. The price peak in 2006-2007 was the first one since years to happen. This means that dairy farmers were not used to it and perhaps needed some time to adjust their management plans in order to cope with the higher price volatility.

Currently manure is a widely discussed topic in context of the abolishment of milk quota and production expansion in the Netherlands. Farms are able to expand in production after the abolishment, however new limits in the form of manure policy regulations will arise. This implies that when farms want to increase in production they need to increase in land as well. The new legislation does not allow dairy farmers to expand their manure production without at least partly applying this to owned or rented land, which will lead to an increase in the 
costs for manure disposal relative to the past period. However, manure production surplus was surprisingly found to have a positive statistically significant effect, indicating that the higher the costs for manure disposal, the more likely a farmer was to expand production in the sample period. An explanation could be that farmers with high manure disposal costs have different expectations on the future and expect higher benefits of expansion compared to farmers with lower manure disposal costs. Whether these expectations are realistic is of course another issue, but farmers differ in the way expectations are formed. Another explanation for this counterintuitive finding could be that these farmers realised that new policies in the dairy sector for curbing manure surpluses were inevitable and that they expected that manure production rights would be introduced and based on historical manure production levels or numbers of cows.

The importance of land market developments is indicated by the statistically significant effect of land area. It was estimated that if the farmer increases land by 10 ha, the probability to increase in production increases by 0.02 ('land area'), which is a rather small effect. However, buying land in the Netherlands is a major investment and (agricultural) land is scarce. Therefore increasing in land area is often difficult for farmers.

We also included a time trend variable in our model in order to capture the effect of anticipating quota abolishment over time. However, the parameter was not significantly different from zero so we deleted this variable from the model. Moreover, we included a dummy variable with value 1 after 2008 to capture the effects of the announced quota abolition in the EU Health Check. Also this parameter was not significantly different from zero (p-value 0.631).

\subsubsection{Farmer's values, goals and strategies}

In the category farmer's values, goals and strategies a significant effect was only found for income from landscape management. In the model it was tested whether or not diversification, measured as the income from three types of side-activities (landscape management, 
recreation and on-farm milk processing), influenced the expansion behaviour of farmers. It was expected that if farmers diversify more, they will be less eager to expand in production.

The statistically significant negative effect for landscape management shows that indeed if farmers focus more on landscape management, they are less eager to expand in production; being involved in landscape management, lowers to probability to expand in production with 0.36 . Apparently farmers that focus on nature and landscape management are different from regular dairy farmers who do not focus on these issues. An interesting finding is the correlation between the different types of diversification and production intensity. These are for landscape management, recreation and on-farm milk processing $-0.23,-0.05$ and -0.03 respectively, meaning that particularly farms involved in landscape management have a lower production intensity.

When a farm wants to increase in production expansion, it often needs to increase its dairy herd as well (i.e. when planned expansion exceeds growth in milk yield per cow). The statistically significant positive effect for livestock shows that if a farmer increases the number of calves and heifers with 10 , the probability to expand in milk production increases with 0.01 .

\subsubsection{Farm characteristics}

With respect to farm characteristics, significant effects were estimated for farm size, production intensity, modernity, availability of external finance and landownership.

As hypothesized in section 3.4, the statistically negative effect for farm size (-0.23) shows that indeed smaller farms are more eager to expand in milk production.

The variable measuring production intensity shows that the probability to expand in milk production is significantly higher for the relative intensive farms (0.06). Seemingly, the benefits of having relatively lower fixed costs outweigh the costs of having relatively higher 
variable costs. Also the correlation between production expansion and production intensity, which is 0.08 , indicates that the relative intensive farms are more expanding in production.

As was stated in the hypothesis, the expected effect of modernity on investments could be in either direction. However, a negative effect (-0.34) was found, indicating that farms with newer equipment, have a probability to expand in production that is 0.34 lower than for farms with older equipment. It was argued that this could be the consequence if farms just invested in capital and first need some time to fully recover financially before actually increasing production.

This statement is in line with the significant effect of external finance. This effect was measured to be negative $(-0.10)$; a high rate of external finance presses down the probability to expand in production. Farms that expanded in recent years may have a higher level of external debt. But whatever the reason for this high level, it reduces the probability of further expansion.

The last significant effect that was found is for landownership. Contrary to our hypothesis, it was found that the higher the share of rented land towards the total land of a farm, the more likely a farmer is to expand in production (0.17). This effect can possibly be explained by the fact that the variable landownership is measured using information on rented and owned land of the last three years. It could be that farms were already anticipating on production expansion, and therefore they increased in land size by renting more land as buying land is difficult. 


\subsection{Discussion}

Surprisingly, the estimation results did not show significant effects for milk price and milk price volatility, which is an interesting finding. As was shown before the milk price shows an increased volatility as compared to the period before 2007. However, the medium term prospect for the farm gate milk price appears to be favourable, which is mainly due to the projected world-wide increase in demand for dairy products, in particular in Asia (OECD-Food and Agriculture Organization of the United Nations, 2013). Although expected otherwise, this research does not significantly show that the projected milk price evolution will affect the expansion of Dutch milk production after quota abolition. The absent response to price volatility is rather surprising given the strong price swings between 2006 and 2010. It could be that Dutch dairy farmers have been used to a long period of relatively stable and policy supported prices. The experience after 2007 was in that respect rather new to them. If price volatility becomes a structural element of the new policy and market context in dairy this may induce farmers to learn to better optimize their behaviour in this respect and therefore a negative response to price volatility could still be possible in the future.

Also important in the context of milk quota abolishment and production expansion is diversification. The pattern of a development into two types of farms (on the one hand more intensive farms and on the other hand more diversified farms) that was found by Samson et al. (2013) will most likely continue in future. Our results show that diversification has a downwards effect on milk production expansion. This implies that after quota abolition diversified farms are less expected to expand in production.

At the moment, obtaining external finance at banks is difficult for farmers. Banks are more reluctant to offer (long-term) loans, and set more stringent requirements to the loans they supply (for example banks increase the level of collateral needed). An important reason for this is the agreement on the Basel-III norms (Basel Committee on Banking Supervision, 2010). These result from the economic crisis in 2008, and contain, compared to the former 
Basel-II norms, more stringent international norms for the ratio of internal finance to external finance at banks. The stricter requirements to loans possibly put a brake on investments and production expansion by farmers in future. The effect of external finance on production expansion, which was found to be negative and significant, will then become even more important in decision making.

It has been argued that land plays a multi-functional role in the dairy sector (feed production, manure disposal). In sections 3.2.2 and 3.2.3 it was stated that the level of manure production surplus and the scarce availability of land respectively are possible new bottlenecks to milk production after quota abolishment. It was found that an increase in land area is a driving factor for increasing milk production. The availability of land is likely to be a constraining factor for increasing milk production in future.

With respect to the variable measuring the manure production surplus a positive statistically significant effect was found, indicating that the higher the costs for manure disposal, the more likely a farmer is to expand in production. In the results section possible reasons for this increase in milk production capacity were pointed out; it stated that farmers differ in the way they form expectations on the benefits and costs of manure production (disposal) in the future. During the period considered here (2000-2010), intensive dairy farmers have been able to dispose their manure surplus (for example farm to farm-exchange, processing, and export) at reasonable economic conditions. This suggests that when a well-functioning manure-market can be established, milk production expansion might continue even when milk production per hectare is already high. However, through the milk quota indirectly a barrier on manure production was set as well. With the adjustments in agricultural policy (i.e. milk quota abolishment and manure policy) this will change and manure becomes a more critical issue for dairy farmers when considering expanding milk production.

The low value for the pseudo R-squared of the model (0.192) indicates that apparently much of the variation in the model is still unexplained. The results also show that there are hardly 
any effects of the included non-economic factors (farmers' values goals and strategies) in our model. However, there could be effects of other non-economic factors, which we were not able to include in the model, as well. Some non-economic factors (e.g. intrinsic preferences of farmers in favour or against nature management and environmental stewardship) are difficult to measure and were therefore not available. Also specific policies and structural developments at higher scales are not included. For this reason we cannot conclude (yet) that non-economic factors do not play a significant role in explaining production behaviour of farmers. This is clearly a limitation of the available dataset. Although it is rich in variables relating to the farm economics, and includes measurable farmer characteristics, other less tangible characteristics are not available and therefore could not be included explicitly in our empirical analysis.

An example of such a not-included factor is the changing political support to the agricultural sector in the Netherlands, due to shifts of political parties in the government. In combination with the often continuous and lasting political discussions on the national implementation of agricultural policies, this leads to uncertainty about the future for farmers. Farmers are more reluctant to invest when there is an uncertain political climate. Moreover, differences in regulations and permits between local governances exist, which constrain in some cases the possibilities for production expansion. These may be strengthened by local protests against farm expansion which may also have an impact on the possibilities to expand for the farms. Such information on protests is difficult to measure and its impact on the expansion behaviour of the farmers is therefore hardly quantifiable. 


\subsection{Conclusions}

The objective of this study is to investigate Dutch dairy farmers' decisions on milk production expansion taking both economic and non-economic factors into account. The conceptual model described in this study shows that a combination of economic, social and environmental variables can be used to analyse farm-level expansion decisions (i.e. increasing staple capacity). This shows that purely economic approaches are too narrow in understanding developments in expansion decisions at the farm level. The more formal description of the decision making process explains why Dutch dairy farmers do not invest in stable capacity every year but only once a while. Also our data recognize this as many zero investments are observed among the farms included in the sample population. Possible explanations are to be found in fixed asset theory (Chavas, 1994), adjustment cost theory (Oude Lansink and Stefanou, 1997; Gardebroek, 2004), and the option theory of investment (Dixit and Pindyck, 1994; Wossink and Gardebroek, 2006; Hinrichs et al., 2008). Our model combines these three theories in formulating that the expansion decision of Dutch dairy farmers depends on the balance between the expected marginal value of expansion (benefits) and the threshold for expansion. Positioning the model like this provides a solid base and a new approach to look at Dutch dairy farmers' production expansion behaviour.

This decision making framework includes expectations on EU, national and local policies, market conditions, farmer's values, goals and strategies and farm characteristics. However, as we discuss above, in practise it turns out that it is rather complex to include these other dimensions explicitly (e.g. politics, intrinsic preferences of farmers, measurement scale). Our research shows that there are external influences that are hard to catch in purely traditional economic research work. In order to have a full understanding of the investment decision making one should think beyond the possibilities of modelling using microeconomic theory. One such, relatively new, branch of literature is called experimental economics (Davis and Holt, 1993), which is developed in order to bridge the gap between economic theory and observation. This theory uses perceptions from the field of psychology and biology in order 
to explain human behaviour, and as such can provide useful and complementing insights to the findings based on purely economic theory. Samson et al. (2013) show in their study the added value of using experimental economics in the context of assessing the impact of policy changes on Dutch dairy farmers' farm income and farming strategies. In future research such an analysis on the intrinsic preferences and attitudes of farmers with respect to investment decisions could possibly be an added value to this study as well.

Empirically, we find that several market conditions, variables relating to farmers' values, goals and strategies, and farm characteristics are main drivers for farmers to increase in milk production. While many factors were expected to affect these expansion decisions, only a few and mainly economic factors, were found to be statistically significant in estimation. These factors include lagged investments in extra stable capacity (negative), manure production surplus (positive), land area (positive), landscape management (negative), livestock (positive), farm size (negative), production intensity (positive), modernity of equipment (negative), external finance (negative) and landownership (positive).

Although the findings show a limited increase in milk production so far (until 2014 most farmers still respected their quota limits, but the quota showed a gradual annual increase as part of the EU's soft landing strategy), the data show that Dutch dairy farms can potentially increase milk production in the future, even already with limited investments. Currently farms underutilize their stable space, as the occupancy of stable space is $71 \%$. After milk quota abolishment farms can therefore increase livestock herd with limited investments.

In the introduction we hypothesized that one of the contributions of our study to the literature is the possibility to draw conclusions at the individual level, as our study is based on micro level data. Individual farms might strongly differ in opportunities to expand in production. We found that farm characteristics such as access to external finance and the rate of modernity of a farm influence the farms' individual capabilities to make investments in order to increase milk production. Although in this conclusion we mainly describe results for 
the whole sample population, viz. estimated parameters are the same for all farms, heterogeneity among individual farms is present as well. Due to the specifications of our model, this heterogeneity is captured in an unobserved farm-specific error component in our model. These farm-specific effects highly differ per farm since they include all farmers' individual attitudes, values, goals and characteristics that are not specified elsewhere in the model. Also the non-measurable non-economic effects, as we described above, are included in this farm-specific effect. 


\section{References}

Aramyan, L.H., Oude Lansink, A.G.J.M., Verstegen, J.A.A.M. (2007). Factors underlying the investment decision in energy-saving systems in Dutch horticulture. Agricultural Systems. 94: 520-527.

Baltagi, B.H. (2008). Econometric Analysis of Panel Data. Wiley, UK, Chichester.

Basel Committee on Banking Supervision (2010). Agreement on Basel-III Norms, press release. Retrieved December 2013, from: http://www.bis.org/press/p100912.pdf.

Bergevoet, R.H.M., Ondersteijn, C.J.M., Saatkamp, H.W., Van Woerkum, C.M.J., Huirne, R.B.M. (2004). Entrepreneurial behaviour of Dutch dairy farmers under a milk quota system: goals, objectives and attitudes. Agricultural Systems 80: 1-21.

Berkhout, P., Van Bruchem, C. (2010). Landbouw-economisch bericht 2010 (in English: Agricultural economic report 2010). LEI Wageningen UR, The Netherlands, The Hague.

Bouamra-Mechemache, Z., Jongeneel, R., Requillart, V. (2008). Impact of a gradual increase in milk quotas on the EU dairy sector. European Review of Agricultural Economics 35: $461-491$.

CBS (2013). Official statistics for The Netherlands. Retrieved August 2013, from http://www. cbs.nl/nl-NL/menu/home/default.htm.

Chavas, J.P. (1994). Production and Investment Decisions Under Sunk Cost and Temporal Uncertainty. American Journal of Agricultural Economics 76: 114-127.

Cotteleer, G., Gardebroek, C., Luijt, J. (2008). Market Power in a GIS-based Hedonic Price Model of Local Farmland Markets. Land Economics 84: 573-592.

Davis, D.D., Holt, C.A. (1993). Experimental economics. Princeton University Press, Princeton, USA, Princeton.

De Frahan, B.H., Baudry, A., De Blander, R., Polomé, P., Howitt, R. (2011). Dairy farms without quotas in Belgium: estimation and simulation with a flexible cost function. European Review of Agricultural Economics 38: 469-495. 
Dixit, A., Pindyck, R.S. (1994). Investment under Uncertainty. Princeton University Press, USA, Princeton.

Dutch Government (2014a). Ministry of economic affairs. Voorstel van Wet Verantwoorde Groei van Melkveehouderij (in English: Law of Responsible Growth Dairy Sector). The Netherlands, The Hague.

Dutch Government (2014b). Ministry of economic affairs. Meststoffenwet (in English: Manure Policy). The Netherlands, The Hague.

Emvalomatis, G. (2012). Productivity Growth in German Dairy Farming using a Flexible Modelling Approach. Journal of Agricultural Economics 63: 83-101.

Emvalomatis, G., Stefanou, S.E., Oude Lansink, A. (2011). A Reduced-Form Model for Dynamic Efficiency Measurement: Application to Dairy Farms in Germany and The Netherlands. American Journal of Agricultural Economics 93: 161-174.

European Commission (2011). European Commission. Proposal for a regulation of the European parliament and of the council establishing rules for direct payments to farmers under support schemes within the framework of the common agricultural policy. Belgium, Brussels, 108p.

European Commission (2012). European Commission. Melkproductie van zes lidstaten in het melkquotumjaar 2011/2012 groter dan toegestaan (press release) (in English: 2011/2012 milk production more than allowed in 6 member-states). Belgium, Brussels, 6p.

European Commission (2013). European Commission. Political agreement on new direction for common agricultural policy (press release). Belgium, Brussels, 3p.

Frawley, J., Reidy, K. (1986). An approach to identify different categories of farmers: an illustration of the use of discriminant Analysis. Irish Journal of Agricultural Economics and Rural Sociology 11: 35-47.

Gardebroek, C. (2004). Capital Adjustment Patterns on Dutch pig farms. European Review of Agricultural Economics 31: 39-59.

Hinrichs, J., Mußhoff, O., Odening, M. (2008). Economic hysteresis in hog production. Applied Economics 40: 333-340. 
Huettel, S., Jongeneel, R. (2011). How has the EU milk quota affected patterns of herd-size change? European Review of Agricultural Economics 38: 497-527.

Jongeneel, R. (2009). Een tijd van komen en gaan, in: Peerlings, J. and Gardebroek, C. (Eds.), Van boterberg naar biobased : de Nederlandse landbouw in perspectief (in English: Dutch agriculture in perspective). Wageningen Academic Publishers, The Netherlands, Wageningen.

Jongeneel, R., Burrell, A., Kavallari, A. (2011). Evaluation of CAP measures applied to the dairy sector. European Commission Directorate-General for Agriculture and Rural Development. Belgium, Brussels.

Jongeneel, R., Van Berkum, S. (2015). What will happen after the EU milk quota system expires in 2015? An assessment of the Dutch dairy sector. LEI Wageningen UR, The Netherlands, The Hague.

Jongeneel, R., Van Berkum, S., De Bont, C., Van Bruchem, C., Helming, J., Jager, J. (2010). European dairy policy in the years to come : quota abolition and competitiveness. LEI Wageningen UR, The Netherlands, The Hague.

Lans, T., Van Galen, M.A., Verstegen, J.A.A.M., Biemans, H.J.A., Mulder, M. (2014). Searching for entrepreneurs among small business owner managers in agriculture. NJAS Wageningen Journal of Life Sciences 68: 41-51.

Läpple, D., Hennessy, T. (2012). The capacity to expand milk production in Ireland following the removal of milk quotas. Irish Journal of Agricultural and Food Research 51: 1-11.

LEI Wageningen UR (2013). Dutch agricultural and horticultural figures. Retrieved August 2013, from http://www3.lei.wur.nl/ltc/.

Lips, M., Rieder, P. (2005). Abolition of Raw Milk Quota in the European Union: A CGE Analysis at the Member Country Level. Journal of Agricultural Economics 56: 1-17.

OECD-Food and Agriculture Organization of the United Nations (2013). OECD-FAO Agricultural Outlook 2013. Retrieved December 2013, from http://dx.doi. org/10.1787/agr_outlook-2013-en. 
Ondersteijn, C.J.M., Giesena, G.W.J., Huirne, R.B.M. (2003). Identification of farmer characteristics and farm strategies explaining changes in environmental management and environmental and economic performance of dairy farms. Agricultural Systems 78: 31-55.

O’Rourke, E., Kramm, N., Chisholm, N. (2012). The influence of farming styles on the management of the Iveragh uplands, southwest Ireland. Land Use Policy 29: 805-816.

Oude Lansink, A. and Stefanou, S.E. (1997). Asymmetric Adjustment of Dynamic Factors at the Firm Level. American Journal of Agricultural Economics 79: 1340-1351.

Oude Lansink, A.G.J.M., Verstegen, J.A.A.M., Van Den Hengel, J.J. (2001). Investment decision making in Dutch greenhouse horticulture. Netherlands Journal of Agricultural Science 49: 357-368.

Reinhard, S., Lovell, C.A.K., Thijssen, G. (1999). Econometric Estimation of Technical and Environmental Efficiency: An Application to Dutch Dairy Farms. American Journal of Agricultural Economics 81: 44-60.

Reinhard, S., Thijssen, G. (1999). Nitrogen efficiency of Dutch dairy farms: a shadow cost system approach. European Review of Agricultural Economics 27: 167-186.

Samson, G.S., Gardebroek, C., Jongeneel, R.A. (2013). Analysing Dutch dairy farmer behaviour towards the provision of public goods: The added value of an economic simulation experiment. Land Use Policy 34: 321-331.

Schmitzberger, I., Wrbka, T., Steurer, B., Aschenbrenner, G., Peterseil, J., Zechmeister, H.G. (2005). How farming styles influence biodiversity maintenance in Austrian agricultural landscapes. Agriculture, Ecosystems \& Environment 108: 274-290.

Solano, C., León, H., Pérez, E., Tole, L., Fawcett, R.H., Herrero, M. (2006). Using farmer decisionmaking profiles and managerial capacity as predictors of farm management and performance in Costa Rican dairy farms. Agricultural Systems 88: 395-428.

Valbuena, D., Verburg, P.H., Bregt, A.K. (2008). A method to define a typology for agent-based analysis in regional land-use research. Agriculture, Ecosystems \& Environment 128: 27-36. 
Van der Ploeg, J.D. (1993). Rural sociology and the new agrarian question - a perspective from the Netherlands. Sociologia Ruralis 33: 240-260.

Van der Ploeg, J.D., Laurent, C., Blondeau, F., Bonnafous, P. (2009). Farm diversity, classification schemes and multifunctionality. Journal of Environmental Management 90: S124-S131.

Willock, J., Deary, I.J., Edwards-Jones, G., Gibson, G.J., McGregor, M.J., Sutherland, A., Dent, J.B., Morgan, O., Grieve, R. (1999). The role of attitudes and objectives in farmer decision making: Business and environmentally-oriented behaviour in Scotland. Journal of Agricultural Economics 50: 286-303.

Witzke, P., Kempen, M., Pérez Domínguez, I., Jansson, T., Sckokai, P., Helming, J., Heckelei, T., Moro, D., Tonini, A., Fellmann, T. (2009). Regional Economic Analysis of Milk Quota Reform in the EU. European Commission, Joint Research Centre, Institute for Prospective Technological Studies, Spain, Sevilla.

Wooldridge, J.M. (2005). Simple solutions to the initial conditions problem in dynamic, nonlinear panel data models with unobserved heterogeneity. Journal of applied econometrics 20: 39-54.

Wossink, A. and Gardebroek, C. (2006). Environmental Policy Uncertainty and Marketable Permit Systems: The Dutch Phosphate Quota Program. American Journal of Agricultural Economics 88: 16-27. 


\section{Appendix 3.1}

Estimation results of the model used in this study

\begin{tabular}{|c|c|c|c|c|}
\hline Category & \multicolumn{2}{|l|}{ Variable } & $\begin{array}{l}\text { Estimated } \\
\text { coefficient }^{\mathrm{a}}\end{array}$ & $\begin{array}{l}\text { Standard } \\
\text { error }\end{array}$ \\
\hline Dependent variable & \multicolumn{2}{|c|}{ Lagged investments in stable capacity $\left(\mathrm{y}_{\mathrm{t}-1}\right)$} & $-0.57^{* * * x}$ & 0.26 \\
\hline \multirow[t]{5}{*}{ Market conditions } & \multicolumn{2}{|c|}{ Milk price $\left(\mathrm{x}_{1}\right)$} & 3.31 & 6.46 \\
\hline & \multicolumn{2}{|c|}{ Milk price volatility $\left(\mathrm{x}_{2}\right)$} & -1.00 & 2.43 \\
\hline & \multicolumn{2}{|c|}{ Manure production surplus $\left(\mathrm{x}_{3}\right)$} & $0.29^{*}$ & 0.17 \\
\hline & \multicolumn{2}{|c|}{ Nitrogen $\left(\mathrm{x}_{4}\right)$} & 0.18 & 0.30 \\
\hline & \multicolumn{2}{|l|}{ Land area $\left(\mathrm{x}_{5}\right)$} & $0.24^{\text {w*ta }}$ & 0.10 \\
\hline \multirow{8}{*}{$\begin{array}{l}\text { Farmers' values, } \\
\text { goals and strategies }\end{array}$} & \multicolumn{2}{|l|}{ Age $\left(x_{6}\right)$} & -6.64 & 8.52 \\
\hline & \multicolumn{2}{|l|}{$\operatorname{Age}^{2}\left(x_{7}\right)$} & 5.98 & 8.21 \\
\hline & \multicolumn{2}{|l|}{ Continuity $\left(\mathrm{x}_{8}\right)$} & 0.04 & 0.30 \\
\hline & \multicolumn{2}{|c|}{ Fulltime farming $\left(\mathrm{x}_{9}\right)$} & $-0.85^{*}$ & 0.50 \\
\hline & \multirow[t]{3}{*}{ Diversification } & Landscape management income $\left(\mathrm{x}_{10}\right)$ & $-4.64^{* * *}$ & 2.06 \\
\hline & & Recreation income $\left(\mathrm{x}_{11}\right)$ & -3.55 & 2.96 \\
\hline & & $\begin{array}{l}\text { On-farm milk processing (cheese, } \\
\text { butter) }\left(\mathrm{x}_{12}\right)\end{array}$ & 0.57 & 0.82 \\
\hline & \multicolumn{2}{|l|}{ Livestock $\left(\mathrm{x}_{13}\right)$} & $0.16^{* * * * *}$ & 0.06 \\
\hline \multirow{8}{*}{$\begin{array}{l}\text { Farm } \\
\text { characteristics }\end{array}$} & \multicolumn{2}{|l|}{ Farm size $\left(\mathrm{x}_{14}\right)$} & $-2.90^{* w_{* * *}}$ & 1.03 \\
\hline & \multicolumn{2}{|l|}{ Modernity $\left(\mathrm{x}_{15}\right)$} & $-4.42^{k * * * *}$ & 1.05 \\
\hline & \multicolumn{2}{|l|}{ Feed costs $\left(\mathrm{x}_{16}\right)$} & 0.43 & 0.54 \\
\hline & \multicolumn{2}{|c|}{ Production intensity $\left(\mathrm{x}_{17}\right)$} & $0.73^{* * * *}$ & 0.26 \\
\hline & \multicolumn{2}{|c|}{ Labour productivity $\left(\mathrm{x}_{18}\right)$} & 0.75 & 2.49 \\
\hline & \multicolumn{2}{|c|}{ Excess production $\left(\mathrm{x}_{19}\right)$} & -0.20 & 0.32 \\
\hline & \multicolumn{2}{|c|}{ External finance $\left(\mathrm{x}_{20}\right)$} & $-1.28^{\text {w***k }}$ & 0.36 \\
\hline & \multicolumn{2}{|c|}{ Landownership $\left(\mathrm{x}_{21}\right)$} & $2.14^{*}$ & 1.13 \\
\hline
\end{tabular}

a Significance ${ }^{* * * * * *} 0.01 ; * 0.05 ; " 0.10$

Source: own elaboration 


\section{Analysing Trade-offs between Milk, Feed and Manure Production on Dutch Dairy Farms ${ }^{1}$}

\section{Abstract}

The abolition of milk quota fuels environmental concerns in the Netherlands. A microeconomic model is developed to analyse the technical relations between milk, roughage and manure production. Production functions for milk, feed and roughage are estimated based on milk quota and manure constraints. Together with an equation for manure production these are used to calculate the costs and benefits of dairy livestock expansion. It turns out that at the margin and at prevailing input and output prices and manure processing costs, it will be attractive for dairy farms to expand production, unless regulatory constraints prevent them from doing so.

Paper by Gerlinda S. Samson, Cornelis Gardebroek and Roel A. Jongeneel, European Review of Agricultural Economics 2017, 44: 475-498. Doi: 10.1093/erae/jbw025 


\subsection{Introduction}

In grass-based dairy production system dairy farmers jointly produce milk and animal manure. Animal manure and fertilizer are combined with land in order to produce an intermediate roughage product that is fed to their livestock. In intensive production systems that occur in specific EU Member States (e.g. Netherlands, Denmark) or regions within Member States (e.g. Brittany in France) this may lead to surplus production of manure, which, if unregulated, may lead to over application and damages to the environment and nature. Until recently the EU milk quota policy contributed to curbing the production and application of animal manure in the Dutch dairy sector. This study, which focuses on the Dutch dairy sector, investigates the implication of environmental regulation applied to intensive grass-based dairy production system while the milk quota are being phased out.

Whereas in many European Union (EU) Member States the milk quota were already no longer restricting milk production before 1 April 2015, which was partly due to the EU's soft landing policy of 2009-2014, in the Netherlands they still were. Due to the annual increase in milk yield per cow, the number of dairy cows needed to produce the milk quota level steadily declined, which reduced the manure production at the farm level. In the period from 1984, the year in which milk quotas were introduced, to 2012 the milk quota only declined by 5\%, whereas the milk yield per cow increased by 51\% (LEI Wageningen UR, 2013).

April 1, 2015 the milk quota were abolished in the EU and policy makers as well as the agribusiness (milk processing, feed industry) were and still are interested in its effects on milk and manure production. Several studies (e.g. Réquillart et al., 2008; Jongeneel and Van Berkum, 2015) indicated that Dutch milk supply might substantially increase after abolishment (estimates roughly vary from $+15 \%$ to $+25 \%$ ). Consequently, the production of manure will increase as well. As such the abolition of milk quota fuels environmental concerns in the Netherlands, as the indirect limit on manure production has disappeared. 
Already since the mid 80-ties, the Dutch government carries out a manure policy in order to manage manure production and the use of it (Dutch Government, 2014). The current policy is based on the European Nitrate Directive (Council of European Communities, 1991), which regulates the application of both Nitrate and Phosphate. Following this policy there are constraints on the quantity of (animal) manure that may legally be applied on land. When a farm produces more animal manure than can be applied on owned or rented land, there is a manure surplus which has to be disposed at a cost (i.e. processed, transferred to other farmers, exported). Moreover, the fifth Action Plan (2014-2017) of the Nitrate Directive and the derogation allowance of the European Commission require the Netherlands to restrict its total phosphate production to 172.9 million $\mathrm{kg}$ (which is currently the most restrictive nutrient and the level of which is equal to the amount that was produced in the year 2002).

Recently, the Dutch government, after consulting the sector, has sharpened its manure policy in order to ensure that the Netherlands will satisfy European environmental standards in the future as well. The manure policy is changing in the direction of more stringent regulation on animal manure excretion standards, and more stringent application norms of animal manure on land (Dienst Regelingen Loket, 2014; Dutch Ministry of Economic Affairs, 2015). As an example, the $5 \%$ uncertainty margin on animal manure excretion has been abandoned from 1 January 2014 onwards, which will most likely lead to a one time increase in the registered manure production. As another example, the application norms for animal manure on sandy soils might become more strict as an amendment to the current so-called derogation norm is likely to be made.

In order to assess the impact of milk quota abolition on production of milk and manure, more insight into the dairy production technology is required. The current literature on the effects of agricultural policy changes (i.e. milk quota abolishment and manure policy changes) on manure production surpluses and (economic) farm management decisions is still relatively scarce. On the one hand several studies exist on the specific modelling of mineral-flows within a farm (e.g. Nousianen et al., 2011; Hadrich et al., 2008; Buysse et al., 2005; 
Aarts et al., 1992). Although these studies recognize the (technical) interaction between the several sub-systems in a farm, i.e. milk output, feed production and manure management, they focus on optimal use of minerals and do not directly take manure policy measures into account. On the other hand, there are more applied agronomic studies that take manure policy into account and which focus on the Dutch dairy sector specifically (e.g. Evers et al., 2009; Krimpen et al., 2010), but in these studies an economic framework capturing the milkfeed-manure-nexus is lacking.

The objective of this chapter is to develop a microeconomic modelling approach that is capable of analysing the effects of agricultural policy changes on the trade-offs between milk, feed and manure production in one coherent framework. In comparison with existing microeconomic studies (e.g. Boots et al., 1997; Ooms and Peerlings, 2005), this implies that alongside the traditional production technology, the feed input side, as well as the role of manure (and manure policy measures) are properly taken into account. In contradiction to sectorial approaches, the advantage of using micro level data is that it can take regulatory constraints holding at micro or farm level into account. It should be recognized that animal manure is not only a by-product of milk production, but also an intermediate input used for fertilization. As such manure is a valuable product that can be a substitute for fertilizer. We follow a primal approach and estimate the production technologies for milk, feed and roughage, while an agronomic calculation approach is used to determine manure production. Trade-off effects between inputs and the implications of these on milk, roughage and manure production are presented and analysed.

In section 4.2 we continue by explaining the theoretical model of this study indicating the technical relations between milk-, roughage- and manure production. Section 4.3 presents the data used in this study which are based on a sample of the Dutch dairy sector. Section 4.4 presents the empirical specifications and estimation methods used, and section 4.5 provides and discusses the results. We end with concluding remarks in section 4.6. 


\subsection{Theoretical model}

The dairy farmer's decision problem can be characterized by a short-run profit maximization problem where output supply and variable input demand are chosen at optimal levels given exogenous output and input prices and levels of quasi-fixed inputs. There are however two important complications to the standard textbook profit maximization problem. First, farmers that are constrained by milk quota cannot produce an optimal milk quantity that exceeds the quota level. For them the quota level is the maximum attainable output level and their profit maximization problem basically becomes a cost minimization problem at given output (quota) level (De Frahan et al., 2011). Second, cows not only produce milk but also manure. This manure can to some extent be applied to grassland to produce roughage but only as far as environmental regulations allow since there are limits to manure application per hectare. The surplus has to be disposed of at a cost.

Since this study focuses mainly on the technical relations between milk-, roughage- and manure production, the model we use is formulated in its primal form where the various production technologies are discussed below. The profit maximization problem is defined as:

$$
\max _{Y, x} \pi=p^{Y} \cdot Y+p^{O t} \cdot O t-w \cdot x-c \cdot M s \quad \text { subject to production technologies }
$$

where $\pi$ is short-run profits, $Y$ is milk output, $p^{y}$ is the milk price the farmer receives, $O t$ is other output, $p^{\text {ot }}$ is the price for other output, $x$ is a vector of variable inputs (including bought roughage, own produced roughage and concentrates), $w$ is a vector of variable input prices, $M s$ is the manure surplus, and $c$ is unit cost of disposing manure. The manure surplus is the difference between what is produced and the amount of manure that can be placed on the (owned and rented) land which is in use by the farmer. Manure production is a function of the number of dairy cows and milk production levels, where the manure that can be placed is a

function of the available land and the maximum application standards. Short-run profits are maximized subject to a composite production technology, consisting of a milk production component and roughage and manure production components. Note that in this general 
notation the milk production level $(Y)$ can be equal to or less than the quota level. In both cases the milk output $Y$ is produced according to the following technology:

$$
Y=f(F d, L i, L b, C y, O t)
$$

where $F d$ is animal feed, $L i$ is dairy cows, $L b$ is an aggregate of family and hired labour, $C y$ is capital for milk production such as buildings and installations, and $O t$ is other output. Animal feed is considered a variable input that is partly produced on the farm (see below), whereas, livestock, labour and capital are considered as quasi-fixed inputs. Other output is included recognizing that dairy farms not only produce milk, but also calves and meat. Following Ooms and Peerlings (2005) this other output is considered as a negative input in the milk production function. $Y$ is assumed to be non-decreasing in $F d, L i, L b$, and $C y$ and non-increasing in $O t$ and concave in inputs.

Animal feed consists of three major components, notably concentrates $(\mathrm{Co})$, own produced roughage $(R o)$, and bought roughage $(R b)$, where $R o$ and $R b$ include products like fresh grass, grass silage, maize, and others. $R o, R b$ and $C o$ are partly substitutable, particularly own and bought roughage, and partly complementary due to different nutrient contents. The relationships among these three fodder types are captured by the following feed production technology, where the production of feed (measured in metabolizable energy units) is written as:

$$
F d=g(C o, R o, R b)
$$

where we assume that $F d$ is non-decreasing and concave in $C o, R o$, and $R b$. Whereas concentrates and bought roughage are purchased and therefore lead to variable costs in equation (1), the (intermediate output) own roughage is produced on the farm itself according to the following intermediate output production function:

$$
R o=h(L a, M a, F r, R a, T p)
$$

where $L a$ is own and rented farmland, $M a$ is applied animal manure, $F r$ is purchased chemical fertilizer. Besides these three inputs, own roughage production also depends on weather 
conditions, represented by rainfall $(R a)$ and temperature $(T p)$. Ro is assumed to be increasing in $L a, M a$, and $F r$ and since we are interested in optimal production decisions among milk, roughage and manure production, we also assume concavity in applied manure $(M a)$, due to diminishing returns to scale. Note that manure application is restricted by (maximum) application standards. The amount of manure applied may equal the amount of manure produced (standards are not restricting application) or less than the total amount of manure produced on the farm (standards are restricting application). In the latter case a farm will have a manure surplus.

Following (legal) Dutch dairy cow manure excretion standards (Remmelink et al., 2012: 76), manure production (and nutrient excretion) is an increasing function of the number of dairy cows $(L i)$, calves and heifers below 1 year $\left(L i_{c<1}\right)$, calves and heifers above 1 year $\left(L i_{c>1}\right)$, and the milk yield per dairy cow $(y=Y / L i)$. This leads to the following function for total manure production on the farm:

$$
M p=k\left(L i, L i_{c<1}, L i_{c>1}, y\right)
$$

Note that several connections between the different production relationships exist. Milk production $(Y)$ is a function of the number of dairy cows $(L i)$, but this variable also (partly) determines manure production $(M p)$. Own produced roughage $(R o)$ is an (intermediate) output at dairy farms, whereas at the same time it is part of total feed input $(F d)$, and therefore indirectly an input for milk production $(Y)$. Moreover, (part of) the produced manure $(M p)$ is applied $(M a)$ to land in roughage production. Finally, the intensity of milk production, which is an implicit outcome of the input-output mix chosen, and which is reflected in a certain milk yield per dairy cow $(y)$, is a determinant of manure production. By choosing a particular feed input mix/level farmers can affect the level of manure produced, as well as the excretion of nitrogen and phosphorus nutrients.

The total quantity of animal manure that farmers can apply to their owned and rented land is restricted by manure application norms (Man) for nitrogen and phosphate use 
(Remmelink et al., 2012: 71-74). According to these standards farmers can apply maximally $170 \mathrm{~kg}$ nitrogen to each ha of agricultural area. An exception is assigned to farms that have over $70 \%$ of grassland; they are temporarily allowed to apply more (i.e. $250 \mathrm{~kg}$ ) nitrogen per ha of agricultural area (derogation). Application standards for phosphate from animal manure differ between grassland and land used for crop production, accounting for differences in crop uptake of phosphate. At its introduction in 2006, the application norm for grassland was $95 \mathrm{~kg}$ phosphate per ha of agricultural area, and for land used for crop production it was $110 \mathrm{~kg}$ phosphate per ha of agricultural area. However there is a gradual reduction of the application norm for phosphate over time. Depending on the condition of the land, in 2015 the application norm for grassland is $90 \mathrm{~kg}$ phosphate per ha of agricultural area (neutral phosphate status), and for land used for crop production it is $60 \mathrm{~kg}$ phosphate per ha of agricultural area (neutral phosphate status). The aim of the manure application norms is to reach a so-called balanced fertilization in 2015; implying that the level of phosphate applied to agricultural land should not exceed the level of phosphate that the agricultural land can process (Krimpen et al., 2010).

Based on the most binding application norm $(N$ or $P)$ as discussed above, the quantity of animal manure that can be applied to owned and rented farm land can be defined. The animal manure surplus $(M s)$ is the difference between the quantity produced from animal manure $(M p)$ and the quantity that can be legally applied at the farm according to the manure application norms (Man) described above ${ }^{2}$ :

$$
M s(L i, y, L a)= \begin{cases}M p(L i, y)-M a n \cdot L a & \text { if } M p(L i, y)>\text { Man } \cdot L a \\ 0 & \text { if } M p(L i, y) \leq M a n \cdot L a\end{cases}
$$

where for simplicity $L i$ includes dairy cows, calves and heifers below 1 year $\left(L i_{c<1}\right)$ and calves and heifers above 1 year $\left(L i_{c>1}\right)$. Farms are obliged to dispose their animal manure surplus outside the farm at a unit costs $c$ as indicated in eq. (1). From this definition it also follows

2 In the Netherlands most dairy farms do not apply animal manure from outside the farm to their land. In this model we therefore assume that farms only apply own produced animal manure. 
that applied manure in eq. (4) equals produced manure for farms that are not manure constrained and it equals the manure application norm for farms that have a manure surplus.

The above model can be used to derive optimal allocation rules for the variable inputs concentrates $(C o)$ and bought roughage $(R b)$ without and with a manure surplus:

Co, no surplus: $\quad \frac{\partial \pi}{\partial C o}=p \cdot \frac{\partial Y}{\partial F d} \cdot \frac{\partial F d}{\partial C o}-w^{C o}=0$

Co, surplus: $\quad \frac{\partial \pi}{\partial C o}=p \cdot \frac{\partial Y}{\partial F d} \cdot \frac{\partial F d}{\partial C o}-w^{C o}-c \cdot \frac{\partial M p}{\partial Y} \cdot \frac{\partial Y}{\partial F d} \cdot \frac{\partial F d}{\partial C o}=0$

$R b$, no surplus: $\quad \frac{\partial \pi}{\partial R b}=p \cdot \frac{\partial Y}{\partial F d} \cdot \frac{\partial F d}{\partial R b}-w^{R b}=0$

$R b$, surplus: $\quad \frac{\partial \pi}{\partial R b}=p \cdot \frac{\partial Y}{\partial F d} \cdot \frac{\partial F d}{\partial R b}-w^{R b}-c \cdot \frac{\partial M p}{\partial Y} \cdot \frac{\partial Y}{\partial F d} \cdot \frac{\partial F d}{\partial R b}=0$

Note that the farmer not only optimizes with respect to $C o$ and $R b$, but implicitly at the same time also with respect to own roughage production $R o$ (see equation 3). This optimization has two aspects: (i) the farmer considers the own roughage-output trade-off (assuming an implicit price $w^{R o}$ of $R o$ this yields a similar optimum condition as those that are derived with respect to $R b$ and $C o$; see the optimum conditions (7) to (10)); (ii) the farmer optimizes with respect to all the inputs $R o, R b$ and $C o$ in such a way that $F d$ is produced in a least cost way. This requires that the technical rate of substitution between the $R o, R b$ and $C o$ inputs is equal to the input price ratio (Varian, 1992: 50). Alternatively, this implies that the shadow price $w^{R o}$ of $R o$ will be a function of the prices of bought roughage $R b$ and compound feed $C o$, or $w^{R o}=w^{R o}\left(w^{R b}, w^{C o}\right)$. In case the farm is having a manure surplus the shadow price $w^{R o}$ is a function of the price for manure disposal as well; $w^{R o}=w^{R o}\left(w^{R b}, \mathbf{w}^{C o}, c\right)$.

The first order conditions show that manure constrained farms have an additional marginal costs next to the input price of feed in the form of marginal manure disposal costs. Due to concavity of the production function in $F d$ manure constrained farms therefore have a lower 
optimal feed use level. Also expressions for the shadow prices of quasi-fixed inputs can be derived. Two interesting shadow prices are obtained for livestock $(L i)$ and $(L a)$, again both for farms without and with a manure surplus:

$L i$, no surplus: $\quad \frac{\partial \pi}{\partial L i}=p \cdot \frac{\partial Y}{\partial L i}+p \cdot \frac{\partial Y}{\partial F d} \cdot \frac{\partial F d}{\partial R o} \cdot \frac{\partial R o}{\partial M a} \cdot \frac{\partial M a}{\partial L i} \quad($ note $\partial M a=\partial M p)$

$L i$, surplus: $\quad \frac{\partial \pi}{\partial L i}=p \cdot \frac{\partial Y}{\partial L i}-c \cdot \frac{\partial M p}{\partial L i}$

La, no surplus: $\quad \frac{\partial \pi}{\partial L a}=p \cdot \frac{\partial Y}{\partial F d} \cdot \frac{\partial F d}{\partial R o} \cdot\left(\frac{\partial R o}{\partial L a}+\frac{\partial R o}{\partial M a} \cdot \frac{\partial M a}{\partial Y} \cdot \frac{\partial Y}{\partial F d} \cdot \frac{\partial F d}{\partial R o} \cdot \frac{\partial R o}{\partial L a}\right)$

La, surplus: $\quad \frac{\partial \pi}{\partial L a}=p \cdot \frac{\partial Y}{\partial F d} \cdot \frac{\partial F d}{\partial R o} \cdot \frac{\partial R o}{\partial L a}-c \cdot\left(\frac{\partial M p}{\partial y} \cdot \frac{\partial Y}{\partial F d} \cdot \frac{\partial F d}{\partial R o} \cdot \frac{\partial R o}{\partial L a}-M a n\right)$

For farms without a manure surplus, the shadow price of a dairy cow (equation 11) consists of the direct marginal value of livestock in milk production and the indirect value of livestock via manure and roughage production on milk production. Farms with a manure surplus cannot apply more manure on their land and therefore lack this second indirect effect (see equation 12). Instead, their shadow price of livestock is lower due to the additional marginal manure disposal costs. The shadow price of land for farms without a manure surplus (equation 13) represents as a first effect the (indirect) marginal value of land derived from the additional milk production via roughage production, and as a second effect the change in roughage production (and derived milk production) as a consequence of the additional manure that is produced, which in this case is all applied to the land. The shadow price for constrained farms (see equation 14) also has as a first term the value of the land as a result of the value of the additional milk that can be produced. The second component is the additional costs for surplus disposal because the additional milk will lead to additional manure excretion. The third component in equation 14 is the manure placement space generated by the additional unit of land (which equals the maximum manure application standard, i.e. the amount of manure that at maximum can be applied on an additional hectare), which is valued at its opportunity cost $c$. Looking at the combined effect of livestock and land, the above 
shows that due to the indirect effects of the input variables to manure and feed, the total marginal value of product is greater than the direct (partial) marginal value of the products in the situation without a surplus, and inferior to the direct (partial) marginal value of the products in the situation with a surplus.

\subsection{Data}

The data for estimating and calculating the production functions were obtained from the Dutch Farm Accountancy Network Data (FADN, LEI Wageningen UR) and the LMM-database (Landelijk Meetnet Mestbeleid, LEI Wageningen UR), which is used to monitor manure production in the Netherlands. The data include 1193 observations on 334 Dutch dairy farms, covers the period 2008 to 2012 and forms an unbalanced panel.

In the empirical analysis three groups of farms are discerned. Group 1 consists of farms that were neither constrained by milk quotas, nor were they having a manure surplus in the sample period. This is by far the smallest of the three groups with only 220 observations on 70 farms. Group 2 consists of 125 farms with 445 observations that were constrained by milk quota, but did not have a manure surplus in most of the years in the dataset. Finally, group 3 consists of 139 farms with 528 observations that were both milk quota and manure constrained in the sample period.

Table 4.1 provides an overview of the data used in this study. Data are presented for the total sample and by the three subgroups. We gathered data on the value of milk production (in euros) from FADN and divided this value by the quantity of milk production (in kilos) of farmers as reported in the FADN as well. This way we obtained the actual milk price farmers received on average for their production each year. This price differs per farm per year, as all farmers receive different prices based on quality differences (i.e. fat- and protein content). In order to get the same price for each farm per year, we took the means per year of these prices. 
Table 4.1 Descriptive statistics of the variables used in the empirical analysis.

\begin{tabular}{|c|c|c|c|c|c|}
\hline \multirow[b]{2}{*}{ Variables } & \multirow[b]{2}{*}{ Dimension } & \multicolumn{2}{|c|}{ Sample mean (st.dev.) } & \multirow[b]{2}{*}{ Group 2} & \multirow[b]{2}{*}{ Group 3} \\
\hline & & All farms & Group 1 & & \\
\hline \multicolumn{6}{|l|}{ Outputs } \\
\hline Milk production $(Y)$ & $\mathrm{kg} * 10^{5}$ & $\begin{array}{l}7.736 \\
(4.468)\end{array}$ & $\begin{array}{l}6.275 \\
(3.769)\end{array}$ & $\begin{array}{l}6.639 \\
(3.439)\end{array}$ & $\begin{array}{l}9.269 \\
(5.003)\end{array}$ \\
\hline Other output $(O t)$ & euros * $10^{4}$ & $\begin{array}{c}-1.781 \\
(1.431)\end{array}$ & $\begin{array}{c}-1.287 \\
(1.204)\end{array}$ & $\begin{array}{c}-1.605 \\
(1.313)\end{array}$ & $\begin{array}{l}-2.135 \\
(1.524)\end{array}$ \\
\hline \multicolumn{6}{|l|}{ Variable inputs } \\
\hline Feed $(F d)$ & energy level * $10^{5}$ & $\begin{array}{l}7.611 \\
(4.210)\end{array}$ & $\begin{array}{l}6.848 \\
(3.805)\end{array}$ & $\begin{array}{l}6.668 \\
(3.316)\end{array}$ & $\begin{array}{l}8.725 \\
(4.750)\end{array}$ \\
\hline Concentrates $(\mathrm{Co})$ & $\mathrm{kg} * 10^{5}$ & $\begin{array}{l}1.975 \\
(1.138)\end{array}$ & $\begin{array}{l}1.801 \\
(1.008)\end{array}$ & $\begin{array}{l}1.715 \\
(0.949)\end{array}$ & $\begin{array}{l}2.267 \\
(1.262)\end{array}$ \\
\hline Bought roughage $(R b)$ & $\mathrm{kg} * 10^{5}$ & $\begin{array}{l}2.209 \\
(2.510)\end{array}$ & $\begin{array}{l}2.106 \\
(2.638)\end{array}$ & $\begin{array}{l}1.269 \\
(1.533)\end{array}$ & $\begin{array}{l}3.044 \\
(2.815)\end{array}$ \\
\hline Produced roughage $(R o)$ & $\mathrm{kg} * 10^{6}$ & $\begin{array}{l}1.517 \\
(0.889)\end{array}$ & $\begin{array}{l}1.383 \\
(0.776)\end{array}$ & $\begin{array}{l}1.468 \\
(0.731)\end{array}$ & $\begin{array}{l}1.613 \\
(1.033)\end{array}$ \\
\hline Applied animal manure $(M a)$ & (effective) $\mathrm{kg} * 10^{3}$ & $\begin{array}{l}3.179 \\
(1.840)\end{array}$ & $\begin{array}{l}2.860 \\
(1.542)\end{array}$ & $\begin{array}{l}3.161 \\
(1.631)\end{array}$ & $\begin{array}{l}3.327 \\
(2.088)\end{array}$ \\
\hline Applied fertilizer $(F r)$ & $\mathrm{kg} * 10^{4}$ & $\begin{array}{l}2.595 \\
(1.771)\end{array}$ & $\begin{array}{l}2.339 \\
(1.666)\end{array}$ & $\begin{array}{l}2.566 \\
(1.521)\end{array}$ & $\begin{array}{l}2.724 \\
(1.987)\end{array}$ \\
\hline \multicolumn{6}{|l|}{ Quasi-fixed inputs } \\
\hline Labour $(L b)$ & hours $* 10^{3}$ & $\begin{array}{l}4.508 \\
(2.134)\end{array}$ & $\begin{array}{l}4.287 \\
(2.463)\end{array}$ & $\begin{array}{l}4.305 \\
(1.464)\end{array}$ & $\begin{array}{l}4.772 \\
(2.418)\end{array}$ \\
\hline Capital for milk prod. (Cy) & euros * $10^{5}$ & $\begin{array}{l}7.173 \\
(4.541)\end{array}$ & $\begin{array}{l}7.035 \\
(5.260)\end{array}$ & $\begin{array}{l}6.183 \\
(4.133)\end{array}$ & $\begin{array}{l}8.064 \\
(4.372)\end{array}$ \\
\hline Dairy Livestock $(L i)$ & number * $10^{1}$ & $\begin{array}{l}9.596 \\
(5.358)\end{array}$ & $\begin{array}{l}8.939 \\
(4.883)\end{array}$ & $\begin{array}{l}8.541 \\
(4.555)\end{array}$ & $\begin{array}{l}10.759 \\
(5.923)\end{array}$ \\
\hline Land $(L a)$ & ha $* 10^{2}$ & $\begin{array}{l}0.563 \\
(0.326)\end{array}$ & $\begin{array}{l}0.539 \\
(0.286)\end{array}$ & $\begin{array}{l}0.576 \\
(0.295)\end{array}$ & $\begin{array}{l}0.564 \\
(0.353)\end{array}$ \\
\hline \multicolumn{6}{|l|}{ Other variables } \\
\hline Rain $(R a)$ & $\mathrm{mm} * 10^{2}$ & $\begin{array}{l}9.195 \\
(0.520)\end{array}$ & $\begin{array}{l}9.163 \\
(0.536)\end{array}$ & $\begin{array}{l}9.174 \\
(0.520)\end{array}$ & $\begin{array}{l}9.225 \\
(0.511)\end{array}$ \\
\hline Temperature ( $T p)$ & ${ }^{\circ} \mathrm{C} * 10^{1}$ & $\begin{array}{l}1.030 \\
(0.061)\end{array}$ & $\begin{array}{l}1.033 \\
(0.058)\end{array}$ & $\begin{array}{l}1.030 \\
(0.062)\end{array}$ & $\begin{array}{l}1.029 \\
(0.062)\end{array}$ \\
\hline Manure production $(M p)$ & $\mathrm{m}^{3}$ manure $* 10^{3}$ & $\begin{array}{l}3.541 \\
(1.962)\end{array}$ & $\begin{array}{l}3.100 \\
(1.634)\end{array}$ & $\begin{array}{l}3.129 \\
(1.580)\end{array}$ & $\begin{array}{l}4.073 \\
(2.234)\end{array}$ \\
\hline $\begin{array}{l}\text { Milk yield per dairy cow } \\
(y(=Y / L i))\end{array}$ & $\mathrm{kg} * 10^{4}$ & $\begin{array}{l}0.807 \\
(0.130)\end{array}$ & $\begin{array}{l}0.717 \\
(0.170)\end{array}$ & $\begin{array}{l}0.783 \\
(0.115)\end{array}$ & $\begin{array}{l}0.865 \\
(0.089)\end{array}$ \\
\hline Manure Surplus (Ms) & $\mathrm{m}^{3}$ manure $* 10^{1}$ & $\begin{array}{l}8.643 \\
(100.835)\end{array}$ & $\begin{array}{r}-11.145 \\
(95.833)\end{array}$ & $\begin{array}{c}-50.573 \\
(83.002)\end{array}$ & $\begin{array}{l}66.796 \\
(82.853)\end{array}$ \\
\hline$n$ farms ( $N$ observations) & & $334(1193)$ & $70(220)$ & $125(445)$ & $139(528)$ \\
\hline
\end{tabular}

Source: own elaboration 
Next, we divided the value of milk production (in euros) obtained from FADN by this average milk price to calculate the quantity of milk produced (in kilos). Calculation of milk production in this way is recommendable since it turns differences in quality of milk as reflected in different milk prices, into quality differences as reflected in produced quantities.

In order to obtain the value of other output (in euros), we gathered data on the total value of livestock production (in euros) from FADN and divided this value by a corrected price for dairy cows (in euros, all prices relative to the price of base year 2008, obtained from LEI Wageningen UR, 2013).

Information on labour is taken directly from the FADN and measured as the time (in hours) worked on the farm by the farmer, (hired and fixed) employees and volunteers.

The new values on different types of capital are reported directly in the FADN. Capital used for milk production is measured as a compound new value (in euros) for installations and buildings.

The number of dairy cows is taken directly from the LMM-database and measured in average numbers per farm per year.

Feed is measured in 'kVEM' and derived directly from the LMM-database (kVEM is a ratio to represent the net-energy of foddertypes, feed is the sum of all fodder fed to livestock). The level of concentrates use (in kilos) is derived directly from the LMM-database. The level of bought roughage used for milk production (in kilos) is measured as the total value spent on roughage as reported in the FADN, divided by the price for roughage (maize price, in euros per kilo for each year) obtained from LEI Wageningen UR (2013). The total quantity of roughage (in kilos) fed every year to livestock is directly available in the LMM-database. By subtracting the quantity of bought roughage (in kilos) from this total quantity (in kilos) we obtain the total quantity of own produced roughage fed to livestock per year (in kilos).

For land we take the total agricultural land area (grassland and land for fodder production) as reported in the LMM (in ha).

Data on animal manure production were obtained from the LMM-database. We calculated the total on-farm animal manure production by summing the manure production in $\mathrm{m}^{3}$ of the dairy cows, calves and heifers on the farm. In order to calculate the animal manure that 
is really applied to the land, we first added the total on-farm animal manure production, the initial stock of animal manure and the inflow of animal manure from sources off-farm. Second, we subtracted the farm outflow of animal manure and the final stock of animal manure from this amount (all in $\mathrm{m}^{3}$ ).

The level of applied fertilizer (in kilos) is obtained from the LMM-database.

Information on rain is taken from the official statistics of the Netherlands (CBS, 2013) and is measured as the quantity of rain in average total millimetre per year.

Information on temperature is also taken from the official statistics of the Netherlands (CBS, 2013) and is measured in average degrees Celsius per year.

The animal manure surplus is derived by adding the total animal manure production, the initial stock of animal manure and the on-farm supply of animal manure. From this amount we subtracted the final stock of animal manure and the farm specific manure application norm (all in $\mathrm{m}^{3}$ ). The result is the animal manure surplus; when the result is positive, the farm is constrained by manure application norms. And when the results is negative, the farm is unconstrained by manure application norms.

\subsection{Empirical model and estimation}

Equations (2)-(4) for milk, feed, and roughage are estimated. During the sample period milk production is subject to a (binding) supply constraint, the milk quota. The specification of the production function for milk however, is not affected by the presence of a supply quota. In order to comply with neo-classical economic theory, equations (2)-(4) need to be continuous, non-negative, strictly increasing in inputs, and strictly quasi-concave in variable inputs.

Many empirical studies estimate production functions using a flexible quadratic functional form (e.g. Ooms and Peerlings, 2005). However, with many inputs this implies a large number of quadratic and interaction terms, potentially leading to multicollinearity. To avoid this problem, we include quadratic and interaction terms for the key inputs $L i$ and $F d$ but only 
single terms for fixed inputs on which the farmer does not optimize in the short-run. This leads to the following specification for milk production:

$$
Y_{h t}=\alpha_{1 h}+\beta_{1} O t_{h t}+\beta_{2} F d_{h t}+\beta_{3} L i_{h t}+\beta_{4} L b_{h t}+\beta_{5} C y_{h t}+\frac{1}{2} \beta_{11} F d_{h t}^{2}+\beta_{12} F d_{h t} L i_{h t}+\frac{1}{2} \beta_{22} L i_{h t}^{2}+\varepsilon_{1 h t}
$$

where $h$ expresses dairy farmers $(h=1, \ldots, \mathrm{H}$ and $\mathrm{H}$ is the total number of farms), $t$ expresses time $\left(t=1, \ldots, \mathrm{T}\right.$ and $\mathrm{T}$ is the total number of years), $\alpha_{1 h}$ are farm-specific effects capturing unobserved heterogeneity among dairy farms in milk production, e.g. management quality but also average quality differences in livestock and feed, and $\varepsilon_{1 h t}$ is a residual term varying over farms and time. Symmetry between feed and livestock is imposed via $\beta_{12}=\beta_{21}$.

The empirical specification for feed production is:

$$
\begin{aligned}
F d_{h t}=\alpha_{2 h}+\gamma_{1} C o_{h t}+\gamma_{2} R o_{h t}+\gamma_{3} R b_{h t}+\frac{1}{2} \gamma_{11} C o_{h t}^{2} & +\gamma_{12} C o_{h t} R o_{h t}+\gamma_{13} C o_{h t} R b_{h t} \\
& +\frac{1}{2} \gamma_{22} R o_{h t}^{2}+\gamma_{23} R o_{h t} R b_{h t}+\frac{1}{2} \gamma_{33} R b_{h t}^{2}+\varepsilon_{2 h t}
\end{aligned}
$$

where symmetry between all variables is imposed via $\gamma_{i j}=\gamma_{j i}$.

The production function for own roughage is specified as:

$$
R o_{h t}=\alpha_{3 h}+\varphi_{1} L a_{h t}+\varphi_{2} M a_{h t}+\varphi_{3} F r_{h t}+\varphi_{4} R a_{t}+\varphi_{5} T p_{t}+\frac{1}{2} \varphi_{11} M a_{h t}^{2}+\varepsilon_{3 h t}
$$

The production function for manure (equation 5) is based on an agronomic accounting system applying the standards as they are defined in the Dutch manure legislation (Dutch Ministry of Economic Affairs, 2010; Remmelink et al., 2012: 2-44). By using these accountancy rules the model is able to reproduce results that comply to reality which increases the representativeness of the results. The total level of manure production is the sum of the manure produced by dairy cows $(L i)$, calves and heifers below 1 year $\left(L i_{c<1}\right)$ and calves and heifers above 1 year $\left(L i_{c>1}\right)$. This function is defined as:

$$
M p_{h t}=\left(13.44+0.0019 y_{h t}\right) L i_{h t}+6.5 L i_{c<1}+14.9 L i_{c>1}
$$


In estimating equations (15)-(17) there are a number of econometric issues to be dealt with.

First, a standard residual term $\varepsilon_{j h t}$ is added to these equations to capture unobservables that vary over time and farms. Even though we include farm-specific effects $\alpha_{j h}$ in our equations, there could still be heteroscedasticity or autocorrelation in the data. Therefore, cluster-robust standard errors (Verbeek, 2012: 390) are used, where clusters are defined by farms.

Second, all three equations include farm-specific fixed effects (FE) $\alpha_{j h}$. The equations are therefore estimated using a Fixed Effects estimation approach based on a within transformation of the data.

Third, some of the explanatory variables could be endogenous. This is a problem generally considered in estimating production functions since producing a certain quantity of output may require a certain amount of inputs. E.g. in order for a dairy cow to produce a certain quantity of milk (output), this dairy cow is to be fed a certain amount of feed (input). Moreover, a farmer may choose a certain quantity of inputs given its unobserved characteristics, captured by $\varepsilon_{j h t}$ (Ackerberg et al., 2006). This already indicates that this problem is most likely for variable inputs and quasi-fixed inputs that are easily adjustable such as feed, but not for inputs such as capital or labour. Moreover, variables that are determined within our system of production functions are expected to be endogenous (milk, feed and feed components, manure). Ooms and Peerlings (2005) tested for endogenous inputs in production functions for Dutch dairy farms and found that exogeneity was accepted for labour, cattle and other output, but rejected for aggregate non-factor input. Based on their results we initially assume that feed is endogenous in the milk production function (15), concentrated feed, own produced roughage, and bought roughage are assumed endogenous in the feed production function (16), and manure and fertilizer are endogenous in the roughage production function (17). Therefore, these equations are estimated using Fixed Effects Instrumental Variable Generalized Method of Moments (FE-IV-GMM) using the following general set of moment conditions: 
$E\left[z_{j h t}\left(\varepsilon_{j h t}-\bar{\varepsilon}_{j h}\right)\right]=0$

where for each equation $j((15)-(17)) z_{\text {jht }}$ is a vector of instruments including all exogenous variables in equation $j$ (depending on the equation these are for example land, labour, capital, or weather variables like rainfall and temperature) supplemented by additional instrumental variables, which are either the exogenous variables from other equations (thus either land, labour, capital and/or weather variables) or additional variables such as market prices for milk or feed. The term $\left(\varepsilon_{j h t}-\bar{\varepsilon}_{j h}\right)$ are the within transformed residuals where $\bar{\varepsilon}_{j h}$ are the farmspecific average residuals. In the results section we provide more details which instrumental variables are used in estimating the equations.

Overidentifying restrictions tests are applied to assess the overall validity of the model and the instruments chosen. Rejection of the null hypothesis in the overidentifying restrictions test would indicate that either the model is incorrectly specified or that one or more of the instrumental variables is invalid. Without additional information it is difficult to tell what the exact problem is. However, note that non-rejection of the null hypothesis does not guarantee model and instrument validity, since there could exist parameter values such that these conditions hold even with invalid instruments. (Verbeek, 2012: 169). Hausman tests are applied to test whether the standard FE are consistent or whether we should use the panel IV-GMM estimates. Estimation is performed using xtivreg2 in Stata 13 (Schaffer, 2010).

Fourth, the equations are estimated for the sample as a whole and for the three groups defined in section 4.3. Chow tests are applied to test whether parameters are significantly different among these groups (Verbeek, 2012: 72). 


\subsection{Results and discussion}

\subsubsection{Milk production function}

The parameter estimates for the milk production function (equation 15) are given in table 4.2 for the complete sample and the three subgroups.

The second column of results are the FE-IV-GMM estimates where $F d, F d^{2}$ and $F d L i$ are assumed to be endogenous and $L b^{2}, L b C y, L a, L a^{2}, L b L a, R a, T p, R a^{2}$ and $T p^{2}$ are used as instruments. Tests for weak instruments indicate that these are strong instruments for the three assumed endogenous variables. Moreover, the overidentifying restrictions test has a test-statistic of 3.59 , which is smaller than the $\chi^{2}(6)$ critical value of 12.59 , indicating that we cannot reject the null hypothesis that the overidentifying restrictions are zero (given the parameters at hand). This provides some confidence in the validity of the model and the instruments. However, with a Hausman test (p-value 0.654) we could not reject the null hypothesis that standard FE estimates are consistent, indicating there is no need to rely on the less efficient FE-IV-GMM estimates ${ }^{3}$. Therefore, we proceed using the standard FE estimates as given in the first column of results for the whole sample and in columns 3-5 for the subgroups. The coefficients for the whole sample all have the correct signs. For the three subgroups this is also often the case, at least for all coefficients that are significantly different from zero. A Chow test firmly rejects the null hypothesis of equal parameters across groups with the test-statistic of 53.53 much larger than the critical $F_{9,1184}$ value of 1.88. For the three subgroups there are some interesting differences. Labour only has a significant parameter for the group of farms that were quota and manure constrained. Table 4.1 in section 4.3 already showed that these are intensive dairy farms with large output, a large dairy herd, much capital and relatively more dependent on bought roughage and concentrates. Apparently labour is also important in the production process of these farms. All three groups have a significant linear

\footnotetext{
3 We also tested a model where other output is assumed endogenous, but in a Hausman tests we could not reject the null hypothesis that the FE-GMM estimates are consistent, confirming the results by Ooms and Peerlings (2005) who also concluded that other output is not endogenous.
} 
Table 4.2 Estimation results for milk production ${ }^{a}$

\begin{tabular}{|c|c|c|c|c|c|}
\hline Milk production & $\begin{array}{l}\text { FE-GMM } \\
\text { All farms }\end{array}$ & $\begin{array}{l}\text { FE-IV-GMM } \\
\text { All farms }\end{array}$ & $\begin{array}{l}\text { FE-GMM } \\
\text { Group } 1\end{array}$ & $\begin{array}{l}\text { FE-GMM } \\
\text { Group } 2\end{array}$ & $\begin{array}{l}\text { FE-GMM } \\
\text { Group } 3\end{array}$ \\
\hline Other output $(\mathrm{Ot})$ & $\begin{array}{l}0.004 \\
(0.018)\end{array}$ & $\begin{array}{l}0.008 \\
(0.031)\end{array}$ & $\begin{array}{l}-0.029 \\
(0.061)\end{array}$ & $\begin{array}{c}-0.032 \\
(0.034)\end{array}$ & $\begin{array}{l}0.046 \\
(0.031)\end{array}$ \\
\hline Labour $(L b)$ & $\begin{array}{l}0.071^{* * * *} \\
(0.033)\end{array}$ & $\begin{array}{l}0.106^{\text {twik }} \\
(0.042)\end{array}$ & $\begin{array}{l}-0.023 \\
(0.085)\end{array}$ & $\begin{array}{l}-0.017 \\
(0.067)\end{array}$ & 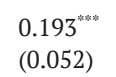 \\
\hline Capital for milk prod. (Cy) & $\begin{array}{l}0.006 \\
(0.011)\end{array}$ & $\begin{array}{l}-0.007 \\
(0.019)\end{array}$ & $\begin{array}{l}0.035 \\
(0.044)\end{array}$ & $\begin{array}{l}0.015 \\
(0.018)\end{array}$ & $\begin{array}{l}0.002 \\
(0.030)\end{array}$ \\
\hline Dairy cows $(L i)$ & $\begin{array}{l}0.483^{\text {***k+k}} \\
(0.087)\end{array}$ & $\begin{array}{l}0.583^{k * * *} \\
(0.258)\end{array}$ & $\begin{array}{l}0.485 \\
(0.467)\end{array}$ & $\begin{array}{l}0.472^{\text {thesk }} \\
(0.153)\end{array}$ & 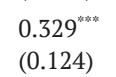 \\
\hline Feed $(F d)$ & $\begin{array}{l}0.655^{* * * *} \\
(0.121)\end{array}$ & $\begin{array}{l}0.611 \\
(0.438)\end{array}$ & $\begin{array}{l}1.043^{m . * k} \\
(0.471)\end{array}$ & $\begin{array}{l}0.801^{\text {**:****x}} \\
(0.189)\end{array}$ & 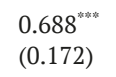 \\
\hline$L i * L i$ & $\begin{array}{c}-0.044^{\text {****k }} \\
(0.012)\end{array}$ & $\begin{array}{l}0.287^{*} \\
(0.155)\end{array}$ & $\begin{array}{l}-0.116^{\text {k**** }} \\
(0.050)\end{array}$ & $\begin{array}{c}-0.077^{\text {**:*2 }} \\
(0.023)\end{array}$ & $\begin{array}{l}0.013 \\
(0.024)\end{array}$ \\
\hline$F d^{*} F d$ & $\begin{array}{c}-0.061^{\text {w.*kx }} \\
(0.020)\end{array}$ & $\begin{array}{l}0.480^{\text {kink }} \\
(0.235)\end{array}$ & $\begin{array}{l}-0.209^{*} \\
(0.108)\end{array}$ & $\begin{array}{c}-0.120^{\text {**⿻三丨 }} \\
(0.044)\end{array}$ & $\begin{array}{l}0.014 \\
(0.039)\end{array}$ \\
\hline$L i^{*} F d$ & $\begin{array}{l}0.094^{* * * * x} \\
(0.031)\end{array}$ & $\begin{array}{l}-0.757^{* * * k} \\
(0.384)\end{array}$ & $\begin{array}{l}0.271^{*} \\
(0.144)\end{array}$ & $\begin{array}{l}0.176^{* * *} \\
(0.067)\end{array}$ & $\begin{array}{c}-0.031 \\
(0.062)\end{array}$ \\
\hline Intercept $^{b}$ & $\begin{array}{c}-1.196^{* * 3 / x} \\
(0.305)\end{array}$ & & $\begin{array}{l}-2.007 \\
(1.899)\end{array}$ & $\begin{array}{l}-1.584^{* * *} \\
(0.754)\end{array}$ & $\begin{array}{r}-0.728 \\
(0.444)\end{array}$ \\
\hline Within $R^{2, \mathrm{c}}$ & 0.77 & - & 0.41 & 0.80 & 0.91 \\
\hline$F$-test slope parameters & $95.23^{m * * * x}$ & $108.12^{* * * * x}$ & $12.36^{\sin x *}$ & $170.18^{* m+\infty x}$ & $815.14^{* \omega m x}$ \\
\hline Overidentifying restrict. test & & 3.59 & & & \\
\hline$n(N)$ & $334(1193)$ & $303(1162)$ & $70(220)$ & $125(445)$ & $139(528)$ \\
\hline
\end{tabular}

a Standard errors between parentheses. Significance level: ${ }^{\text {sant }} 0.01 ;$;" $0.05 ; " 0.10$

${ }^{\mathrm{b}}$ Intercept in standard FE is the average of all farm-specific effects, FE-IV-GMM does not include this

${ }^{\mathrm{c}}$ For FE-IV-GMM the $\mathrm{R}^{2}$ is not reported since it has no interpretation due to correlation between covariates and residuals (Verbeek, 2012: 158)

Source: own elaboration

term for feed, and groups 1 and 2 also have a significant negative quadratic term, indicating a positive but decreasing marginal return for feed. However, for group 3 the quadratic term is positive, though not significantly different from zero. A similar observation can be made for livestock.

Based on the estimated production functions elasticities were calculated for each observation and averaged for each farm using the parameter estimates for the sample as a whole and for the estimates based on subgroups. These are presented in table 4.3. 
Table 4.3 Average elasticities of milk production ${ }^{a}$

\begin{tabular}{lllll}
\hline & All farms & Group 1 & Group 2 & Group 3 \\
\hline Other output $(\mathrm{Ot})$ & -0.001 & 0.008 & 0.011 & -0.011 \\
& $(0.001)$ & $(0.008)$ & $(0.028)$ & $(0.004)$ \\
Labour $(\mathrm{Lb})$ & 0.050 & -0.024 & -0.020 & 0.109 \\
& $(0.028)$ & $(0.035)$ & $(0.071)$ & $(0.043)$ \\
Capital for milk production $(\mathrm{Cy})$ & 0.006 & 0.050 & 0.020 & 0.001 \\
& $(0.003)$ & $(0.068)$ & $(0.064)$ & $(0.001)$ \\
Dairy cows $(\mathrm{Li})$ & 0.432 & 0.472 & 0.554 & 0.405 \\
& $(0.201)$ & $(0.637)$ & $(1.955)$ & $(0.048)$ \\
Feed $(\mathrm{Fd})$ & 0.638 & 0.788 & 1.007 & 0.566 \\
Scale parameter & $(0.132)$ & $(1.009)$ & $(2.542)$ & $(0.070)$ \\
& 1.125 & 1.293 & 1.572 & 1.071 \\
\hline
\end{tabular}

a Standard deviation in parentheses

Source: own elaboration

On average most of the signs of the input elasticities are positive, as one would expect based on economic theory, with labour being an exception for groups 1 and 2 . The average values also show that livestock and feed have the biggest impact on milk production. The (average) production elasticities for milk production are comparable to values found in earlier research on the Dutch dairy sector (Ooms and Peerlings, 2005; Thijssen, 1992: 26). Boots et al. (1997) however, found higher elasticities for capital ( 0.31 for buildings and 0.43 for machinery). This difference in elasticities could be due to the aggregation of data for measuring capital in our model. Also our model is based on more recent data. The average scale parameter derived from the elasticities for milk production is 1.13 for the whole sample. This indicates increasing returns to scale. This average value is somewhat larger than value of 1.04 found by Ooms and Peerlings (2005). Note that the averages are somewhat larger for groups 1 and 2, but lower for group 3. However, the standard deviation for groups 1 and 2 is also substantial, indicating large heterogeneity in returns to scale within these groups. 


\subsubsection{Feed production function}

Estimation results for the feed production function (equation 16) are presented in table 4.4. The feed equation reflects how total energy from feed is derived from concentrates, own roughage and produced roughage.

Table 4.4 Estimation results for the feed equation ${ }^{a}$

\begin{tabular}{|c|c|c|c|c|c|}
\hline Feed production & $\begin{array}{l}\text { FE-GMM } \\
\text { All farms }\end{array}$ & $\begin{array}{l}\text { FE-IV-GMM } \\
\text { All farms }\end{array}$ & $\begin{array}{l}\text { FE-IV-GMM } \\
\text { Group } 1\end{array}$ & $\begin{array}{l}\text { FE-IV-GMM } \\
\text { Group } 2\end{array}$ & $\begin{array}{l}\text { FE-IV-GMM } \\
\text { Group } 3\end{array}$ \\
\hline Concentrates $(\mathrm{Co})$ & $\begin{array}{l}0.683^{\text {w*3*x }} \\
(0.256)\end{array}$ & $\begin{array}{l}0.967^{\text {w*k }} \\
(0.492)\end{array}$ & $\begin{array}{l}-0.950 \\
(1.001)\end{array}$ & $\begin{array}{c}-0.612 \\
(0.967)\end{array}$ & $\begin{array}{l}0.322 \\
(0.687)\end{array}$ \\
\hline Own roughage $(R o)$ & $\begin{array}{l}2.285^{\text {*.*k/k}} \\
(0.290)\end{array}$ & $\begin{array}{l}3.798^{\text {k*knk}} \\
(0.397)\end{array}$ & $\begin{array}{l}2.690 \\
(2.345)\end{array}$ & $\begin{array}{l}3.702^{\text {*w*kx }} \\
(1.325)\end{array}$ & $\begin{array}{l}4.773^{* * * * *} \\
(0.459)\end{array}$ \\
\hline Bought roughage $(R b)$ & $\begin{array}{l}0.264^{* * * *} \\
(0.049)\end{array}$ & $\begin{array}{l}0.332^{\text {kwkw }} \\
(0.087)\end{array}$ & $\begin{array}{l}0.202 \\
(0.277)\end{array}$ & $\begin{array}{l}0.278 \\
(0.192)\end{array}$ & $\begin{array}{l}0.567^{* * * * *} \\
(0.058)\end{array}$ \\
\hline $\mathrm{Co}^{*} \mathrm{Co}$ & $\begin{array}{l}-0.013 \\
(0.090)\end{array}$ & $\begin{array}{l}-0.190^{*} \\
(0.100)\end{array}$ & $\begin{array}{l}1.190^{\text {kstakn }} \\
(2.613)\end{array}$ & $\begin{array}{c}-0.567^{\text {w*k }} \\
(0.159)\end{array}$ & $\begin{array}{l}-0.046 \\
(0.055)\end{array}$ \\
\hline$R o^{*} R o$ & $\begin{array}{l}-0.059 \\
(0.119)\end{array}$ & $\begin{array}{c}-0.336^{\text {k.w.k }} \\
(0.111)\end{array}$ & 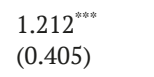 & $\begin{array}{c}-1.380^{\text {****k }} \\
(0.515)\end{array}$ & $\begin{array}{c}-0.265^{\text {क*** }} \\
(0.102)\end{array}$ \\
\hline$R b^{*} R b$ & $\begin{array}{l}-0.004 \\
(0.004)\end{array}$ & $\begin{array}{l}-0.003 \\
(0.016)\end{array}$ & $\begin{array}{l}0.029^{* \prime} \\
(0.015)\end{array}$ & $\begin{array}{l}0.028 \\
(0.033)\end{array}$ & $\begin{array}{l}-0.017 \\
(0.014)\end{array}$ \\
\hline$C o^{*} R o$ & $\begin{array}{l}0.024 \\
(0.234)\end{array}$ & $\begin{array}{l}0.341 \\
(0.253)\end{array}$ & 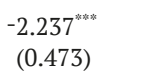 & $\begin{array}{l}2.159^{\text {*k*kx}} \\
(0.597)\end{array}$ & $\begin{array}{l}0.133 \\
(0.199)\end{array}$ \\
\hline$C o^{*} R b$ & $\begin{array}{l}0.046^{* \prime} \\
(0.027)\end{array}$ & $\begin{array}{l}0.071 \\
(0.078)\end{array}$ & $\begin{array}{l}-0.210^{\text {kikn }} \\
(0.095)\end{array}$ & $\begin{array}{l}0.232^{*} \\
(0.131)\end{array}$ & $\begin{array}{l}0.096 \\
(0.064)\end{array}$ \\
\hline$R o^{*} R b$ & $\begin{array}{c}-0.069^{\text {w*k }} \\
(0.033)\end{array}$ & $\begin{array}{c}-0.091 \\
(0.063)\end{array}$ & $\begin{array}{l}0.194 \\
(0.134)\end{array}$ & $\begin{array}{l}-0.389^{*} \\
(0.225)\end{array}$ & $\begin{array}{c}-0.200^{* * 3 \times 2} \\
(0.036)\end{array}$ \\
\hline Intercept ${ }^{b}$ & $\begin{array}{l}2.405^{\text {***kx}} \\
(0.621)\end{array}$ & & & & \\
\hline Within $R^{2, \text { c }}$ & 0.72 & - & - & - & - \\
\hline$F$-test slope parameters & $82.12^{* * * * x}$ & $44.44^{* w * x}$ & $139.95^{m * * a}$ & $172.47^{* \ldots+m}$ & $87.42^{m, k n k}$ \\
\hline Overidentifying restrict. test & & 11.24 & 11.47 & 12.35 & 8.80 \\
\hline$n(N)$ & $334(1193)$ & $303(1162)$ & $62(212)$ & $114(434)$ & $127(516)$ \\
\hline
\end{tabular}

${ }^{a}$ Standard errors between parentheses. Significance level: ${ }^{* * * k} 0.01 ;{ }^{* * n} 0.05 ; " 0.10$

${ }^{\mathrm{b}}$ Intercept in standard FE is the average of all farm-specific effects, FE-IV-GMM does not include this

${ }^{\mathrm{c}}$ For FE-IV-GMM the $R^{2}$ is not reported since it has no interpretation due to correlation between covariates and residuals (Verbeek, 2012: 158)

Source: own elaboration 
Since concentrates, own roughage and bought roughage are all variables inputs that the farmer decides upon in the short-run, we assumed that these variables and their cross-products are endogenous. Therefore, we estimated this equation using FE-IV-GMM using $L b, C y, L a, R a$, $T p$, and their cross-products as instrumental variables (19 instruments in total). The need for estimating this equation using FE-IV-GMM was confirmed by a Hausman test in which the null hypothesis that the more efficient FE-GMM estimates (given in the first column) are consistent was rejected (test-statistic of 125.26 is larger than the critical $\chi^{2}(9)$ value 16.92). The FE-IV-GMM parameter estimates have the correct signs for the whole sample (column 2). Total energy is increasing in all three food components (concentrates, own roughage and bought roughage) at a decreasing rate. For the sample as a whole, all three parameters for the single terms are significantly different from zero, as well as the quadratic terms for concentrates and own roughage. The other parameters for cross-products are not significantly different from zero, suggesting there is no complementarity or substitution between the three feed components for the sample as a whole. Looking at the subgroups (columns 3-5) the results are different though, suggesting substitutability between own and bought roughage for groups 2 and 3 as expected. Farms in group 2 also show complementarity between concentrates and roughage, both own and bought. Note that the results for group 1, which has the smallest number of observations, are not in line with microeconomic theory. All three quadratic terms are positive and statistically significant, suggesting increasing marginal products for all three feed types. This suggests that farmers are not using these feed types optimally, since they could gain from increasing feed use.

For the sample as a whole and for the three subgroups the overidentifying restrictions test has test-statistics (values given in table 4.4$)$ that are smaller than the $\chi^{2}(10)$ critical value of 18.31, indicating that we cannot reject the null hypothesis that the overidentifying restrictions are zero for all four models. This provides some confidence in the validity of the model and the instruments used. 
Based on the different sets of parameter estimates for the full sample and the subgroups, we calculated individual farm elasticities for the three feed types in total energy. Averages and standard deviations of these individual farm elasticities are presented in table 4.5.

Table 4.5 Average elasticities of feed production ${ }^{a}$

\begin{tabular}{lllll}
\hline & All farms & Group 1 & Group 2 & Group 3 \\
\hline Concentrates $(\mathrm{Co})$ & 0.225 & 0.010 & 0.199 & 0.161 \\
& $(0.054)$ & $(0.307)$ & $(0.329)$ & $(0.055)$ \\
Own roughage $(R o)$ & 0.658 & 0.540 & 0.616 & 0.671 \\
& $(0.136)$ & $(0.288)$ & $(0.247)$ & $(0.166)$ \\
Bought roughage $(\mathrm{Rb})$ & 0.097 & 0.082 & 0.059 & 0.129 \\
& $(0.074)$ & $(0.083)$ & $(0.094)$ & $(0.087)$ \\
\hline
\end{tabular}

a Standard deviation in parentheses

Source: own elaboration

Total feed is most responsive to changes in own roughage, and least in bought roughage. Interestingly, there are no large differences in average elasticities for own and bought roughage between the groups, although farms in group 3 (quota and manure constrained) are on average most responsive to changes in bought roughage. Total energy is on average not very responsive to concentrates in group 1 , whereas the average for this elasticity is highest for group 2. Interestingly though, the spread in individual elasticities is also large for group 2, whereas it is rather small for group 3.

\subsubsection{Roughage production function}

The final function that was estimated is the roughage production function (equation 17; see table 4.6). 
Table 4.6 Estimation results for roughage production ${ }^{a}$

\begin{tabular}{|c|c|c|c|c|c|}
\hline Roughage production & $\begin{array}{l}\text { FE-GMM } \\
\text { All farms }\end{array}$ & $\begin{array}{l}\text { FE-IV-GMM } \\
\text { All farms }\end{array}$ & $\begin{array}{l}\text { FE-GMM } \\
\text { Group } 1\end{array}$ & $\begin{array}{l}\text { FE-GMM } \\
\text { Group } 2\end{array}$ & $\begin{array}{l}\text { FE-GMM } \\
\text { Group } 3\end{array}$ \\
\hline Land $(L a)$ & 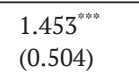 & $\begin{array}{c}-0.529 \\
(1.753)\end{array}$ & $\begin{array}{l}0.695 \\
(0.475)\end{array}$ & $\begin{array}{l}1.201^{\text {w*th }} \\
(0.501)\end{array}$ & $\begin{array}{l}2.198^{\text {****x }} \\
(0.639)\end{array}$ \\
\hline Applied animal manure $(M a)$ & $\begin{array}{l}0.225^{\text {w.k }} \\
(0.095)\end{array}$ & $\begin{array}{l}1.298^{*} \\
(0.680)\end{array}$ & $\begin{array}{l}0.201 \\
(0.133)\end{array}$ & $\begin{array}{l}0.288^{* * *} \\
(0.126)\end{array}$ & $\begin{array}{l}0.068 \\
(0.141)\end{array}$ \\
\hline Applied fertilizer $(F r)$ & $\begin{array}{l}0.044^{* * n} \\
(0.017)\end{array}$ & $\begin{array}{l}0.138 \\
(0.189)\end{array}$ & $\begin{array}{l}0.062^{* * *} \\
(0.024)\end{array}$ & $\begin{array}{l}0.017 \\
(0.023)\end{array}$ & $\begin{array}{l}0.057^{*} \\
(0.033)\end{array}$ \\
\hline Rain $(R a)$ & 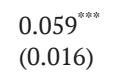 & $\begin{array}{l}0.076^{* * *} \\
(0.032)\end{array}$ & $\begin{array}{l}0.075^{*} \\
(0.041)\end{array}$ & $\begin{array}{l}0.027 \\
(0.023)\end{array}$ & $\begin{array}{l}0.072^{\text {***** }} \\
(0.024)\end{array}$ \\
\hline Temperature $(T p)$ & $\begin{array}{c}-0.638^{\text {***\%x }} \\
(0.113)\end{array}$ & $\begin{array}{c}-0.750^{\text {****x }} \\
(0.158)\end{array}$ & $\begin{array}{c}-0.777^{*} \\
(0.405)\end{array}$ & $\begin{array}{c}-0.562^{\text {;**.*x }} \\
(0.161)\end{array}$ & $\begin{array}{c}-0.646^{* * * * x} \\
(0.168)\end{array}$ \\
\hline$M a^{*} M a$ & $\begin{array}{c}-0.029^{\text {3**\% }} \\
(0.009)\end{array}$ & $\begin{array}{c}-0.097^{* * *} \\
(0.040)\end{array}$ & $\begin{array}{c}-0.018 \\
(0.026)\end{array}$ & $\begin{array}{c}-0.030^{*} \\
(0.017)\end{array}$ & $\begin{array}{c}-0.027^{* * *} \\
(0.011)\end{array}$ \\
\hline Intercept $^{b}$ & $\begin{array}{l}0.367 \\
(0.258)\end{array}$ & & $\begin{array}{l}0.596 \\
(0.514)\end{array}$ & $\begin{array}{l}0.534^{*} \\
(0.311)\end{array}$ & $\begin{array}{l}0.398 \\
(0.419)\end{array}$ \\
\hline Within $\mathrm{R}^{2, \mathrm{c}}$ & 0.19 & - & 0.14 & 0.12 & 0.27 \\
\hline$F$-test all parameters & $14.26^{* \omega * \pi}$ & $5.79^{* * * * *}$ & $12.07^{* * * *}$ & $4.91^{\text {s*in }}$ & $13.33^{\text {*k*ke }}$ \\
\hline$n(N)$ & $334(1193)$ & $302(1153)$ & $70(220)$ & $125(445)$ & $139(528)$ \\
\hline
\end{tabular}

a Standard errors between parentheses. Significance level: ${ }^{* * * * t} 0.01 ;{ }^{* * * *} 0.05 ; " 0.10$

${ }^{\mathrm{b}}$ Intercept in standard FE is the average of all farm-specific effects. FE-IV-GMM does not include this

${ }^{\mathrm{c}}$ For FE-IV-GMM the $R^{2}$ is not reported since it has no interpretation due to correlation between covariates and residuals (Verbeek, 2012: 158)

Source: own elaboration

Assuming $M a, M a^{2}$ and $F r$ to be endogenous and using $L b, C y, L b^{2}, C y^{2}$ and $L b C y$ as instrumental variables, the FE-IV-GMM model was estimated. Tests for weak instruments confirmed the strength of these instruments and the test statistic of the overidentifying restrictions test, 1.44 is smaller than the $\chi^{2}(3)$ critical value of 7.81 , indicating that we cannot reject the null hypothesis that the overidentifying restrictions are zero. The Hausman test does not reject the null hypothesis that the standard FE-GMM estimates are consistent (p-value 0.111), suggesting that manure, manure squared and fertilizer are not endogenous and we can proceed using the standard FE-GMM estimates as given in the first column of results in table 4.6. For the overall sample, all slope parameters are significantly different from zero and with the theoretically correct signs. Estimation results show that the level of rain and temperature significantly influence the production level of roughage. Both are necessary in the production 
process. The results show that the more rain and the lower the temperature, the higher the production of roughage is. Rain and temperature may relate non-linearly to roughage production, but for simplicity we only included linear terms of these variables in the model. For the three subgroups the parameter estimates have the same signs, although coefficient size and statistical significance differs among groups. A Chow test rejects the null hypothesis of equal parameters among the three groups, with the $F$-test statistics of 3.75 exceeding the critical $F_{7,1172}$-value of 2.01, confirming differences in roughage production structures among the three subgroups.

Also for roughage production farm-specific elasticities were calculated and these are presented in table 4.7 .

Table 4.7 Average elasticities of roughage production ${ }^{a}$

\begin{tabular}{lllll}
\hline & All farms & Group 1 & Group 2 & Group 3 \\
\hline Land $(L a)$ & 0.517 & 0.251 & 0.452 & 0.729 \\
& $(0.233)$ & $(0.065)$ & $(0.103)$ & $(0.337)$ \\
Applied animal manure $(\mathrm{Ma})$ & -0.001 & 0.164 & 0.147 & -0.303 \\
& $(0.730)$ & $(0.101)$ & $(0.278)$ & $(0.777)$ \\
Applied fertilizer $(\mathrm{Fr})$ & 0.072 & 0.096 & 0.029 & 0.091 \\
& $(0.044)$ & $(0.044)$ & $(0.011)$ & $(0.052)$ \\
Rain $(\mathrm{Ra})$ & 0.403 & 0.547 & 0.184 & 0.447 \\
& $(0.144)$ & $(0.157)$ & $(0.070)$ & $(0.133)$ \\
Temperature $(\mathrm{Tp})$ & -0.487 & -0.649 & -0.439 & -0.450 \\
& $(0.175)$ & $(0.186)$ & $(0.167)$ & $(0.135)$ \\
\hline
\end{tabular}

a Standard deviation in parentheses

Source: own elaboration

Not surprisingly roughage production is mostly responsive to land, although varying widely among groups, and weather conditions. Changes in applied manure and fertilizer have much less pronounced effects on roughage production. The average negative elasticity for applied manure for group 3 could be due to the fact that these farms are manure constrained. They simply cannot apply more manure to their land, leading to little variation in applied manure within farms over time, which is reflected in the statistically insignificant linear parameter for 
manure for group 3. In other words, the manure elasticities for group 3 are poorly estimated. This is also reflected in the large standard deviation for this group.

\subsubsection{Effects of dairy livestock expansion}

After the milk quota are abolished, it is expected that the overall Dutch milk production will increase (Jongeneel and Van Berkum, 2015). From the data it can be seen that farms were already anticipating on this increase by investing in extra stable capacity a few years in advance of 2015. After quota abolishment these farms are likely to further increase milk production by increasing the number of livestock. When more milk is produced, also more animal manure will be produced. More milk production will result in higher income from production. In the following the (marginal) trade-offs farmers will face are further explored using the estimation results and assumptions on milk, roughage, and feed prices and manure disposal costs ${ }^{4}$.

As regards the effect on the manure-side, different scenarios exist. In this chapter we divided the farms in three groups. Since the first group was not restricted by their milk quota, their situation will not change, price effects apart, when milk quota are abolished. Therefore, in the following we focus on the second and third group. Farms that are not constrained by manure application norms are able to increase in milk production (and manure production) without facing manure surplus disposal costs directly. But farms that are constrained by manure application norms and possibly producing a surplus of manure have to pay manure surplus disposal costs. The effects on the cost-side are different for this group of farms.

\footnotetext{
4 Ideally assessing the implications from quota abandonment and manure regulation should be analysed using a micro-simulation exercise (see De Frahan et al., 2011 for an example) but such an exercise was beyond the scope of this chapter.
} 
Table 4.8 shows the effects of increasing the livestock herd by one dairy cow on the revenues and costs for dairy farms evaluated at 2012 data $^{56}$ (which is the most recent year of the available panel data). Assuming profit maximizing behaviour, farmers will only expand if this contributes to their profits. It is shown that the additional revenue from milk production

Table 4.8 Average marginal effects on revenues and costs of increasing livestock ${ }^{a}$

\begin{tabular}{|c|c|c|c|c|}
\hline & All farms & $\begin{array}{l}\text { Group } 1 \\
\text { Quota } \\
\text { unconstrained } \\
\text { no manure } \\
\text { surplus }\end{array}$ & $\begin{array}{l}\text { Group } 2 \\
\text { Quota } \\
\text { constrained } \\
\text { no manure } \\
\text { surplus }\end{array}$ & $\begin{array}{l}\text { Group } 3 \\
\text { Quota } \\
\text { constrained } \\
\text { manure surplus }\end{array}$ \\
\hline \multicolumn{5}{|l|}{ Change in physical units } \\
\hline Milk (kg) & $\begin{array}{l}7805.57 \\
(1793.62)\end{array}$ & $\begin{array}{l}7362.90 \\
(1706.60)\end{array}$ & $\begin{array}{l}7152.10 \\
(1184.01)\end{array}$ & $\begin{array}{l}8363.88 \\
(1965.04)\end{array}$ \\
\hline Own roughage (kg) & $\begin{array}{l}3685.96 \\
(1388.61)\end{array}$ & $\begin{array}{c}3991.59 \\
(832.27)\end{array}$ & $\begin{array}{l}3638.96 \\
(976.63)\end{array}$ & - \\
\hline Manure (m³ slurry) & $\begin{array}{l}28.27 \\
(3.41)\end{array}$ & $\begin{array}{l}27.43 \\
(3.24)\end{array}$ & $\begin{array}{l}27.03 \\
(2.25)\end{array}$ & $\begin{array}{l}29.33 \\
(3.73)\end{array}$ \\
\hline Manure (kg P) & $\begin{array}{l}42.41 \\
(5.11)\end{array}$ & $\begin{array}{l}41.14 \\
(4.86)\end{array}$ & $\begin{array}{l}40.54 \\
(3.37)\end{array}$ & $\begin{array}{l}44.00 \\
(5.60)\end{array}$ \\
\hline Feed demand (kEUM) & $\begin{array}{l}7069.71 \\
(946.12)\end{array}$ & $\begin{array}{l}6763.72 \\
(825.86)\end{array}$ & $\begin{array}{l}6927.75 \\
(1047.44)\end{array}$ & $\begin{array}{l}7260.94 \\
(880.09)\end{array}$ \\
\hline \multicolumn{5}{|l|}{ Revenues $(€)$} \\
\hline Milk & $\begin{array}{l}2784.25 \\
(639.79)\end{array}$ & $\begin{array}{l}2626.35 \\
(608.74)\end{array}$ & $\begin{array}{l}2551.16 \\
(422.34)\end{array}$ & $\begin{array}{l}2983.70 \\
(700.93)\end{array}$ \\
\hline Own roughage & $\begin{array}{l}212.50 \\
(80.05)\end{array}$ & $\begin{array}{l}230.12 \\
(47.98)\end{array}$ & $\begin{array}{l}209.79 \\
(56.30)\end{array}$ & - \\
\hline \multicolumn{5}{|l|}{ Costs $(€)$} \\
\hline Manure disposal \& handling & $\begin{array}{l}424.10 \\
(51.12)\end{array}$ & $\begin{array}{l}- \\
-\end{array}$ & - & $\begin{array}{l}439.97 \\
(56.00)\end{array}$ \\
\hline Manure $\mathrm{P}$ processing & $\begin{array}{l}84.81 \\
(10.22)\end{array}$ & - & - & $\begin{array}{l}87.99 \\
(11.20)\end{array}$ \\
\hline Feed (bought) & $\begin{array}{l}1102.88 \\
(147.59)\end{array}$ & $\begin{array}{l}1055.14 \\
(128.83)\end{array}$ & $\begin{array}{l}1080.73 \\
(163.40)\end{array}$ & $\begin{array}{l}1132.71 \\
(137.29)\end{array}$ \\
\hline Revenues - Costs $(€)$ & $\begin{array}{l}1385.00 \\
(501.01)\end{array}$ & $\begin{array}{l}1307.59 \\
(525.76)\end{array}$ & $\begin{array}{l}1599.13 \\
(358.77)\end{array}$ & $\begin{array}{l}1322.73 \\
(620.40)\end{array}$ \\
\hline
\end{tabular}

aStandard deviations between parentheses Source: own elaboration

5 For reasons of transparency and in order to be complete, calculations for farms in group 1 are also provided in table 4.8 .

6 The results in table 4.8 are calculated based on the estimations for the sample as a whole. The estimations per group were not usable (i.e. wrong sign and/or not significant) and provided unreliable results. 
from adding one dairy cow is $€ 2551$ for farms in group 2 and $€ 2983$ for farms in group 3 . The average for all farms is $€ 2784$. The average farm gate raw milk price was $€ 35.67 / 100 \mathrm{~kg}$ in 2012 (LEI Wageningen UR, 2016). For farms in group 2 that are not constrained by the amount of manure they produce, the manure will have a value as an (organic) fertilizer that can be applied on the land where it induces a roughage yield increase.

Roughage is in turn, via the production function for feed, an input for milk production. Since farms do not have to buy this input at the market, the value of animal manure can be seen as an (intermediate) benefit instead of a cost of production (see explanation Section 4.2). It is shown that the additional revenue of roughage production from adding one dairy cow is $€ 210$ for farms in group 2. Farms that have a manure surplus are already applying organic manure to the maximum rate allowed by the application standards and cannot further increase the application levels (hence, in table 4.8 the change in physical units of own produced roughage for group 3 is zero). As a consequence they do not derive a benefit from the additionally produced manure, but rather face a cost associated with the additional manure disposal ${ }^{7}$. The average for all farms is $€ 213$. The average price for roughage was $€ 57.65 / 1000 \mathrm{~kg}$ in 2012 (LEI Wageningen UR, 2016). The lower part of Table 4.8 represents the manure disposal costs where it is assumed that the additional manure produced for a surplus farm will have to be handled and processed, with a cost of $€ 15$ per $\mathrm{m}^{3}$ of slurry handled and a phosphate processing cost of $€ 2$ per kg phosphate (Alfa Accountants, 2015). Attracting an additional dairy cow, while keeping the land input fixed requires that additional feed is bought. The change in feed demand (expressed in thousand Energy Units Milk), provided that the dairy cow herd increases with one dairy cow, can be derived from the demand function for feed (this can be solved from equation 2). For feed (consisting of compound feed as well as roughage) a price of $€ 0.156 / \mathrm{kEUM}$ is used (based on market prices prevailing in 2012, Wageningen UR Livestock Research (2016)).

7 Assuming full compliance with the manure legislation. If this does hold not and farmers would over apply manure this potentially could also generate a negative impact on roughage production. 
The calculations in Table 4.8 show that for all farms together extending the dairy herd has a positive return of revenues over costs. Farms in group 2 would benefit most. These include the farms that do not have a manure surplus, and therefore do not face manure disposal costs. It can be seen that the manure disposal and processing costs take a significant part in the additional costs of expanding the livestock stable. Even more interesting is it to look at the spread around the calculated values; the standard deviations are relatively high compared to the averages, particularly for group 3 , the manure constrained farms. This indicates that the variation within each group is large.

Whether it is attractive for a farmer to expand his herd also depends on other costs such as labour costs and the costs of a cow place. A dairy farmer according to our data spends about 54 hours per dairy cow a year (standard deviation 23.8 hours). The investment costs of a cow place are about $€ 5000$ (Alfa Accountants, 2015), which implies an annual cost of about $€ 500$ (assuming 5\% interest and 5\% depreciation). In case a farmer in group 2 has still to invest in his stable when adding a cow, the average gross remuneration for his labour will be $€ 1599-€ 500=€ 1099$ / 54 hours $=€ 20.35$ per hour. The same analysis holds for a farmer in group 3, the average gross remuneration for his labour will be $€ 1323$ - $€ 500=€ 823 / 54=€ 15.24$ per hour. Given these calculated gross remunerations and taking into account the variation in the average net revenues of farms, it still is at the margin attractive for several of them to expand in production, especially when there is slack family labour or stable capacity available. Note that in these calculations no costs are taken into account that might come from additional regulatory constraints with respect to manure production, but only processing costs of manure are accounted for. 


\subsection{Concluding remarks}

In order to better understand the constraints Dutch dairy farmers face before and after quota abolition, this chapter focuses on estimating the production technology in such a way that the milk-feed-manure interactions and trade-offs are explicit. The technical information derived from this model provides a framework to analyse questions on relevant agricultural policy changes.

A major concern that is often addressed in estimating production functions is the supposed endogeneity of certain inputs. This was explicitly taken into account in the empirical analysis. Estimating the production functions separately for three groups based on quota and manure constraints was also supported empirically. This underlines that farms in these subgroups differ in their production processes.

The model opens up possibilities to further analyse the farmers' potential response to the abolishment of the milk quota, taking into account the heterogeneity between farms with respect to being quota and/or manure constrained. A first assessment of our results suggests that it might be attractive for dairy farmers that are currently not having a manure surplus as well as for several of those that are already having a manure surplus to (marginally) expand their number of livestock and milk supply. The slack capacity with respect to their stable and own labour are important factors that determine the final benefit of production expansion for these farms. It is not so much the manure processing costs, but rather new regulatory constraints with respect to manure production and application on own land that will affect the possibilities for future milk supply growth in the Netherlands. When future legislation would require dairy farmers that expand their dairy herd also to buy additional land, for example, this will have a further negative impact on the attractiveness to expand milk production. 


\section{References}

Aarts, H.F.M., Biewinga, E.E. and Keulen van, H. (1992). Dairy farming systems based on efficient nutrient management. Netherlands Journal of Agricultural Science 40: 285-299.

Ackerberg, D., Benkard, L., Berry, S., Pakes, A. (2007). Econometric Tools for Analyzing Market Outcomes. In: Heckman J., Leamer E. (eds.) The Handbook of Econometrics. Amsterdam: North-Holland, chapter 63.

Alfa Accountants (2015) Wat zijn de kosten van een extra melkkoe na 1 april 2015? (in English: What are the costs of an extra dairy cow after 1 April 2015?) Retrieved July 2015, from http://www.melkvee.nl/partner/20/nieuws/6564/ wat-zijn-de-kosten-van-een-extra-melkkoe-na-1-april-2015-.

Boots, M., Oude Lansink, A., and Peerlings, J. (1997). Efficiency loss due to distortions in Dutch milk quota trade. European Review of Agricultural Economics 24: 31-46.

Buysse, J. Huylenbroeck van, G. Vanslembrouck, I. and Vanrolleghem, P. (2005). Simulating the influence of management decisions on the nutrient balance of dairy farms. Agricultural Systems 86: 333-348.

CBS (2013). Official statistics for The Netherlands. Retrieved August 2013, from http://www. cbs.nl/nl-NL/menu/home/default.htm.

Council of European Communities (1991). The Nitrates Directive. Official Journal of the European Communities 34: L 375.

De Frahan, B.H., Baudry, A., De Blander, R., Polomé, Ph., and Howitt, R. (2011) Dairy farms without quotas in Belgium: estimation and simulation with a flexible cost function. European Review of Agricultural Economics 38(4): 469-495.

Dienst Regelingen Loket (2014). Gebruiksruimte en gebruiksnormen (in English: Application space and application norms). Retrieved April 2014, from http://www.drloket. nl/onderwerpen/mest/dossiers/dossier/wijzigingen-mestbeleid-vanaf-2014/ gebruiksruimte-en-gebruiksnormen. 
Dutch Government (2014). Mestbeleid (in English: Manure policy). Retrieved April 2014, from http://www.rijksoverheid.nl/onderwerpen/mest.

Dutch Ministry of Economic Affairs (2015). Nederlands mestbeleid (in English: Dutch manure legislation). Retrieved July 2015, from https://www.rijksoverheid.nl/onderwerpen/ mest/inhoud/mestoverschot-terugdringen.

Dutch Ministry of Economic Affairs (2010). Handreiking bedrijfsspecifieke excretie (in English: Guide for farm-specific manure excretion). Retrieved January 2013, from http://www.hetlnvloket.nl/onderwerpen/mest/dossiers/dossier/ gebruiksruimte-en-gebruiksnormen/productie-dierlijke-meststoffen/ handreiking-bedrijfsspecifieke-excretie-melkvee.

Evers, A.G., Haan de, M.H.A. and Sebek, L. (2009). Economisch perspectief verlaging fosforgehalte in krachtvoer (in English: Economic perspectives on reducing phosphate levels in concentrates). Lelystad, The Netherlands: Animal Sciences Group, Wageningen UR.

Hadrich, J.C. Wolf, C.A. Black, J.R.Harsh, S.B. (2008). Incorporating Environmentally Compliant Manure Nutrient Disposal Costs into Least-Cost Livestock Ration Formulation. Journal of Agricultural and Applied Economics 40: 287-300.

Jongeneel, R. and Van Berkum, S. (2015) What will happen after the EU milk quota system expires in 2015? An assessment of the Dutch dairy sector. The Hague, LEI-Wageningen UR, Report No. 2015-041.

Krimpen van, M. Middelkoop van, J. Sebek, L. Jongbloed, A. and Hoop de, W. (2010). Effect van fosforverlaging in melkveerantsoenen en varkensvoeders op fosfaatexcretie via de mest (in English: Effects of phosphate reduction in the ration of dairy cows and pigs on phosphate excretion from manure). Lelystad, The Netherlands: Wageningen UR Livestock Research.

LEI Wageningen UR (2013). Agricultural and horticultural figures. Retrieved January 2013, from http://www.lei.wur.nl/NL/statistieken/Land-+en+tuinbouwcijfers/.

LEI Wageningen UR (2016). Agricultural and horticultural figures. Retrieved February 2016, from http://www.wageningenur.nl/nl/Expertises-Dienstverlening/ Onderzoeksinstituten/LEI/Data-1/Agrarische-prijzen.htm/. 
Nousianen, J. Tuori, M. Turtola, E. and Huhtanen, P. (2011). Dairy farm nutrient management model. Model description and validation. Agricultural Systems 104: 371-382.

Ooms, D.L. and Peerlings, J.H.M. (2005). Effects of EU dairy policy reform for Dutch dairy farming: a primal approach using GMM estimation. European Review of Agricultural Economics 32: 517-537.

Remmelink, G. Blanken, K. Middelkoop van, J. Ouweltjes, W. and Wemmenhove, H. (eds.) (2012). Handboek Melkveehouderij (in English: Guide to Dairy Farming). Lelystad, The Netherlands: Wageningen UR Livestock Research.

Réquillart, V. Bouamra-Mechemache, Z. Jongeneel, R. and Penel, C. (2008). Economic analysis of the effects of the expiry of the EU milk quota system. Toulouse, France: Institute D’Economie Industrielle (IDEI).

Schaffer, M.E. (2010). xtivreg2: Stata module to perform extended IV/2SLS, GMM and AC/ HAC, LIML and k-class regression for panel data models.Retrieved June 2015, from http://ideas.repec.org/c/boc/bocode/s456501.html.

Thijssen, G.J. (ed.) (1992). Micro-economic Models of Dutch Dairy Farms. Wageningen, The Netherlands: Wageningen Academic Publishers.

Varian, H.R. (1992). Microeconomic analysis. New York, Norton \& Company.

Verbeek, M.A. (2012). A Guide to Modern Econometrics (4th edition). Chichester, John Wiley \& Sons.

Wageningen UR Livestock Research (2016). Agricultural nutritive prices. Retrieved February 2016, from http://www.wageningenur.nl/nl/Expertises-Dienstverlening/ Onderzoeksinstituten/livestock-research/Faciliteiten-producten/ Voederwaardeprijzen-Rundvee.htm/. 


\section{Were Manure Application Norms Effective in Limiting Dairy Cattle on Dutch Dairy Farms? ${ }^{1}$}

\section{Abstract}

This chapter investigates whether manure application norms were effective in limiting the number of dairy cows on Dutch dairy farms in the period 2008 to 2012. Assuming short-run profit maximization including manure processing costs for dairy farms with a manure surplus, a shadow price equation for dairy cows is derived that is estimated using panel data techniques. A parameter test shows that the marginal processing costs of additional manure did not lower the shadow price of dairy cows for surplus farms, suggesting that this policy in the period 2008 to 2012 was not effective in preventing expansion of dairy cows on surplus farms.

1 Unpublished paper by Gerlinda S. Samson, Cornelis Gardebroek and Roel A. Jongeneel. 


\section{$5.1 \quad$ Introduction}

One of the environmental issues in the European Union is the overproduction of phosphate from animal manure (European Sustainable Phosphorus Platform, 2017). For this reason, the European Union assigned maximum phosphate production levels to each member state. In 2015, the Dutch phosphate production passed its national ceiling of 172.9 million kg phosphate for the first time in five years. Due to an increase in the number of livestock (mainly in the Dutch dairy sector) the phosphate production increased to 180.1 million $\mathrm{kg}$ in 2015 . In 2016, the total phosphate production decreased to 177 million $\mathrm{kg}$, however this is still above the national ceiling (Statistics Netherlands, 2017a).

Figure 5.1 shows the development of the total phosphate production for the livestock sector in the Netherlands. As can be seen, the dairy sector is responsible for a large part of the total phosphate production. The increase in the number of livestock was a response of the dairy sector to the abolishment of milk quota in 2015. Between 2008 and 2015, the total number of dairy cows of 2 years and older increased on average with $1.6 \%$ per year. The average number of dairy cows per ha increased from 1.61 to 1.83 between 2008 and 2016. As a result the phosphate production per ha increased from $100.1 \mathrm{~kg}$ per ha to $108.3 \mathrm{~kg}$ per ha between 2008 and 2016 (Statistics Netherlands, 2017a).

As of 2006 the Dutch manure policy already directed maximum animal manure application norms for the use of phosphate in order to cope with the overproduction of phosphate. Between 2006 and 2016 the application norms for phosphate from animal manure production decreased and became more strict every year (Dutch government, 2005). When the phosphate production per hectare increases and the maximum application norms for phosphate from animal manure decrease, the problem of overproduction of phosphate becomes even more significant. The Dutch government therefore introduced several other manure policies during the years as well. This led to a complex system of different regulations for manure production and application, nevertheless there was still phosphate overproduction. 
mln. kg.

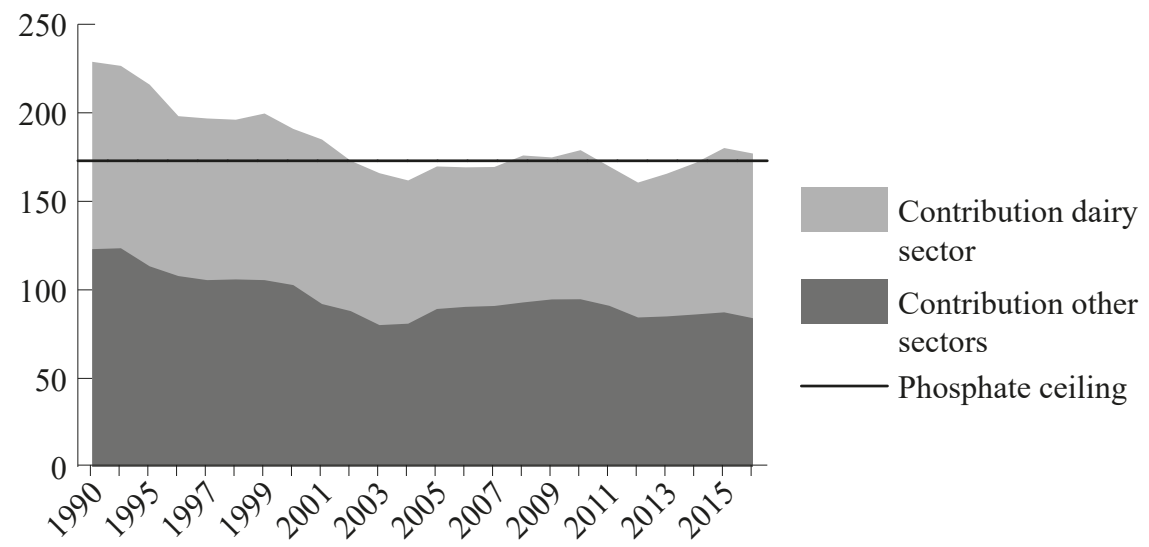

Figure 5.1 Phosphate production Netherlands

Source: Statistics Netherlands (2017b)

In this chapter, we focus on the period 2008 and 2012, when the Dutch manure policy consisted of only the system of application norms, and analyse whether or not this manure policy was restrictive for the dairy farms to increase in livestock. If the average farm is producing more phosphate than allowed, it does not necessarily mean that all farms produce more phosphate than allowed. We analyse whether different growth strategies between dairy farms can be distinguished. Moreover, we investigate the differences in characteristics between farms that increased in livestock while producing more phosphate than the application norm allowed and farms that increased in livestock while producing within the application norm of phosphate.

Our chapter contributes to the current agricultural economic literature in two ways. First, our analysis provides more insights about growth strategies and characteristics of Dutch dairy farms operating under a system of manure regulations. These insights could be helpful in making effective decisions in the current debate on the Dutch manure policy. Second, we provide a detailed and complete overview of the development of the complex Dutch manure policy. In light of recent developments of Dutch animal phosphate production levels, 
the Dutch government revised its manure policy. These revisions are included in this chapter as well.

The remainder of this chapter is structured as follows. The next section provides a detailed overview of Dutch manure policy. Section 5.3 discusses the data used in this study. In section 5.4 a first exploration of the data, focusing on developments in the Dutch dairy sector, is provided. Section 5.5 outlines the model specification and estimation, and section 5.6 shows the results of this chapter. Finally, in section 5.7, some concluding remarks are presented.

\subsection{Overview Dutch manure policy}

\subsubsection{Development of the manure policy in the Netherlands}

For Dutch dairy farmers, the Dutch manure policy officially came into force on 27 November 1986 when the 'Meststoffenwet' (in English: policy on fertiliser use) was introduced (Dutch government, 1986). Its main purpose is to protect the soil as a result of the use of animal manure and other fertilizers. The policy contains directives on the production and use of manure, and on the trade, processing and tariffs on manure surpluses. Over the years the policy was adapted several times in order to comply with new EU policy.

From 1998 until 2005, an important part of the Dutch manure production was regulated via the mineral accounting system (in Dutch: Mineralenaangiftesysteem, MINAS) (Dutch government, 1996). This system contained several regulations on the production and use of minerals in animal manure. Although the protocols were clear and regulated, the fines for overproduction were low and the farmers often used more (animal) manure than they were officially allowed (Hees et al., 2012). This resulted in major overproduction, and the EU regulations on maximum levels of manure production were not met. 
As a response, and in order to comply with EU policy, the Dutch government abolished MINAS and instead presented a more detailed and structured system of manure application norms. On 15 September 2005, the government introduced three different application norms for the use of animal manure and fertilizers (Dutch government, 2005). These norms, which came into force as of 2006, determine the maximum use of animal manure, phosphate and nitrogen on land in kg per farm. If a farm exceeds either one of the three norms, it has a manure surplus, or so-called farm surplus, which is penalised by letting them pay a fine for every $\mathrm{kg}$ in excess.

With respect to the maximum norm for use of animal manure, the European Commission allowed derogation to the Netherlands in 2006 (Dutch government, 2007). This implies that the norm for use of animal manure for derogation-farms temporarily was allowed to be $250 \mathrm{~kg}$ nitrogen per ha instead of the legally prescribed $170 \mathrm{~kg}$ nitrogen per ha. Every four years the derogation is reviewed and it will be determined whether or not The Netherlands will get derogation for the next period. The next revision is in 2018.

The system of application norms is more strict on the use and production of minerals than the old MINAS system. In 2014, the system became even more tight in managing the use of animal manure and fertilisers when the Dutch government made it compulsory to process part of the farm surpluses (Dutch government, 2013). On top of the fine that needs to be paid for the surplus, a farm is obliged to process part of the farm surplus as well.

In combination with the milk quota (already introduced in 1985), which put a maximum limit on milk production and thus indirectly on manure production as well, the Dutch manure production stayed within EU policy norms. However, in 2015 the milk quota were going to be abolished (European Commission, 2010). This meant a potential environmental risk for the Dutch dairy sector as limits to milk production, and thus manure production, would disappear. 
In July 2014 the Dutch government expressed its concerns about the situation in the dairy sector and proposed a new component of the manure policy; the act on a responsible growth of the dairy sector (Dutch government, 2014a). This act provides guidelines for the dairy sector to grow within European environmental policy limits. To this end, the increase in the phosphate production of dairy livestock with respect to the phosphate production level in the base-year 2013 (the so-called dairy phosphate surplus) must be compensated with additional land and/or should be processed.

In October 2014 an ex-ante evaluation study on this act showed that the proposed guidelines were not sufficient in order to cope with the major increase and overproduction of phosphate in the dairy sector (Dutch government, 2014b). Amongst other, the policy would not put a stop to the growth of dairy livestock and the EU limit on the maximum level of phosphate use would be exceeded. As a response, the Dutch government asked the sector itself to manage manure production to stay within EU production limits. Although the sector monitored its production well, and even introduced new technologies such as feed with lower phosphate content (Agricultural Organization Netherlands, 2010), the manure production exceeded the maximum allowed phosphate production level for the first time in five years in 2015. At that time, the total phosphate production of the Dutch dairy sector was 90.4 million $\mathrm{kg}$ (Statistics Netherlands, 2016). This manure overproduction is so high that the derogation is at risk; if the Dutch manure production is not quickly to decrease, the European Commission will withdraw the rights for derogation as of 2018. This means that the need to force the Dutch farmers to produce within EU manure production limits is even more urgent. The goal is to reach a manure production level of 84.9 million $\mathrm{kg}$ phosphate (or less) in 2018.

In order to reach that goal, the Dutch government adapted the proposed act on a responsible growth of the dairy sector and made it more strict. In March 2015 the definite act, which eventually came into force on 1 January 2016, was presented (Dutch government, 2015). The main purpose of this act is to guarantee land-based growth in the dairy sector. To this end the government set up a structured system of clear regulations on the amount of manure the 
farms with a dairy phosphate surplus need to process or buy additional land for (these clear regulations were not present in the proposed act yet).

In addition to the act, the Dutch government proposed another component to the manure policy in order to also guarantee Dutch phosphate production levels to stay within the EU maximum limits. In September 2016 the system of phosphate production rights was presented (Dutch government, 2016a). Under this system, a farm is not allowed to produce more phosphate than the total number of phosphate production rights it has been assigned to. The number of phosphate production rights assigned to a farm is based on the number of livestock a farm has at 2 July 2015. In order to reach the goal of 2018, a general reduction is applied to the number of phosphate rights the farmers obtain. This reduction is aimed to be $8 \%$ at its maximum (Dutch government, 2016a). The phosphate rights will be tradable between farms, but rights will be siphoned off when they are traded until the total phosphate production is below the national ceiling.

At first, the system of phosphate production rights was supposed to come into force on 1 January 2017. However, in October 2016 the Dutch government announced that the system conflicts with EU policy regulations on state support (Dutch government, 2016b), and therefore needs to be adapted. Currently the Dutch government discusses the content of the system with the EU. The new proposed date to introduce the phosphate production rights is 1 January 2018.

The system of phosphate production rights (as of 2018) is an addition to the already existing Dutch manure policy components of application norms (as of 2006), compulsory manure processing (as of 2014) and the act on a responsible growth of the dairy sector (as of 2016). Together these components form the Dutch manure policy. 


\subsubsection{Two types of manure surplus}

Based on the application norms that were introduced in 2006, we can distinguish farms that have a farm surplus and farms that do not have a farm surplus. Every dairy farm is confronted with three different application norms for the use of nitrogen and phosphate in manure and the use of animal manure. The norm assigned to each farm depends on the size of the agricultural land, the soil type and the type of crop that is produced on the land. If they use more manure than their application norm prescribes, they have a farm surplus.

Farms can handle these farm surpluses in different ways. They have to pay a fine for every $\mathrm{kg}$ manure that they produce in excess. However, farms can also arrange contracts with other farms in order to offset their manure and decrease their farm surplus. As of 2014 farms are obliged to process part of their farm surplus. The percentage of farm surplus that needs to be processed differs per year and depends on the region where the farm is located. In 2016 these percentages were 55\%, 35\% and 10\% for farms located in the southern, eastern and other regions respectively (National Organization for Enterprises Netherlands, 2016).

Farms having a farm surplus can be further distinguished into farms that have a dairy phosphate surplus and farms that do not have a dairy phosphate surplus. The level of dairy phosphate surplus is calculated by subtracting the level of production of phosphate in the reference year 2013 and the application norm for phosphate, from the total production of phosphate in that specific year. Farms are obliged to process part of this dairy phosphate surplus. The amount that they are allowed to process depends on their production level of phosphate in the reference year 2013 and the growth of phosphate production since then. Farms need to buy extra land for the part that cannot be processed, or they need to decrease (phosphate) production.

The percentages of phosphate production that needs to be processed and the part of phosphate production that needs to be handled on extra land depends on the dairy phosphate 
surplus per ha. Farms with a dairy phosphate surplus of $20 \mathrm{~kg}$ per ha (or less) are obliged to process $100 \%$ of their surplus. Farms with a dairy phosphate surplus between $20 \mathrm{~kg}$ and $50 \mathrm{~kg}$ per ha are obliged to process $75 \%$ of their surplus and need to buy extra land for the other $25 \%$ (or decrease in production). Farms with a dairy phosphate surplus of 50kg per ha (or more) are obliged to process $50 \%$ of their surplus and need to buy extra land for the other 50\% (or decrease in production) (National Organization for Enterprises Netherlands, 2016). Figure 5.2 summarizes the classification of Dutch dairy farms according to their manure surpluses.

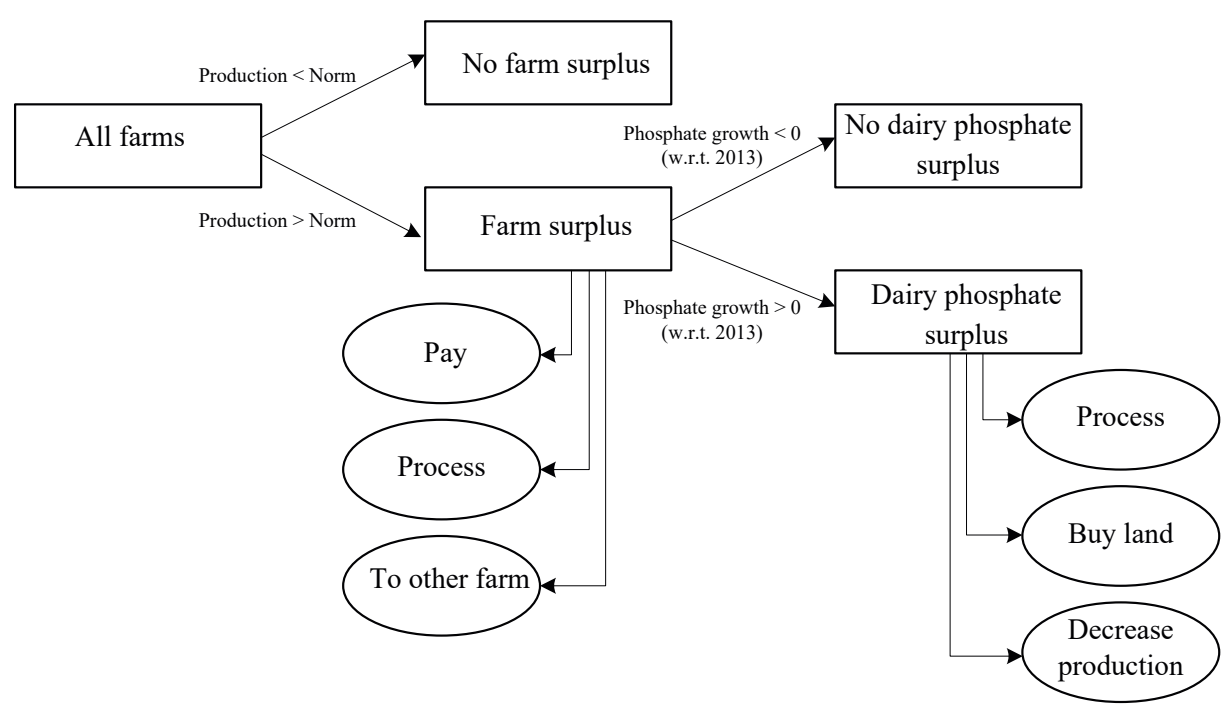

Figure 5.2 Manure surpluses on Dutch dairy farms

Source: own elaboration 


\subsection{Data}

Our sample data exist of 1193 observations on 334 Dutch dairy farms. The data cover the period 2008 to 2012 and is obtained from the Dutch Farm Accountancy Network Data (FADN, Wageningen Economic Research) and the LMM-database (Landelijk Meetnet Mestbeleid, Wageningen Economic Research). The data form an unbalanced panel and only 132 farms are all years in the panel.

Table 5.1 provides an overview of the data used in this study. The number of dairy cows is taken directly from the LMM-database and measured in average numbers per farm per year. We gathered data on the value of milk production (in euros) from FADN and divided this value by the quantity of milk production (in kilos) of farmers as reported in the FADN as well. This way we obtained the actual milk price farmers received on average for their production each year. This price differs per farm per year, as all farmers receive different prices based on quality differences (i.e. fat- and protein content). The market price for a dairy cow was obtained from the database of Wageningen Economic Research (2017). In order to take into account the depreciation of a cow (on average a cow is used for milk production for five years), we divided this market price by 5 (Boer and Zijlstra, 2013). Information on labour is taken directly from the FADN and measured as the time (in hours) worked on the farm by the farmer, (hired and fixed) employees and volunteers. The values on different types of (new) capital are reported directly in the FADN. Capital used for milk production is measured as a compound new value (in euros) for installations and buildings. For land we take the total agricultural land area (grassland and land for fodder production) as reported in the LMM (in ha). Data on animal manure production were obtained from the LMM-database. We calculated the total on-farm animal manure production by summing the manure production in $\mathrm{m}^{3}$ of the dairy cows, calves and heifers on the farm. Next, the animal manure surplus is derived by adding the total on-farm animal manure production, the initial stock of animal manure and the on-farm supply of animal manure. From this amount we subtracted the final stock of animal manure and the farm specific manure application norm (all $\mathrm{in}^{3}$ ). The result is 
the animal manure surplus; when the result is positive, the farm is constrained by manure application norms. And when the result is negative, the farm is unconstrained by manure application norms.

Table 5.1 Descriptive statistics of the variables used in the empirical analysis

\begin{tabular}{lll}
\hline Variables & Dimension & Sample mean (st.dev.) \\
\hline Dairy Livestock & number* $10^{1}$ & $9.596(5.358)$ \\
Milk price & euros & $0.338(0.050)$ \\
Price of dairy cow & euros $* 10^{2}$ & $1.897(0.422)$ \\
Labour & hours $* 10^{3}$ & $4.508(2.134)$ \\
Capital for milk production & euros $* 10^{5}$ & $7.173(4.541)$ \\
Land & ha $10^{2}$ & $0.563(0.326)$ \\
Manure production & $\mathrm{m}^{3}$ manure $10^{3}$ & $3.541(1.962)$ \\
Manure Surplus & $\mathrm{m}^{3}$ manure $10^{1}$ & $8.643(100.835)$ \\
& & \\
$n$ farms (N observations) & $334(1178)$ & \\
\hline
\end{tabular}

Source: own elaboration

\subsection{Recent developments in the Dutch dairy sector}

In this paragraph we describe developments in the Dutch dairy sector using our sample data. Eventually we want to answer the question whether or not the manure policy was already limiting the growth of farms in the past. In order to answer this question, we will first have a closer look at the manure production and the development of manure surpluses on Dutch dairy farms. Between 2008 and 2012, there were 109 farms in our dataset that always had a manure surplus, and 96 farms which never had a manure surplus. Table 5.2 shows the percentage farms that had a manure surplus. The percentages increase every year. This is not only due to the (slightly) increase in milk and manure production, that can be seen in table 5.2 as well, but it is mainly due to a decrease in manure application norms for phosphate as well. In 2008 and 2009 the manure application norm for phosphate was on average 100kg per hectare, whereas in 2010, 2011 and 2012 it was on average 95kg per hectare. 
Table 5.2 Manure surplus and average milk and manure production ${ }^{a}$

\begin{tabular}{llll}
\hline & $\begin{array}{l}\text { Farms with } \\
\text { manure surplus } \\
\text { (in \%) }\end{array}$ & $\begin{array}{l}\text { Average milk } \\
\text { production } \\
\text { (in 10 } \mathbf{~ k g )}\end{array}$ & $\begin{array}{l}\text { Average manure } \\
\text { production } \\
\text { (in } \mathbf{1 0}^{3} \mathbf{~ m}^{3} \text { ) }\end{array}$ \\
\hline 2008 & 38.2 & $7.120(3.909)$ & $3.258(1.743)$ \\
2009 & 47.5 & $7.536(4.233)$ & $3.468(1.908)$ \\
2010 & 55.8 & $8.136(4.550)$ & $3.692(2.009)$ \\
2011 & 62.8 & $7.973(4.594)$ & $3.612(2.008)$ \\
2012 & 68.0 & $8.046(4.749)$ & $3.631(2.040)$ \\
\hline
\end{tabular}

${ }^{a}$ Standard deviation between brackets

Source: own elaboration

Next, we analyse the farms that expanded production and see if different strategies can be distinguished. Farm expansion can be measured in different ways; one way is to measure the development of the number of livestock or level of milk production. Another way is to measure the change in the number of hectares a farm has. In context of the manure policy, in which manure application norms determine the maximum level of phosphate farms are allowed to apply per hectare, both measures are interesting to look at. Farms can follow different expansion strategies; a farm that increases the number of livestock and level of milk production while keeping the number of hectares constant follows an intensification path. Contrarily, a farm that increases the number of hectares while keeping the number of livestock and milk production constant follows an extensification path. The intensity of farming is measured by the level of milk production per hectare. An extensive farm has a relatively lower level of milk production per hectare than an intensive farm.

Table 5.3 shows the average growth in livestock and land per year. Between 2008 and 2012, the average percentage growth in number of livestock was $2.5 \%$ per farm per year and the average percentage growth in land was $1.4 \%$ per farm per year. Through the years, farms increased in both livestock and land. However, the percentage increase in land is relatively low. Land is relatively scarce in The Netherlands and therefore requires significant investments of farms to obtain. Still, every year farms stop farming and their land becomes available to other farms. 
Table 5.3 Growth of livestock and land area ${ }^{a}$

\begin{tabular}{lllll}
\hline Year & $\begin{array}{l}\text { Average number } \\
\text { of livestock }\end{array}$ & $\begin{array}{l}\text { Average \% growth } \\
\text { livestock } \\
\text { (wrt previous year) }\end{array}$ & $\begin{array}{l}\text { Average number } \\
\text { of hectares }\end{array}$ & $\begin{array}{l}\text { Average \% growth } \\
\text { land } \\
\text { (wrt previous year) }\end{array}$ \\
\hline 2008 & $88.4(47.281)$ & & $54.1(30.524)$ & \\
2009 & $93.3(51.587)$ & $2.1(7.833)$ & $55.4(30.914)$ & $0.9(10.196)$ \\
2010 & $98.4(53.267)$ & $2.4(8.077)$ & $57.3(31.651)$ & $0.9(8.943)$ \\
2011 & $97.5(54.272)$ & $2.9(18.652)$ & $56.3(31.228)$ & $2.3(17.960)$ \\
2012 & $99.0(55.793)$ & $2.5(6.224)$ & $55.6(30.925)$ & $1.6(9.960)$ \\
\hline
\end{tabular}

${ }^{\text {a }}$ Standard deviation between brackets

Source: own elaboration

A distinction can be made between farms that were producing more manure than their manure application norm and farms that were not. Although the application norms are not really restricting the milk and manure production of farms (since it is possible to process the surplus manure outside the farm), for simplicity we will refer to manure constrained and manure unconstrained farms in this chapter. From the farms that increased in livestock, $32.4 \%$ were unconstrained and 39.2\% were constrained in manure production. Similar results are found for farms that increased in land area; 28.4\% were unconstrained and 29.9\% were constrained in manure production. Although some farms were constrained in manure production, they still increased in livestock. This could indicate that these farms were producing an even higher manure surplus per hectare. However, some farms also increased in land area, which increases the application space for manure. In total $22.6 \%$ of the farms increased livestock while not increasing land. Of these farms, $62.4 \%$ were constrained by manure application norms. These farms became more intensive, while already facing a manure production surplus. In total 9.3\% of the farms increased in land, while not increasing in livestock. Of these farms, $51.4 \%$ were constrained by manure application norms. These farms already became more extensive, but still face a manure production surplus.

Figure 5.3 provides a closer look into the development of the average number of livestock per hectare of these two types of farms that follow different strategies. Not surprisingly, the number of livestock per hectare is higher for an intensive farm than for an extensive 
farm. Between 2009 and 2010 both types of farms increase in livestock. In the next years the average number of livestock on intensive farms increases further, whereas the livestock on the extensive farm is relatively stable.

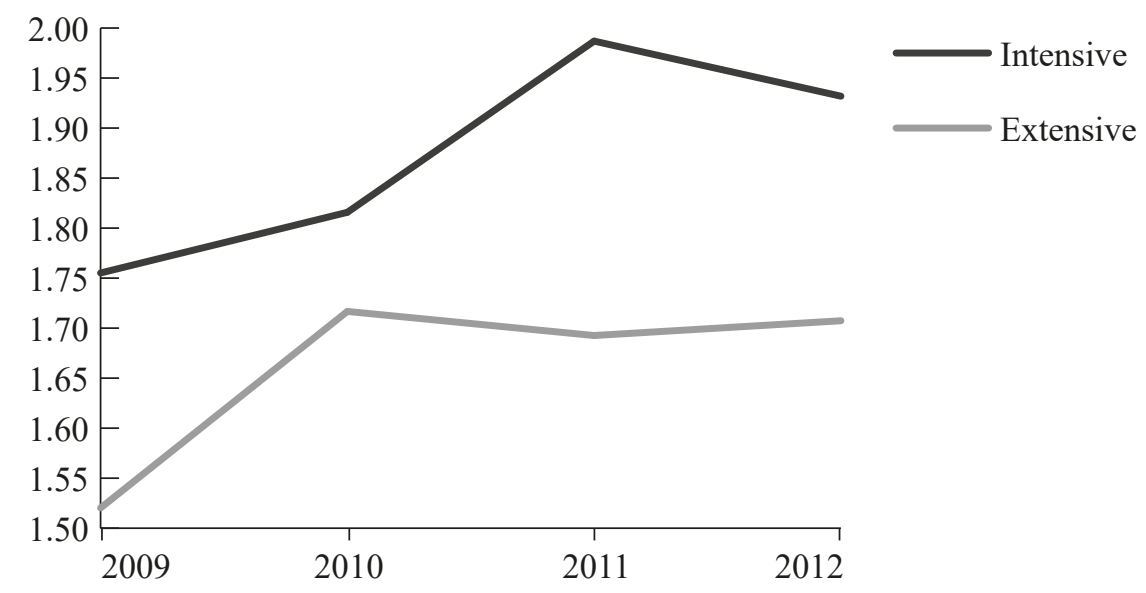

Figure 5.3 Number of livestock per hectare

Source: own elaboration

Figure 5.4 shows the development of the phosphate production per hectare for the two types of farms. The dashed line shows the maximum application norm per hectare. As can be seen, the intensive farms are producing at a manure surplus, and are even increasing the average
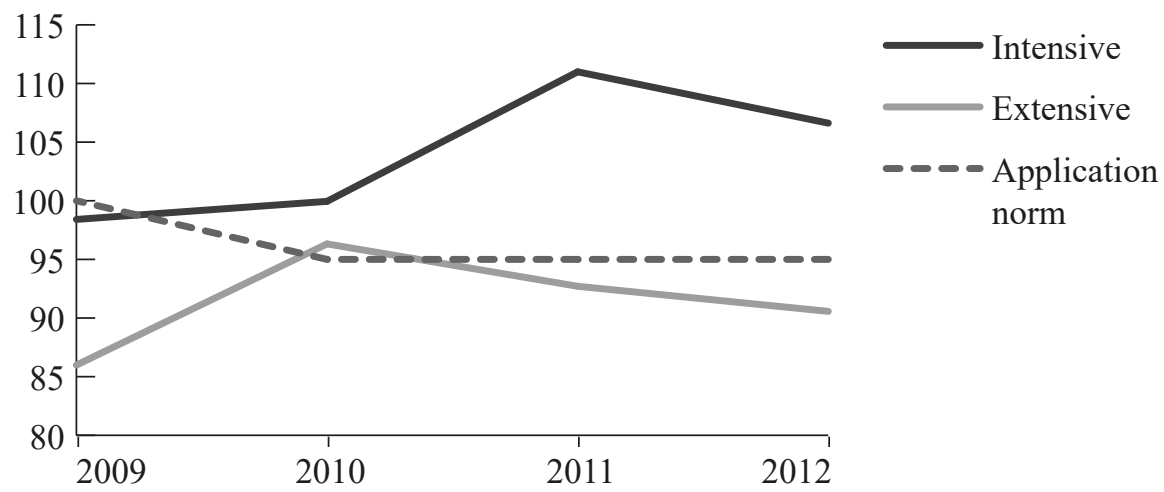

Figure 5.4 Phosphate production per hectare

Source: own elaboration 
phosphate production per hectare between 2010 and 2011. However, between 2011 and 2012 the phosphate production per hectare is decreasing again. The extensive farms are producing below the application norm. The figure shows that the extensive farms are even decreasing in phosphate production per hectare.

\subsection{Model specification and estimation}

Assume that dairy farmers maximize the following expression for total profits, which includes manure processing costs for farmers that have a manure surplus:

$$
\Pi=\pi(p, w, L i, Z)-c \cdot[M p(L i, y)-M a n \cdot L a] \cdot I(M s>0)
$$

where $\Pi$ is total profits including manure production costs, $\pi$ is short-run profits of dairy farming, which is a function of output prices $(p)$, variable input prices $(w)$, dairy cows $(L i)$, and a vector of quasi-fixed factors $Z$ that includes labour, capital and land. Farms that have a manure surplus, which is indicated by the indicator function $I(M s>0)$ having a value 1 , have manure processing costs, which is a function of the per unit processing costs $c$ and the total manure surplus. The latter is the difference between total manure production $M p(L i, y)$, which depends on the number of dairy cows $(L i)$ and the milk production per cow (y) (Remmelink et al., 2012: 2-44), and the quantity of manure that can legally be applied to the land, equalling the product of the manure application norm (Man) and the amount of land $(L a)$ the dairy farmer has. Note that dairy farms with no manure surplus have a value 0 for the indicator function. From this expression the shadow price of livestock (dairy cows) can be derived:

$$
s_{L i}=\frac{\partial \pi}{\partial L i}-c \cdot \frac{\partial M p}{\partial L i} \cdot I(M s>0)
$$

Besides livestock it is assumed that the short-run profit function is a function of the milk price farmers receive $\left(p_{m}\right)$ and three quasi-fixed inputs, viz. labour $(L b)$, capital $(K)$ and land $(L a)$. Using a flexible quadratic functional form for $\pi$ and the expression for calculating the amount 
of manure per dairy cow as given by Remmelink et al. $(2012: 2-44), \mathrm{Mp}=(13.44+0.019 \cdot y) \cdot \mathrm{Li}$ gives the following empirical expression for the shadow price of dairy cows:

$$
s_{L i}=\alpha_{0}+\alpha_{1} p_{m}+\alpha_{2} L i+\alpha_{3} L b+\alpha_{4} K+\alpha_{5} L a-c \cdot(13.44+0.019 \cdot y) \cdot I(M s>0)
$$

Shadow prices are not observed but are usually calculated based on the parameters of the flexible functional form for $\pi$. Alternatively, if we assume that farmers choose their number of cows optimally, we can set the shadow price equal to the one-year price of dairy cows $\left(w_{L i}\right)$ and solve for the optimal number of cows. After reparameterizing this yields the following demand function for cows that can be estimated:

$$
L i=\beta_{0}+\beta_{1} p_{m}+\beta_{2} w_{L i}+\beta_{3} L b+\beta_{4} K+\beta_{5} L a+\beta_{6} \cdot(13.44+0.019 \cdot y) \cdot I(M s>0)
$$

This expression allows us to test whether the manure surplus costs had a negative impact on the number of dairy cows for farms that had a manure surplus or not by testing whether $\beta_{6}$ is negative and significantly different from zero.

The data are available for 334 dairy farms in the period 2008-2012, but due to the unbalanced nature of the data there are only 1178 observations. Nevertheless, the panel structure allows for estimating equation (4) using panel data techniques. A fixed effects procedure is chosen allowing for farm-specific intercepts $\beta_{0 \mathrm{i}}$ in the equation, reflecting unobserved differences in e.g. management or technical characteristics of farms.

\subsection{Results and discussion}

The parameter estimates for the livestock demand function are provided in the second column of table 5.4. All estimates are significantly different from zero. The own price effect of a dairy cow to the supply of a dairy cow is negative which is according to neo-classical economic theory. All other variables have a positive influence on the livestock demand. The milk price has a positive effect on livestock demand; the higher the milk price, the more livestock is 
wanted. This makes sense as a farmer can earn relatively more income by increasing livestock at increasing milk prices, than at stable or decreasing milk prices. The positive signs of capital for milk production and labour indicate that both are complements to livestock demand; the more capital and/or labour, the more livestock can be handled on dairy farms. The most interesting is the positive result for the manure surplus constraint. Apparently this constraint does not put a limit on livestock demand. Instead, we estimate that it even increases the demand for livestock.

The goal of the applications norms was to keep the phosphate production of the dairy sector within limits and the total phosphate production below the national ceiling. When a farm exceeds its maximum phosphate application level, it needs to pay a fine for every kg of phosphate production in excess. The costs of these fines however, turned out to be relatively low compared to the extra income generated by the milk production (Samson et al., 2017).

Table 5.4 Estimation results for number of livestock ${ }^{a}$

\begin{tabular}{|c|c|c|c|}
\hline Number of Livestock & $\begin{array}{l}\text { FE } \\
\text { All farms }\end{array}$ & $\begin{array}{l}\mathrm{RE}^{\mathrm{b}} \\
\text { Strategy intensification }\end{array}$ & $\begin{array}{l}\mathrm{RE}^{\mathrm{b}} \\
\text { Strategy extensification }\end{array}$ \\
\hline Milk price & $\begin{array}{l}1.699^{* *} \\
(0.684)\end{array}$ & $\begin{array}{l}2.675 \\
(2.007)\end{array}$ & $\begin{array}{l}3.699^{w *} \\
(1.712)\end{array}$ \\
\hline Price of dairy cows & $\begin{array}{r}-0.162^{\circ *} \\
(0.065)\end{array}$ & $\begin{array}{l}0.458 \\
(0.317)\end{array}$ & $\begin{array}{l}-0.684^{n k x} \\
(0.339)\end{array}$ \\
\hline Labour & $\begin{array}{l}0.464^{\text {onk }} \\
(0.051)\end{array}$ & $\begin{array}{l}0.268^{m, p} \\
(0.092)\end{array}$ & $\begin{array}{l}0.315^{\omega *} \\
(0.124)\end{array}$ \\
\hline Capital & $\begin{array}{l}0.169^{\text {s*ik }} \\
(0.017)\end{array}$ & $\begin{array}{l}0.299^{\text {anks }} \\
(0.040)\end{array}$ & $\begin{array}{l}0.192^{m * a} \\
(0.068)\end{array}$ \\
\hline Land & $\begin{array}{l}6.316^{0.0 \times} \\
(0.477)\end{array}$ & $\begin{array}{l}11.622^{* * n} \\
(0.661)\end{array}$ & $\begin{array}{l}10.580^{\text {ning }} \\
(0.922)\end{array}$ \\
\hline $\begin{array}{l}\text { Manure surplus } \\
\text { constraint }\end{array}$ & $\begin{array}{l}0.008^{* * w \times x} \\
(0.002)\end{array}$ & $\begin{array}{l}0.017^{m * a} \\
(0.007)\end{array}$ & $\begin{array}{l}0.047^{m \infty x_{0}} \\
(0.010)\end{array}$ \\
\hline Intercept & $\begin{array}{l}2.322^{0 * w n} \\
(0.335)\end{array}$ & $\begin{array}{c}-1.914^{m, n e} \\
(0.647)\end{array}$ & $\begin{array}{c}-0.359 \\
(0.980)\end{array}$ \\
\hline Within $R^{2}$ & 0.47 & 0.08 & 0.27 \\
\hline$F$-test slope parameters & $22.88^{* \ldots+\infty}$ & - & - \\
\hline$n(N)$ & $329(1178)$ & $188(266)$ & 99 (109) \\
\hline
\end{tabular}

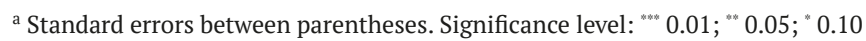

${ }^{\mathrm{b}} \mathrm{FE}$ estimation is not convenient here because there is few variability in data as there are not many observations per group. Instead we use RE estimation.

Source: own elaboration 
Even taking into account all other types of costs, it seemed that the additional costs of the fine could not diminish the increase in the number of livestock. This might be a possible explanation for the effect we find here.

In column three and four of table 5.4 the estimation results for livestock demand are provided when the sample is divided into two groups; farms that follow an intensification path and farms that follow an extensification path, respectively. As can be seen, results are very similar to the estimations of the sample as a whole. For intensive farms, the sign for the market price of a cow is positive, but this is not significant. Also these estimates show a positive significant effect of the manure surplus constraint on livestock demand. Apparently there is no difference in their approach to livestock demand between intensive and extensive farms.

However, compared to the sample as a whole and the intensive farms, extensive farms have a slightly stronger response on the manure surplus constraint. In figures 5.3 and 5.4 we saw that the number of livestock per hectare and the phosphate production per hectare were decreasing. Extensive farms were on average producing less phosphate than the application norm allowed. This means that farms have space to increase in milk and manure production within limits of their application norms for phosphate.

\subsection{Concluding remarks}

In this chapter we focused on the period 2008 and 2012, when the Dutch manure policy consisted of only the system of application norms, and analysed whether or not this manure policy was restrictive for the dairy farms to increase in livestock. We found that the manure application norms did not restrict milk and manure production in the past. Instead we found that it had a positive effect on the demand for livestock. Moreover, the same results were found for farms using different growth strategies. Although, this positive effect is counterintuitive, it may be explained from a correlation between large numbers of cows and a manure surplus. 
Which lessons can be learned and used in context of the actual debate on the new manure policy legislation in the Netherlands? Apparently application norms alone were not sufficient to keep phosphate production in the Netherlands below the overall national ceiling. In fact, the manure surplus constraint was not even restricting livestock demand, and therefore missed its purpose to control phosphate production. An explanation is that the manure processing costs are too low to really restrict manure surplus farms in expanding. As was pointed out in this chapter, the Dutch government introduced extra regulations later on. However, the Dutch phosphate production is still not below the limits set by the EU. The Dutch government needs to find a manure policy regulation that effectively limits livestock demand significantly. When they succeed, this will put a stop to the increase in the number of livestock per farm, and eventually it might lead to a decrease in the total phosphate production of the Dutch dairy sector. 


\section{References}

Agricultural Organization Netherlands (2010). Fosfaatcovenant. Fosfaatverlaging via het voerspoor (in English: Phosphate covenant). Projectplan 13 december 2010, LTO Nederland en Nevedi. The Netherlands, The Hague.

Boer, M., Zijlstra, J. (2013). Differences between dairy farms in longevity of dairy cows. Livestock Research, Wageningen UR, report no. 666, 19p.

Dutch government (1986). Meststoffenwet (in English:Fertilizer legislation). Retrieved January 2017, from http://wetten.overheid.nl/BWBR0004054/2014-01-01\#HoofdstukIII.

Dutch government (1996). Wijziging van de Meststoffenwet (in English: Changes in fertilizer legislation). Kamerstuk Tweede Kamer der Staten-Generaal. 24 782. Nr.3 Memorie van toelichting. The Netherlands, The Hague.

Dutch government (2005). Wet van 15 september 2005 tot wijziging van de Meststoffenwet (invoering gebruiksnormen) (in English: Law of 15 September 2005 to implement changes in fertilizer legislation). Staatsblad van het Koninkrijk der Nederlanden, 481. Th Netherlands, The Hague.

Dutch government (2007). Evaluatie Meststoffenwet (in English: Evaluation fertilizer legislation). Kamerstuk Tweede Kamer der Staten-Generaal. 28 385. Nr. 83. The Netherlands, The Hague.

Dutch government (2013). Wet van 18 december 2013 tot wijziging van de Meststoffenwet (invoering mestverwerkingsplicht) (in English: Law of 18 December 2013 to implement changes in fertilizer legislation). Staatsblad van het Koninkrijk der Nederlanden. The Netherlands, Wassenaar.

Dutch government (2014a). Regels voor een verantwoorde groei van de melkveehouderij (Wet verantwoorde groei melkveehouderij) (in English: Law on responsible growth of the dairy sector). Kamerstuk, voorstel van wet. The Netherlands, The Hague.

Dutch government (2014b). Ex ante evaluatie wetsvoorstel verantwoorde groei melkveehouderij (in English: ex-ante evaluation of law on responsible growth of the dairy sector). Kamerbrief. The Netherlands, The Hague. 
Dutch government, (2015). Aanbieding AMvB grondgebonden groei melkveehouderij (in English: Proposition of policy measure on responsible growth of the dairy sector). Kamerbrief. The Netherlands, The Hague.

Dutch government (2016a). Wijziging van de Meststoffenwet in verband met de invoering van een stelsel van fosfaatrechten (in English: Adjustment of fertilizer legislation concerning the implementation of the system of phosphate rights). Tweede kamer der Staten generaal. Kamerstuk 34 532, voorstel van Wet. The Netherlands, The Hague.

Dutch government (2016b). Wijziging van de Meststoffenwet in verband met de invoering van een stelsel van fosfaatrechten (in English: Adjustment of fertilizer legislation concerning the implementation of the system of phosphate rights). Kamerstuk 34532. Brief 18. The Netherlands, The Hague.

European Commission (2010). Evolutie van de marktsituatie en de daaruit volgende voorwaarden voor een vlotte, geleidelijke afschaffing van de melkquotaregeling (in English: Evolution of the market situation and the forthcoming conditions for a gradual abolition of the milk quota system). Definitieve verslag van de Europese Commissie aan het Europees Parlement en de Raad. 8.12.2010 COM(2010) 727. Belgium, Bruxelles.

European Sustainable Phosphorus Platform (2017). European Platform on phosphorus in Europe. Retrieved January 2017, from http://www.phosphorusplatform.eu/.

Hees, E.M., Rougoor, C.W., Van der Schans, F.C. (2012). Van mestbeleid naar bemestingsbeleid. Relaas van een ontdekkingsreis (in English: From manure policy to fertilizer legislation). Centrum voor landbouw en milieu (CLM). The Netherlands, Culemborg.

National Organization for Enterprises Netherlands (2016). Manure. Retrieved October 2016, from http://www.rvo.nl/onderwerpen/agrarisch-ondernemen/mest-en-grond/mest.

Remmelink, G. Blanken, K. Middelkoop van, J. Ouweltjes, W. and Wemmenhove, H. (eds.) (2012). Handboek Melkveehouderij (in English: Guide to Dairy Farming). Lelystad, The Netherlands: Wageningen UR Livestock Research.

Samson, GS., Gardeboek, C., Jongeneel, R. (2017). Analysing trade-offs between milk, feed and manure production on Dutch dairy farms. European Review of Agricultural Economics 44: 475-498 
Statistics Netherlands (2016). Fosfaatplafond overschreden door toename mestproductie (in English: Phosphate ceiling exceeded because of increased manure production). Retrieved October 2016, from https://www.cbs.nl/nl-nl/nieuws/2016/02/ fosfaatplafond-overschreden-door-toename-mestproductie.

Statistics Netherlands (2017a). Official statistics for the Netherlands. Retrieved January 2017, from http://statline.cbs.nl/.

Statistics Netherlands (2017b). Fosfaatplafond overschreden (in English: Phosphate ceiling exceeded). Retrieved January 2017, from http://statline.cbs.nl/Statweb/publication $/ ? \mathrm{DM}=\mathrm{SLNL} \& \mathrm{PA}=82505 \mathrm{NED} \& \mathrm{D} 1=13 \& \mathrm{D} 2=0 \% 2 \mathrm{c} 2 \% 2 \mathrm{c} 5 \% 2 \mathrm{c} 9 \% 2 \mathrm{c} 12 \% 2 \mathrm{c} 17-19 \& \mathrm{D} 3=0$ $\& D 4=\mathrm{a} \& \mathrm{HDR}=\mathrm{G} 3 \& \mathrm{STB}=\mathrm{G} 1 \% 2 \mathrm{cT} \% 2 \mathrm{cG} 2 \& \mathrm{VW}=\mathrm{G}$.

Wageningen Economic Research (2017). Agrimatie (in English: Agricultural information). Former Dutch Agricultural Economic Research Institute(LEI). Retrieved January 2017, from http://www.agrimatie.nl/. 


\section{Synthesis}

This final chapter reflects on the thesis as a whole. It starts with discussing the general research objective and research questions. Next, the main conclusions and their implications are presented. The chapter ends with a critical reflection on this $\mathrm{PhD}$ research and the thesis as a whole.

\subsection{Research objective and questions}

Already since the 1960's, the Dutch dairy sector has been subject to changes in European and national agricultural and environmental policies. Dutch dairy farmers, which are considered to be among the most productive and competitive farmers in EU dairy production, are challenged to adapt their farming strategies to cope with growing global competition and societal demand for sustainable production.

This thesis concentrates on analysing Dutch dairy farmer response in this changing environment in the period 2000 until now. More specifically, it focuses on responses to three main policy issues, namely the changes in the Common Agricultural Policy with respect to the direct payment system, the abolishment of milk quotas in Europe, and the Dutch manure policy.

The general objective of this research is to analyse the responses of Dutch dairy farmers in the situation of changing agricultural and environmental policies (i.e. transition from DP system to a flat-rate payment system, milk quota abolishment and the reformed Dutch manure policy), thereby taking into account economic as well as non-economic factors. This objective is explored in four separate research papers, presented in chapters 2 through 5. 
Chapter 2 focuses on the first research question, i.e. "What is the effect of a transition from the direct payment system to a flat rate payment system on the farm income and farming strategies of Dutch dairy farmers?" For the analysis, an economic simulation experiment is used. Two main findings are drawn from this paper. First, the study shows that it is most likely that the transition has a negative effect on the income of Dutch dairy farmers. Moreover, it shows that the dairy farmers make their short-run decisions within a longer run strategychoice framework. Second, it is found that the economic simulation experiment is a flexible methodological approach. Its main valuable characteristics are the relaxation of some neo-classical economic assumptions and the flexibility towards incorporating heterogeneity among farmers in the analysis. It also allows for taking the effects of social variables and environmental policy into account.

Research question 2 "Which economic and non-economic factors determine milk production expansion by Dutch dairy farmers?” is assessed in chapter 3. The model used here combines economic, social and environmental variables to analyse farm-level expansion decisions. It shows that purely economic approaches are too narrow in understanding developments in expansion decisions at the farm level. It is found that several market conditions, variables relating to farmers' values, goals and strategies, and (social) farm characteristics are important drivers in farmers' expansion decisions. However, the results also show that economic variables are still very important in farmers' decision making processes.

Chapter 4 addresses the third research question, i.e. "What are the interactions between Dutch milk and manure production and how can these relations be integrated in one modelling approach to analyse the effects of agricultural policy changes?” The developed model opens up possibilities to further analyse the farmers' potential responses to the abolishment of the milk quotas, taking into account the heterogeneity between farms with respect to being quota and/or manure constrained. It is found that at the margin and at prevailing input and output prices and manure processing costs, it will be generally attractive for dairy farms to expand milk production, unless regulatory constraints will prevent them from doing so. 
Research question 4 "Was the system of manure application norms restrictive for the dairy farms to increase in livestock?” is assessed in chapter 5. It is analysed using a microeconometric approach in which a shadow price function for dairy cows is derived from a profitmaximization problem and estimated using FADN data. The results show that farmers' stocking behaviour was not significantly constrained by manure application norms. It is found that the system of manure application norms was not effective in preventing expansion of dairy cows on surplus farms in the period 2008 to 2012.

\subsection{General conclusions and implications}

Although dairy farmers were facing different agricultural policy regulations, their behaviour was rather consistent over the years. When studying the behaviour of intensive and extensive farms separately, no significant differences in strategy are found. Generally it is found that active Dutch dairy farmers, which continue farming in the future as well, followed an expansion strategy. Even when land is scarce and major investments are required, there is a development towards an increase in farm-scale as well as an increase in the number of livestock.

Chapter 2 shows that in farming strategies economic motives, such as income preservation, increasing labour productivity and technological innovation, play a significant role. However, this thesis also investigates the added value of taking social and environmental aspects into account, and finds that these factors matter as well (chapters 3 through 5). Examples of social variables that are important in farmers' decision making on production expansion are diversification, such as landscape management, and their goals and attitude towards the management of livestock.

The environmental aspects of farming became increasingly important when milk quotas were abolished and farms increased milk production and as a result also their manure 
production. This led to more farms facing a manure surplus which needed to be disposed at a cost. However, even when already having a manure surplus, farms were still expanding their milk production. This study finds that in the period 2001 to 2012 a key factor in the decision making process of farmers to expand in production has been the availability of slack stable capacity. When stable space is available, farms can increase in livestock relatively easily and at low costs. It is found that the (extra) manure disposal costs are too low to put a limit to the increase in production in this period.

Currently the problem of overproduction of manure in the Dutch dairy sector is serious (in 2015 phosphate production of the Dutch dairy sector exceeded its allocated sectoral phosphate ceiling of 84.9 million $\mathrm{kg}$ phosphate by about 9 per cent). This study shows, in chapter 5 , that not the manure disposal costs but rather regulatory constraints with respect to manure production and application on own land can affect the possibilities for future milk supply growth in the Netherlands. The newly introduced policy regulations of the Dutch government require that dairy farmers, if they want to expand their dairy herd, also need to buy additional land (as of 1 January 2016). Buying land, assuming that it is available, is expensive and will therefore almost solely be an option for the relatively larger farms which in general have better access to external capital.

The newly introduced policy also contains a system of phosphate production rights as of January 2018. The number of phosphate production rights assigned to a farm is based on the number of livestock a farm has at 2 July 2015 minus 4 percent (correction for manure production in excess of the phosphate ceiling). For many Dutch dairy farms this implies they need to reduce their number of livestock. This reduction is expected to solve (part of) the problem of phosphate overproduction per ha, which reduces the need to increase land areas. In anticipation of this system the government introduced several supporting measures in order to encourage farmers to reduce livestock stable capacity (Dutch government, 2016). One of these measures is the awarding of a premium per dairy cow that is eliminated from the farm. 
This measure seems to be successful; the total livestock number decreased by 40 thousand dairy cows in the first months of 2017 already.

So, what to expect from the Dutch dairy sector in the future? Most likely the expansion path that many Dutch dairy farmers took will continue. Maintaining a high labour productivity and competitive production structure is needed in order to sustain in the future. For smaller dairy farms, the future will be challenging, even if they just want to continue farming without expanding in production. Just like in the past some farmers will be forced to stop farming, either because they retire or because they cannot compete.

However, this thesis shows that most Dutch dairy farmers proved to be very innovative and adaptive to changing policy circumstances. For example, some farmers diversified farm activities and integrated landscape management or recreational activities in their daily routine in order to diversify income. Although this may not be an option for large and highly specialised farms, it may provide opportunities for additional income generation for smaller producers. Moreover, during the milk quota period the Dutch dairy sector was one of the top producers in Europe. When the milk quotas were abolished the farmers managed to keep their prime position in European dairy farming; together with Ireland the Netherlands showed a large expansion in terms of milk production, irrespective of the low milk prices prevailing in 2015 and 2016 (Rabobank, 2017). This supports the findings of this thesis.

In addition, initiatives were taken to cooperate with the business sector. In 2015, one such initiative was the reduction of phosphate production by lowering the content of phosphate in compound feed (Nederlandse Zuivelorganisatie, 2017a). Another important initiative is the agreement on the phosphate reduction plan of the dairy sector. In this plan representatives of the dairy farmers (trade union of the Dutch dairy sector) and several leading dairy companies (such as FrieslandCampina and Arla Foods) propose a package of measures to reduce phosphate production in the Dutch dairy sector in 2017 (Nederlandse Zuivelorganisatie, 2017b). In a slightly different way this plan has been imposed on the dairy sector (Dutch Phosphate 
production Reduction Decree). Furthermore, the Netherlands introduced a dairy farm retirement program (Dutch government, 2016). The target of this program is a reduction of 1000 dairy farms (having an estimated average herd size of 60 dairy cows) and a reduction of the Dutch dairy cow herd by 60 thousand livestock units. Most likely more initiatives in order to reduce overproduction of animal manure will arise in the future.

\subsection{Discussion}

This section describes the decisions, and their implications, made in executing this research. Moreover, the difficulties encountered during this research are discussed.

\subsubsection{Policy selection}

One of the main issues to deal with in this thesis are the rapidly changing agricultural and environmental policies while doing research. In order to do a reliable and thorough study, it takes time to develop models and run tests. When the model is finished, there is a fair chance that the policy under investigation is already adapted again. An example is the investigation of the possible impacts on the Dutch dairy farmer behaviour of proposal for the European Common Agricultural Policy as of 2013, which is assessed in chapter 2. By the time this chapter was published, the Common Agricultural Policy was already implemented. For this reason, when writing a new chapter, I focused on the actual issues being discussed at that time. The focus of chapter 2 is on changes in the first and second pillar of the Common Agricultural Policy, whereas in chapter 3 I focus on the abolishment of the milk quotas and in chapter 4 and 5 changes in the environmental policy are analysed. 


\subsubsection{Sample selection}

In The Netherlands, there is a variety of dairy farms that can be distinguished. For example, besides traditional dairy farms there exist organic dairy farms and farms that gain their income partly from dairying and partly from other activities (such as care farming or a camping site). Although the occurrence of these farms is increasing (CBS, 2017), these farms are excluded from the analysis in chapters 3 through 5 .

The main reason to exclude them is that this thesis focuses on analysing the behaviour of traditional dairy farmers. Organic farms generally have different farming strategies than traditional dairy farmers. Also their milk price is different. Farmers that gain their main income from other activities as well cannot be compared to the farmer behaviour of traditional dairy farmers, since their farming goals are different. Investigating differences between these types of farms and traditional dairy farms could be an interesting extension of this research, but is beyond the scope of this thesis.

Not only the used production method distinguishes farmer behaviour. In chapter 2 it is found that there are differences in farmer behaviour between farmers from different regions of The Netherlands as well. In order to draw more specific conclusions, it would have been interesting to further incorporate these differences in the other chapters of the research as well. However, location data is only available for a small selection of the farms in the sample. Using only these observations would severely reduce the available sample such that it would not be representative anymore.

\subsubsection{Data}

Like in most empirical research, some limitations came across when accessing the data. First, the data used is obtained from the Dutch FADN and LMM-databases. These databases provide the most detailed and useful information for this study. Since the Dutch FADN-database is 
a sample selection of dairy farms, not all Dutch dairy farms are included in the analysis. Moreover, when synchronising the FADN-database with the LMM-database, some farms cannot be matched, which decreases the sample size somewhat more. Also, due to the time needed for processing and updating the database, it is decided to have 2012 as the latest year, although it is recognized that after that date a number of interesting developments took place.

Second, one of the main findings at the start of this thesis is that, besides economic variables, social and environmental variables are also important factors in the decision making process of Dutch dairy farmers (chapter 2). In the third chapter I therefore incorporate these variables explicitly into the analysis. Nevertheless, economic variables are found to still matter most in farmers' decision making processes. In chapter 4 and 5, where I focus on technical relations between milk and manure production, I choose to use economic variables only. Using only these variables still yields relevant results.

\subsubsection{Research method}

In this thesis I primarily choose to use econometric research methods to investigate the research questions. An exception is chapter 2 in which I use experimental economics. This chapter shows that experiments put some of the assumptions of neoclassical economic methods at stake, and therefore add value to the more traditional economic research methods (such as econometrics). In particular with respect to measuring heterogeneity among personal (or emotional) characteristics of farmers, which are difficult to quantify in traditional economic methods, experiments are very useful.

For this reason it would have enlarged the scope of this research to incorporate experimental research techniques in the other chapters as well. Unfortunately, due to several reasons it is not possible to use these techniques throughout the thesis. One reason is that experiments are very costly and time consuming. The selection of a proper sample population that 
is representative for the whole Dutch dairy sector is rather complex. Also, carrying out experiments is labour intensive. During this project there was not enough finance, labour and time available to execute experiments. As a result, the data collected would have been incomplete, and reliable conclusions on the whole dairy farmer population could not have been drawn.

Econometric research methods are particularly useful in situations where historical data are available. Based on historical data it is possible to analyse changes over time. A potential drawback of econometric methods is that relations between variables are predetermined; optimal solutions are fixed and conclusions are drawn on these specific relations. Since I assume farmers rationale behind decision making is static over time, at least in the research period of this thesis, using econometric research methods is still applicable.

Another method which is often used to analyse these type of research questions is mathematical programming. Mathematical programming is useful to analyse situations in which historical data are scarce and the aim is to analyse possible effects of policy changes that are not yet implemented. However, historical data are largely available, and the purpose of this study is not to focus on future policy changes, but on changing farmer behaviour under current policy. Moreover, a drawback of mathematical programming is the possibility of corner solutions, which implies that trade-offs between variables cannot be made. Furthermore, mathematical programming models have a strong optimization focus and may overestimate the speed of adjustment of farmers relative to what is observed in reality. The econometric approach, which takes into account an error term and accepts that farmers may not behave fully in accordance with economic theory and its profit maximization assumption, is then a preferred approach. This especially holds for chapters 4 and 5, where a microeconomic model is developed aimed at analysing trade-offs between milk, feed and manure production as they have been observed from (past) farmer behaviour. 


\subsubsection{Manure production}

In this thesis, a distinction is made between farms with and without a manure surplus. In order to calculate this manure production surplus, the farm application norms for nitrogen and phosphate are compared with the actual level of on-farm nitrogen and phosphate production. Although data on manure production at the mineral level are available, it is not possible to obtain reliable data on the mineral content of compound feed and fodder. Therefore the interaction between feed intake and manure production at the mineral level is not investigated.

However, if these data would have been available, the effectiveness of reducing the phosphate production by lowering the content of phosphate in compound feed could be investigated. This is one of the initiatives of the dairy sector in cooperation with the business sector (Nederlandse Zuivelorganisatie, 2017a). Although chapters 4 and 5 still analyse interesting and relevant research questions, I would like to investigate this 'feedtrack', as I think it is one of the most interesting ambitions of the dairy sector as a solution to the problem of phosphate overproduction.

Moreover, the analysis on manure production can be extended by incorporating a market for manure. Even more so since phosphate production rights will be tradable in the future which makes this a very relevant area to investigate. However, in the Netherlands, this manure market is complex. Besides the formal market, there exist many 'shadow' markets due to mutual arrangements between farmers. For example, dairy farmers may trade their manure with neighbouring horticultural farmers against a self-negotiated price. This means that a 'real' market price is hard to measure. Also precise data on the amount of manure transferred are hard to obtain, which makes the manure market difficult to investigate.

So, at the end of this thesis, it can be concluded that the Dutch dairy sector is an interesting topic to analyse as it is influenced by all kind of changes and developments in agricultural and environmental policy. This sector provides exciting opportunities to further explore in future 
research. Especially in the context of manure production, which will be regulated by a system of phosphate production rights as of next year. One such interesting topic to investigate can be the introduction of these rights and the different within (and over) sector tradability regimes. Another topic can be the analysis of the environmental efficiency of farms in the context of different farm management options. Furthermore, a long-term assessment of (agricultural and environmental policy) developments in de Dutch dairy sector and its impact on farmer responses can be investigated. 


\section{References}

CBS (2017). Official statistics for The Netherlands. Retrieved May 2017, from https://www.cbs. nl/nl-nl/nieuws/2017/04/groei-biologische-landbouw-in-pluim-en-melkveesector.

Dutch government (2016). Maatregelenpakket fosfaatreductie (in English: Measures on phosphate reduction). Kamerbrief. The Netherlands, The Hague.

Nederlandse Zuivelorganisatie (2017a). Dutch Dairy Organization. Retrieved April 2017, from http://www.nzo.nl/nl/blog/2015/06/01/ zuivelsector-neemt-maatregelen-beperking-fosfaatproductie/.

Nederlandse Zuivelorganisatie (2017b). Dutch Dairy Organization. Retrieved April 2017, from http://www.nzo.nl/nl/blog/2016/12/14/ voorgenomen-fosfaatreductieplan-zuivelsector/.

Rabobank (2017). Cijfers en trends melkveehouderij (in English: Facts and figures Dutch dairy sector). Retrieved March 2017, from https://www.rabobankcijfersentrends.nl/index. cfm?action=branche\&branche=Melkveehouderij. 


\section{Summary}

The Netherlands is one of the main dairy producers in the European Union (EU). The Dutch dairy sector can be characterized as a highly productive and competitive sector. The sector is affected by the European Common Agricultural Policy (CAP) and European environmental policies, such as the European Nitrate Directive. Already since the start of the CAP in the 1960s, there have been many changes and revisions of this policy in order to cope with a changing, and challenging European agricultural environment. These changes also had their impact on the Dutch dairy sector. In order to protect their competitive position in the European Union, the Dutch dairy farmers are challenged to adjust their farming strategies.

A notable example of the CAP impacting the dairy sector is the milk quota system, which was introduced in 1984 and abolished in 2015. The abolishment provided dairy farmers with the option to expand in milk production. However, when farmers increase milk production their animal manure production increases as well. The Dutch manure policy includes limitations and obligations to the use of (animal) manure exist. This affects the farmer behaviour with respect to optimizing production. They have to take decisions on optimal land allocation and manure processing costs into account as well.

This thesis focuses on analysing the Dutch dairy farmer behaviour in this changing political environment. The general objective of this research is to analyse the responses of Dutch dairy farmers in the situation of a changing agricultural and environmental policy context (i.e. changes in the subsidy payment system, milk quota abolishment and the reformed Dutch manure policy), thereby taking into account economic as well as non-economic factors. The objective leads to four research questions, which are assessed in separate chapters of this thesis. It contributes to the literature in two ways. First, by analysing farmers strategies and 
choices it takes into account non-economic factors such as social characteristics of farmers and changing policy regulations. Second, the interaction between milk and manure production is integrated in the modelling approach.

Chapter 2 deals with the first research question "What is the effect of a transition from the direct payment system to a flat rate payment system on the farm income and farming strategies of Dutch dairy farmers?” The impact of proposed policy changes on the behaviour of farmers is a highly discussed topic in European policy analysis. Most often traditional neo-classical economic research methods are used for the analysis. But one of the limitations of these methods could be that they do not take the relevant natural environment into consideration, which might reduce the predictive contents. In order to bridge the gap between economic theory and observed farmer behaviour one can use experimental economics.

This chapter examines the value of experiments for assessing the impact of the proposed Common Agricultural Policy of 2013 on farm income and farming strategies. Hereby the focus is specifically on the impact of an alternative direct payment system based on a flat rate and green payments. An economic simulation experiment was used to analyze Dutch dairy farmer behaviour towards the provision of public goods under an alternative direct payments system. The economic simulation experiment used in this chapter was developed by Wageningen Economic Research (former Dutch Agricultural Economic Research Institute(LEI)) and carried out in November through December 2010. In total 35 dairy farmers were selected to participate in the simulation experiment.

The results show that in farming strategies economic motives, such as income preservation, increasing labour productivity and technological innovation, play a significant role. Moreover, it is shown that the suitability of and rewards for the provision of green services play a significant role in their uptake by farmers. Moreover, this research compared the characteristics of the experimental research method to more traditional microeconomic research approaches. It is concluded that using an economic simulation experiment in analysing Dutch 
dairy farmer behaviour adds value in several ways. In addition to neo-classical economic research methods, the simulation experiment adds a more flexible approach. For example it does not presume cost minimization or profit maximization. Also homogeneity of production factors is not assumed, and it allows for heterogeneous price expectations.

Chapter 3 analyses the second research question "Which economic and non-economic factors determine milk production expansion by Dutch dairy farmers?” A conceptual model is developed that shows how policies, market conditions, and farmers' values and goals affect the expansion decisions of Dutch dairy farmers. This conceptual model shows that not only economic, but also social and environmental variables are important factors in expansion decisions of Dutch dairy farmers. Zooming in on the dynamic decision making process itself, three investment theories are combined to explain investment decisions. This framework is the basis for a dynamic random effects probit model that is used to estimate the effects of various economic, environmental and farm structural factors on farmers' expansion behaviour.

The results show that production intensity matters when analysing production expansion behaviour of Dutch dairy farms. Compared to extensive farms, intensive farms have a higher probability for milk production expansion. The availability of land however is an important precondition. Production diversification, which is usually found at extensive farms, decreases the probability for milk production expansion. Although the findings do not directly show an increase in milk production during the sample period (farmers still respected their quota limits), the results indicate that Dutch dairy farms can potentially increase milk production in the future. In 2010 farms underutilized their stable space, as the occupancy of stable space was only $71 \%$. After milk quota abolishment farms can therefore increase livestock herd and milk production with limited investments.

Chapter 4 deals with the third research question "What are the interactions between Dutch milk and manure production and how can these relations be integrated in one modelling approach 
to analyse the effects of agricultural policy changes?” Using Fixed Effects (Instrumental Variable) Generalized Method of Moments (FE(-IV)-GMM), production functions for milk, feed and roughage are estimated taking into account prevailing milk quotas and manure constraints. Together with an equation for manure production these production functions are used to calculate the costs and benefits of dairy livestock expansion. The model opens up possibilities to further analyse the farmers' potential response to the abolishment of the milk quotas, taking into account the heterogeneity between farms with respect to being quota and/or manure constrained. The results suggest that at the margin and at prevailing input and output prices and manure processing costs, it will be attractive for dairy farms to expand production, unless regulatory constraints prevent them from doing so.

Chapter 5 analyses the fourth research question "Was the system of manure application norms restrictive for dairy farms to increase in livestock in the period 2008 to 2012?” It is analysed whether different growth strategies between dairy farms can be distinguished. Moreover, differences in characteristics between farms that increased in livestock while producing more phosphate than the application norm and farms that increased in livestock while producing within the application norm of phosphate are investigated.

Assuming short-run profit maximization including manure processing costs for dairy farms with a manure surplus, a shadow price equation for dairy cows is derived that is estimated using panel data techniques. A parameter test shows that the marginal processing costs of additional manure did not lower the shadow price of dairy cows for surplus farms, suggesting that in the period 2008 to 2012 this policy was not limiting expansion of dairy cows on surplus farms. Instead it is found that it had a positive effect on the demand for livestock. Moreover, the same results were found for farms using different growth strategies.

In order to study the research questions 2 through 4 (chapters 3 through 5), yearly data (from the period 2001 to 2012) on various economic and non-economic variables were gathered from two databases; the Dutch Farm Accountancy Data Network (FADN) and the National 
Monitoring Network Manure (LMM). The final dataset included 1193 observations on 334 Dutch dairy farms and formed an unbalanced panel.

The four separate research questions provide input to assessing the general research objective of this study. Although the dairy farmers were facing different agricultural policy regulations, their farmer behaviour was almost consistent over the years. Generally it is found that active Dutch dairy farmers, which are expected to continue farming in the future, followed an expansion strategy. There is a development towards an increase in farm-scale as well as an increase in the number of livestock.

Currently the problem of overproduction of manure in the Dutch dairy sector is serious (in 2015 phosphate production of the Dutch dairy sector exceeded its allocated sectoral phosphate ceiling of 84.9 million $\mathrm{kg}$ phosphate by about 9 per cent). This study shows that not the manure disposal costs but rather regulatory constraints with respect to manure production and application on own land can affect the possibilities for future growth in milk supply in the Netherlands. 


\section{Acknowledgements}

The making of this thesis was quite an adventure for me. In the end of 2010, when Koos asked me to apply for this $\mathrm{PhD}$, I did not know the impact it was going to have on the start of my career and my social live. Now, seven years later, I am so happy to finally be able to write these acknowledgements and to say: I am done!

With tears and laughter I look back at the past few years, in which this research was always present in the back of my head. It was not always easy, and sometimes even hard, to find my focus and sit down for my work at the computer again. After the first two years I experienced a little 'breakdown'. The research was going steady, but I was not sure if this was the right direction for me to go. Exactly then, there was an interesting program I could join: to do an internship at a secondary school. I am still happy that my co-promotors agreed that I signed up for this program, as it was the best decision I made. Suddenly it became clear: the interaction with students and the transfer of knowledge to others, the things I missed so much in my daily $\mathrm{PhD}$ work, I could all combine perfectly in being a teacher. A new plan was born.

In 2014, I started my education to get my teaching degree in economics at the VU Amsterdam. I decided to finish my PhD part time. In 2015, I found my dream job as a teacher at ECL in Haarlem, which in practice meant that I had only one day left per week to spend on my thesis work. The combination of doing a PhD and being a teacher at the same time was perfect but stressful. The research provided the intellectual challenge, and in turn the teaching provided the energy I needed to finish it. However, if it was not for the motivation and perseverance I got from the people surrounding me, I was never able to finish this $\mathrm{PhD}$. I am very grateful to all of them and would like to mention a few in particular. 
At first, I would like to thank my co-promotors Koos Gardebroek and Roel Jongeneel. Conducting this research really was a joint effort. I am happy to have benefitted from your knowledge and experience along the way. But most of all I appreciate the endless time and effort you put in my work, and the patience you had to travel this journey with me.

Next, I would like to thank my promotor Justus Wesseler, and my colleagues and the other $\mathrm{PhD}$ students from the Wageningen Agricultural Economics and Rural Policy group, for the input they gave on my work, for sharing this experience with me and for making this $\mathrm{PhD}$ possible. Special thanks go to the ladies of the secretariat, and to Karen especially for our endless social talks and for putting work into perspective. I also want to pay my gratitude to my inspiring colleagues from Wageningen Economic Research (former LEI). In the first years of my $\mathrm{PhD}$, we frequently shared office space, discussed the ups-and-downs in work, and made beautiful walks during lunch break in The Hague, which I appreciated a lot.

Special thanks go to Esther. We started together and made this adventure reality. As a real friend, you shared all ups-and-downs, tears and laughter in social live and work, and I am very glad you are my paranymph. Also I would like to thank Anniek, my other paranymph and best friend. You were there when I hit rock bottom and showed what best friends are for. Now, I am proud to share this important moment together.

When writing these words, I notice how hard it is to mention everyone by name and pay them the special attention they deserve for supporting (and distracting) me along this way. But the people involved will know when I say: Thank You! To my beloved friends from secondary school, to my compassionate friends in Haarlem, to my dearest LV-friends from Wageningen, to my sweet 'swimming' friends, to my encouraging homies from Hoogstraat 14a, to my new group of friends from Raalte and Zwolle, to my teaching friends from VU, to my former colleagues from ECL Haarlem, and of course to my new, welcoming family Jan, Gerry, Lieke and Dennis. Moreover, I would like to thank the Peek family and their beautiful 'ladies' for their contribution to the cover of this thesis. 
I think only other PhD students, and maybe their partners, can truly understand the impact a PhD has on your (social) life. It just is a tough journey. I would never have made it if the following people, who played a significant role in my daily life, were not there to support me. Thank you, Papa, Mama, Robin, Sabrina, Quinn, Marc and Kirsten, for giving me unconditional love and trust, and providing distraction on the right moments. Dear Tabe, you were there when I started this adventure and for sure you know (and shared) the impact of this PhD. Thank you for always being there when needed, and helping me to take the right directions. Also, Sjoerd and Gerrie, thank you for your endless support and believing in me.

Last, but certainly foremost, I would like to thank my best friend and partner Luuk. Thank you for your love, support and endurance. Thank you for putting things into perspective and showing the important things in life. You did a tremendous job on the lay-out and cover design of this thesis. We made the last steps in finishing this $\mathrm{PhD}$ together.

I am so very proud to finally say: I made it! 


\section{Biography}

Gerlinda Sabrina Samson was born on 15 December 1985 in Zwolle, the Netherlands. In 2004, she finished her secondary education and started to study at the Wageningen University. Here she studied International Development Studies with a specialization in development economics, and obtained her Master's degree in 2010. Part of her master thesis was a 6 month internship at the Commonwealth Scientific and Industrial Research Insitutute (CSIRO) in Townsville, Australia, and a 6 month stay in Montevideo, where she conducted a research towards the functioning of farmer cooperatives in Uruguay.

In November 2010, Sabrina started as a $\mathrm{PhD}$ candidate at the Wageningen Agricultural Economics and Rural Policy Group (AEP) and the Wageningen Economic Research institute (former LEI). As part of her $\mathrm{PhD}$ research, she has presented papers at various scientific conferences (e.g.EAAE) and followed various courses given by amongst others the Wageningen School of Social Sciences (WASS). In addition, she assisted with courses and practicals at the AEP group. In October 2017 she completed her $\mathrm{PhD}$ thesis.

In 2015, Sabrina obtained her Master's degree in teaching economics at the VU Amsterdam. She currently works as an economics teacher at the Centre for Sports and Education in Zwolle. 


\section{Gerlinda Sabrina Samson Wageningen School of Social Sciences (WASS) Completed Training and Supervision Plan}

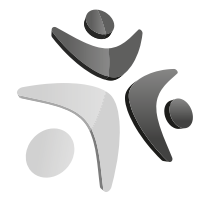

Wageningen School of Social Sciences

\begin{tabular}{|c|c|c|c|}
\hline Name of the learning activity & Department/Institute & Year & ECTS* \\
\hline \multicolumn{4}{|l|}{ A) Project related competences } \\
\hline $\begin{array}{l}\text { International Postgraduate Course } \\
\text { EU Policy for agriculture, food and rural areas }\end{array}$ & Wageningen Business School & 2010 & 1.5 \\
\hline Agricultural and Rural Policy (AEP-30306) & Wageningen University & 2011 & 6 \\
\hline Advanced Microeconomics (AEP-60306) & Wageningen University & 2011 & 6 \\
\hline Wageningen Summer Course in Spatial Econometrics & Wageningen University & 2011 & 1.5 \\
\hline Microeconomic Panel Data & NAKE & 2011 & 3 \\
\hline \multicolumn{4}{|l|}{ B) General research related competences } \\
\hline $\begin{array}{l}\text { Techniques for Writing and Presenting a Scientific } \\
\text { Paper }\end{array}$ & Wageningen Graduate Schools & 2010 & 1.2 \\
\hline Project and Time Management & Wageningen Graduate Schools & 2011 & 1.5 \\
\hline $\begin{array}{l}\text { 'Changes in Direct Payments and Farmers' Strategies: } \\
\text { Experimental Evidence from Game Simulation with } \\
\text { Dutch Dairy Farmers' }\end{array}$ & $\begin{array}{l}13^{\text {th }} \text { EAAE Congress, Zurich, } \\
\text { Switzerland }\end{array}$ & 2011 & 1 \\
\hline $\begin{array}{l}\text { 'The Cost Function Structure of Dutch Dairy Farms: } \\
\text { Effects of Quota abolition and Price Volatility' }\end{array}$ & $126^{\text {th }}$ EAAE Seminar, Capri, Italy & 2012 & 1 \\
\hline $\begin{array}{l}\text { 'Analysis of factors affecting production expansion } \\
\text { behaviour of Dutch dairy farmers' }\end{array}$ & $\begin{array}{l}5^{\text {th }} \text { EAAE PhD Workshop, Leuven, } \\
\text { Belgium }\end{array}$ & 2013 & 1 \\
\hline $\begin{array}{l}\text { 'Analysis of factors affecting production expansion } \\
\text { behaviour of Dutch dairy farmers' }\end{array}$ & $133^{\text {rd }}$ EAAE Seminar, Chania, Greece & 2013 & 1 \\
\hline $\begin{array}{l}\text { 'The value of economic simulation experiments in } \\
\text { analyzing changes in direct payments and Dutch dairy } \\
\text { farmers'strategies' }\end{array}$ & $\begin{array}{l}\text { Wageningen School of Social } \\
\text { Sciences PhD day }\end{array}$ & 2012 & 1 \\
\hline WER-Activities (Introduction in Artis/BDL) & $\begin{array}{l}\text { Wageningen Economic Research } \\
\text { (former Landbouw Economisch } \\
\text { Instituut) }\end{array}$ & 2011 & 0 \\
\hline Assistant practical's Advanced Econometrics & Wageningen University & $\begin{array}{l}2012- \\
2014\end{array}$ & 2 \\
\hline Writing Research Proposal & Wageningen University & 2010 & 2 \\
\hline \multicolumn{4}{|l|}{ C) Career related competences/personal development } \\
\hline AcKlas 'Meer academici voor de klas' & Wageningen University & 2012 & 6 \\
\hline Last Stretch of the PhD Programme & Wageningen Graduate Schools & 2014 & 0 \\
\hline Career Orientation & Wageningen Graduate Schools & 2014 & 1.5 \\
\hline Total & & & 37.2 \\
\hline
\end{tabular}

${ }^{*}$ One credit according to ECTS is on average equivalent to 28 hours of study load 


\section{Colophon}

The research described in this thesis was financially supported by Wageningen Economic Research (WER).

Financial support from the Agricultural Economics and Rural Policy Group for printing this thesis is gratefully acknowledged.

Cover design: Luuk Bruggeman

Printed by: GVO drukkers \& vormgevers B.V. 